\title{
$n^{\circ}$ 2020-03
}

\section{The Unintended Consequences of Anti-Piracy Laws on Markets with Asymmetric Piracy: The Case of the French Movie Industry}

\section{Christophe BELLEGO' Romain DE NIJS ${ }^{2}$}

\footnotetext{
${ }^{1}$ CREST-ENSAE. E-mail : christophe.bellego@ensae.fr

${ }^{2}$ CREST - ENSAE and Ecole Polytechnique. E-mail:romain.de-nijs@polytechnique.edu
} 


\title{
The Unintended Consequences of Anti-Piracy Laws on Markets with
}

\section{Asymmetric Piracy: The Case of the French Movie Industry*}

\author{
Christophe Bellégo ${ }^{\dagger}$ and Romain De Nijs ${ }^{\ddagger}$
}

March 7, 2020

\begin{abstract}
Using the French anti-piracy law known as HADOPI as a natural experiment, we study the asymmetric effects of online piracy on cinema admissions. Applying four estimation strategies at different levels of observation (town, movie, country, and consumer), we find that the introduction of the law is associated with a $9 \%$ increase in the market share of American movies. This increase occurs at the expense of other movies. Although we find an increase in overall admissions, this effect is not statistically significant. These findings primarily originate from a high initial level of asymmetric piracy between American and other movies, which was attenuated by the anti-piracy law, resulting in a fiercer competition between movies. The results can also be explained by the behavior of younger consumers, and might be caused by consumers' budget or time constraints. We exclude positive shocks on the relative quality of American movies, the advent of 3D movies, supply side reactions by firms, and word of mouth effects of illegal downloads as explanations for this redistributive effect.
\end{abstract}

Keywords: Internet; Online piracy; Redistributive effects; Natural Experiments; Movies.

\footnotetext{
* An earlier version of this paper circulated under the title "The Redistributive Effect of Online Piracy on the Box Office Performance of American Movies in Foreign Markets". We thank Michael L. Anderson, Luc Behagel, Marc Bourreau, Hadrien De Nijs, Benjamin E. Hermalin, Przemyslaw Jeziorski, Laurent Linnemer, John Morgan, Corinne Prost, Sébastien Roux, Felix Vardy, Mauricio Varela, Michael Visser, Michael X. Zhang and seminar participants at Paris School of Economics, CREST, EARIE, Toulouse School of Economics, and INSEE for insightful discussions and suggestions. This work was supported by a grant from the Centre National de la Recherche Scientifique (CNRS). Any remaining errors are ours.

${ }^{\dagger}$ Corresponding author; CREST - ENSAE; email:christophe.bellego@ensae.fr

${ }^{\ddagger}$ CREST - ENSAE and École Polytechnique; email:romain.de-nijs@polytechnique.edu
} 


\section{Introduction}

Online piracy is a widespread phenomenon that accounts for about $25 \%$ of aggregate Internet traffic in North America and Europe (Sandvine (2011)), generating potential large negative effects on the revenues of rights holders. Thus, governments and rights holders have initiated numerous anti-piracy actions. However, these actions may generate unexpected redistributive effects because products might be exposed to different levels of online piracy. In many markets of the digital economy, some products are more prone to online piracy than some of their substitutes. First, products can incorporate technologies that offer different protection levels against piracy. In the video game market for example, there are important differences between different platforms or games. PC games are much easier to pirate than consoles version because a console necessitates a physical intervention on the hardware. Games embedding Digital Rights Management (DRM) technologies ${ }^{1}$ are also more difficult to pirate than other games. Second, the greater or lesser availability of products in one country is also likely to influence the probability that they will be available via piracy in other countries. For instance, the sequential introduction of U.S. movies into foreign markets may facilitate the spread of their illegal copies in these markets. Third, some products are "piracy-proof" by nature. In the software market, for example, free software is by definition not subject to piracy, but this is not the case for paid software. Similarly, in the music industry, the experience of attending a live concerts cannot be pirated, while music albums can.

In these situations of asymmetric piracy, competition is somehow distorted. Piracy-proof products may experience high levels of legal sales because consumers buy less of other products available via piracy than they otherwise would have. Then, products that initially suffer from a high level of piracy are likely to benefit more from the introduction of an instrument fighting piracy than more piracy-proof products. Therefore, the implementation of the law against piracy may lead to an increase in legal sales of most pirated products, but the result on the less pirated products is more ambiguous. One may expect the sales of the latter not to decrease, or even to increase thanks to a virtuous circle initiated by a decrease in online piracy. However, the sales of non-pirated products could decrease if consumers do not expand their legal consumption budget (Thaler (1985)). Such a redistributive effect between products would be less expected and more surprising.

In this article, we test the potential asymmetric effect of anti-piracy legislation in the context of the theatrical film market in France using the HADOPI law as a natural experiment. This law was adopted at the end of 2009 in France to prevent Internet users from illegally downloading cultural goods. Several papers have investigated the effects of online piracy (Waldfogel (2012a), Belleflamme and Peitz (2012)), but

\footnotetext{
1. DRM technologies mostly requires authentication of users on an online server, making them hard to pirate.
} 
the consequences of asymmetric piracy and its potential side effects following the introduction of protective laws has, to the best of our knowledge, never been studied empirically or theoretically. A notable exception is Zentner (2005), who provides macro-level evidence of this mechanism in the recorded music market.

Understanding the effects of asymmetric piracy has important implications for firms whose profits may be affected by such legislation as well as for governments for the design of their policy. The various stakeholders may not necessarily be aware of the asymmetric nature of online piracy and its resulting impacts on consumer behavior. This issue is substantial because it emphasizes the possible unintended consequence of anti-piracy laws. This question is timely because six countries (France, New Zealand, Sweden, South Korea, Taiwan and the United States) have recently enacted similar legislation to fight piracy on the Internet. ${ }^{2}$ More generally, this issue contributes to the empirical literature on how the Internet affects the offline activity of individuals (See for instance Ghose et al. (2006), Gentzkow (2007), Forman et al. (2009), Liebowitz and Zentner (2012), or Zentner et al. (2012)).

The market for movies in French theaters is particularly suitable for studying the possible asymmetric effects of an anti-piracy law for several reasons. First, there is a significant difference in online piracy level between American and French films. As we will show later, French films are much less available online illegally during their theatrical exhibition in France than American ones. American movies are usually released in the United States a few weeks earlier than in foreign markets (including France), and criminal networks that supply the online market with illegal copies are relatively more organized and active on the American continent, thereby allowing greater proliferation of their illegal copies on the Internet. Second, French movies are essentially the main competitor of American movies in French theaters, which can lead to significant and measurable effects. ${ }^{3}$ Third, foreign earnings represent a substantial share of the total gross of the U.S. motion picture industry, and France is the largest theatrical market in Europe. ${ }^{4}$

Exploiting this natural experiment setting, we investigate to what extent we could observe such a redistributive effect between French and American movies using four identification strategies at different levels of observation (town, movie, country, and consumer) on a new set of data over the period surrounding the adoption of the law. We test whether the enactment of the anti-piracy law has led to a market expansion effect (an increase in the total number of movie admissions), to a redistributive effect (an increase in the market share of U.S. movies that is detrimental to other movies), or to both effects. The four approaches

2. The Copyright Alert System (CAS) has been implemented in the United States in February 2013. Unlike other countries, the CAS does not constitute a law but is the result of an agreement between right holders and Internet service providers. The CAS terminated its program on January 2017.

3. Between 2008 and 2011, U.S. movies account for $50 \%$ of tickets sold while French ones account for $42 \%$.

4. According to BoxOfficeMojo, foreign earnings accounted for $62.5 \%$ of total lifetime grosses of the top-10 most successful U.S. movies in 2013. Moreover, France is often among the top 3 world's largest markets for U.S. exports. 
are mutually reinforcing and indicate that the law is associated with a $9 \%$ increase in the market share of American movies at the expense of other (domestic) movies. We find an increase in total admissions, but the effect is not statistically significant. We also find evidence suggesting that the HADOPI effect is mainly driven by the behavior of younger individuals. Hereafter, we discuss in more details the conclusions of each approach.

The first analysis shows that towns with a higher level of online piracy (i.e., with a higher coverage rate of broadband Internet) experienced a higher increase in American movie admissions, and a higher decrease in other (French) movie admissions, after the introduction of the HADOPI law. In addition, we find statistically weak evidence of a market expansion effect associated with the law. ${ }^{5}$ By examining the same movies across different towns, this approach excludes an important competing explanation, namely that American (resp. French) films could have experienced a positive (resp. negative) quality shock in France concomitant with but unrelated to the HADOPI law. This empirical strategy also excludes the advent of 3D movies as another explanation of the result. Lastly, we find no obvious preexisting trends in any of the outcomes of interest in the months preceding HADOPI, which supports its exogeneity.

The three other analyses complement this result. The effect on American movie sales may be related to a supply reaction from U.S. film distributors compared to French ones, or compared to their release strategy in other European countries. To test this hypothesis, we compare American to French movies in the second analysis, and we compare American movies across relevant European countries, devoting careful attention to the choice of control groups with the method developed by Hilger et al. (2011), in the third analysis. In both cases, we find no supply reaction to the HADOPI law by American distributors in France, in terms of either quantity, quality, or speed of the movies they export to France. The second analysis also rules out the word of mouth effect of online piracy (Peukert et al. (2017)) as an explanation of our result, and it identifies the movie genres that are the most affected by HADOPI. In the fourth analysis, we study movie sales from different groups of consumers. We find that sales to younger consumers, who are more likely to illegally download movies, have increased for American movies since the HADOPI law was passed, compared to French movies and older consumers.

In addition, these three other analyses confirm the growth in sales of American movies and they provide statistically weak evidence of a market expansion effect after the implementation of the law. In the third analysis, we find evidence that HADOPI increased overall admissions (by 8\%), but we cannot reject the null hypothesis that there was no market expansion. In the fourth analysis, we find no market expansion effect. To sum up, we find evidence suggesting an increase in total admissions, but the standard error of

5. In a robustness test, we estimate the demand for movies with a logit model. A counterfactual simulation actually confirms the absence of a significant market expansion effect. 
the effect is too large to conclude this with sufficient statistical confidence, and the size of the effect varies a lot between different specifications. Therefore, we cannot be sure that there really was an increase in total admissions. In addition, the market expansion seems to be smaller than the business stealing effect.

The underlying behavior of consumers rationalizing these results would be as follows. Without an anti-piracy law, some people illegally consume American movies online and legally watch other (French) movies in theaters because illegal copies of American movies are easily available on the Internet during their theatrical exhibition, but this is much less the case for other movies. When an anti-piracy law is implemented, they shift to legal consumption of American movies in theaters because it is now too risky to illegally obtain them online. Furthermore, as a side effect, they reduce their attendance for other movies in theaters, due to specific budget and time constraints. This might reflect the idea of mental accounting developed by Thaler (1985), and Heath and Soll (1996), who show that individuals set budgets for categories of expenses and then try not to diverge from it. As a result, the total industry profit is mainly redistributed to the advantage of American movies.

Several articles are closely connected to ours. Comparing France to other countries, Danaher et al. (2014) find a positive effect of the HADOPI law on weekly aggregate digital music sales in France. McKenzie (2017) studies the effect of several anti-piracy laws using international comparisons on the box office performance of movies and finds no market expansion effect. Adermon and Liang (2014) show that a Swedish anti-piracy law substantially decreased Internet traffic and increased music sales. Bhattacharjee et al. (2006) study the effect of legal threats from the Recording Industry Association of America toward Internet users and show that individuals have decreased the number of files shared. Peukert et al. (2017) and Danaher and Smith (2014) study the effects of the shutdown of Megaupload on movies' box office performance and video sales, respectively. Danaher and Smith (2014) find an increase in digital revenues of movies (7\%). Peukert et al. (2017) show that the closing of Megaupload has benefited large blockbusters and has hurt some movies with small audience. Similarly, Zhang (2018) finds that the removal of protection against piracy increases sales of niche products in the music industry. Finally, Aguiar et al. (2018) show that the closure of a large illegal video streaming platform in Germany has not increased legal sales because individuals can use alternative illegal platforms.

This article is also related to the empirical literature on the effects of piracy on legal sales. Several papers show that online piracy does not strongly affect total sales, Zentner (2010) finds no significant link between high-speed Internet penetration (a proxy for online piracy) and total box office revenues in a set of countries. Bai and Waldfogel (2012) use surveys on students and find a small negative effect of online movie piracy on legal consumption in theaters. Regarding the recorded music market, Oberholzer-Gee 
and Strumpf (2007) also find no significant effect of file sharing on sales. Several other papers find a displacement effect between illegal sharing and legal purchases: see Hennig-Thurau et al. (2007), Rob and Waldfogel (2007), Danaher et al. (2010), Danaher and Waldfogel (2012), and Ma et al. (2014) in the context of the movie industry; see Liebowitz (2006), Rob and Waldfogel (2006), Zentner (2006), Bhattacharjee et al. (2007), and Liebowitz (2008) for papers on the recorded music industry; and Reimers (2016) for the book industry. Finally, Zentner (2005) observes a negative correlation between Internet penetration and sales of music genres that are more heavily pirated but, as it is not the focus of his paper, he only provides macro-level evidence in a cross-country analysis. Readers are referred to Waldfogel (2012a), Smith and Telang (2012), Waldfogel (2012b), and Danaher et al. (2017) for more complete reviews of the literature.

\section{Description of online piracy of movies and of HADOPI}

\subsection{The asymmetry in online piracy}

Illegal copies mainly originate from camcording and video copies. According to the MPAA, camcording, which refers to thieves who use a digital recording device in a movie theater, accounts for the highest share of newly released movies that are pirated. Then, approximately two or three weeks before a film's video release, DVD and Blu-ray copies are sent to distributors. Thereafter, it is very difficult to identify the origin of the leak, and video copies become easily available on illegal markets. Illegal copies of films are occasionally made from advance copies used for screening and marketing purposes called 'screeners'. Illegal copies can also be made from a stolen film print or digital file from a theater, film depot, courier service, or other industry-related facility for making or financing films.

Camcording and the theft of advance copies are very common practices in North America but not in France. ${ }^{6}$ In addition, American movies are often released sooner in the U.S. than in France, which is confirmed by data collected on the movie website www.allocine.fr about the release dates of all American films introduced in France. In 2008, the median (mean) difference between the French theatrical release and the American one was 47 (59) days. Although this difference has decreased over time, it has remained largely positive. It was 47 (91) days in 2009, 40 (87) days in 2010, and 33 (57) days in 2011.

As a consequence, an illegal copy of an American movie is often available before its theatrical release in France, but this is not the case for most French movies. This asymmetry in online piracy is particularly

6. According to the ALPA, the main French association combating audiovisual piracy, there are almost no illegal copies coming from the theatrical exhibition of movies, and very few pirate teams specialized in camcording in France between 2007 and 2011. Other interviews with experts from the MPAA and from the HADOPI's government agency also confirm this. Moreover, the supply of pirate copies of American films is international and designed for the international market, while the supply of illegal of French films is mostly domestic. 
strong during the theatrical exhibition stage of movies. French movies become more exposed to online piracy as soon as they are released on the video market (that is, about one semester after the theatrical release), with illegal copies that start to quickly spread on the Internet. ${ }^{7}$ Therefore, American movies in France are relatively more exposed to piracy during the theatrical exhibition stage because of the asymmetric supply of illegal copies on the Internet. Several empirical figures support these arguments. Tables 1 and 2 draw on a report released by the ALPA in 2008 on illegal downloading of movies in France. ${ }^{8}$ They clearly illustrate that U.S. movies tend to be much more frequently illegally downloaded than French ones and are downloaded sooner and in most cases before their release in France. For the top-10 downloaded American or French movies, these tables show that the downloading of U.S. movies is relatively high while their demand in theaters (as measured by total admissions) is comparable to that for French movies.

Table 1 - Top-10 downloaded French movies (June 2008)

\begin{tabular}{|c|c|c|c|c|c|}
\hline Title & $\begin{array}{c}\text { Number } \\
\text { of daily } \\
\text { downloading }\end{array}$ & Total admissions & $\begin{array}{l}\text { Date of } \\
\text { French } \\
\text { release }\end{array}$ & $\begin{array}{c}\text { Date of first } \\
\text { detected illegal } \\
\text { downloading }\end{array}$ & $\begin{array}{c}\text { Time lag between } \\
\text { first illegal downloading } \\
\text { and French release }\end{array}$ \\
\hline Bienvenue chez les Ch'tis & 9800 & 20400000 & $27 / 02 / 2008$ & $05 / 03 / 2008$ & 7 \\
\hline Persepolis & 3500 & 1500000 & $27 / 06 / 2007$ & $13 / 10 / 2007$ & 108 \\
\hline La Môme & 1400 & 5300000 & $14 / 02 / 2007$ & $15 / 10 / 2007$ & 243 \\
\hline Disco & 4400 & 2400000 & $02 / 04 / 2008$ & $10 / 04 / 2008$ & 8 \\
\hline Survivre avec les Loups & 2400 & 600000 & $16 / 01 / 2008$ & $25 / 01 / 2008$ & 9 \\
\hline JCVD & 2400 & 170000 & $04 / 06 / 2008$ & $06 / 06 / 2008$ & 2 \\
\hline 15 ans et demi & 800 & 400000 & $30 / 04 / 2008$ & $08 / 05 / 2008$ & 8 \\
\hline Chasseurs de Dragon & 600 & 550000 & $26 / 03 / 2008$ & $07 / 04 / 2008$ & 12 \\
\hline Sans arme, ni haine, ni violence & 500 & 380000 & $16 / 04 / 2008$ & $28 / 04 / 2008$ & 12 \\
\hline L'Homme sans âge & 500 & 100000 & $14 / 11 / 2007$ & $26 / 11 / 2007$ & 12 \\
\hline
\end{tabular}

Table 2 - Top-10 downloaded U.S. movies (June 2008)

\begin{tabular}{|c|c|c|c|c|c|}
\hline Title & $\begin{array}{c}\text { Number } \\
\text { of daily } \\
\text { downloading }\end{array}$ & Total admissions & $\begin{array}{l}\text { Date of } \\
\text { French } \\
\text { release }\end{array}$ & $\begin{array}{c}\text { Date of first } \\
\text { detected illegal } \\
\text { downloading }\end{array}$ & $\begin{array}{l}\text { Time lag between } \\
\text { first illegal downloading } \\
\text { and French release }\end{array}$ \\
\hline Jumper & 24500 & 1200000 & $20 / 02 / 2008$ & $18 / 02 / 2008$ & -2 \\
\hline Cleaner & 14300 & 300000 & $14 / 05 / 2008$ & $22 / 05 / 2008$ & 8 \\
\hline Iron Man & 14000 & 2600000 & $30 / 04 / 2008$ & $05 / 05 / 2008$ & 5 \\
\hline Cloverfield & 13800 & 840000 & $06 / 02 / 2008$ & $25 / 01 / 2008$ & -12 \\
\hline Horton & 13000 & 1600000 & $02 / 04 / 2008$ & $17 / 03 / 2008$ & -16 \\
\hline Transformers & 12900 & 2000000 & $25 / 07 / 2007$ & $13 / 10 / 2007$ & 80 \\
\hline Juno & 12500 & 800000 & $06 / 02 / 2008$ & $20 / 12 / 2007$ & -48 \\
\hline There will be blood & 12400 & 530000 & $27 / 02 / 2008$ & $11 / 01 / 2008$ & -47 \\
\hline Bee movie & 11900 & 1250000 & $12 / 12 / 2007$ & $25 / 11 / 2007$ & -17 \\
\hline No country for old men & 11900 & 950000 & $23 / 01 / 2008$ & $28 / 11 / 2007$ & -56 \\
\hline
\end{tabular}

7. In the hypothetical case where illegal copies of French movies would also be available illegally online during their theatrical exhibition, we would obtain a situation similar to that observed on the video market and French movies would also be pirated during their theatrical exhibition.

8. Le téléchargement illégal des oeuvres cinématographiques francophones, ALPA, 2008. 
To strengthen the assumption that U.S. movies are available online illegally while this is less the case for French movies during their theatrical exhibition, we collected data on isohunt.com. Isohunt.com is one of the oldest online BitTorrent files index and the third most popular torrent website in the world in 2008 according to TorrentFreak. From that website, we gathered all torrent links, with the inception date of each link, available on the $19^{\text {th }}$ of July 2012. It was not possible to get the total number of downloads for each file as torrent websites only display the number of ongoing downloads. We merged data from isohunt.com with data from the CNC containing the release date of all movies introduced on the French theatrical market between 2007 and 2011. The median French movie is available via an illegal torrent link 168 days after its release in French theaters while the median US movie is available 11 days before its French theatrical release. Besides, the data show that supply of illegal copies is much more developed for US movie (433 torrent links) than for French ones (47 torrent links).

Finally, it should be noted that DVD counterfeiting is not very prevalent in France, according to interviews with experts working in piracy-fighting institutions like ALPA or SEVN. This form of piracy is more popular in developing countries than in developed ones, which are better equipped with broadband Internet.

\subsection{The HADOPI law}

The French HADOPI law is a "law promoting the distribution and protection of creative works on the Internet". The law was presented to the National Assembly in March 2009, where it was at first supported and then rejected. The law was enacted in October 2009 after more than one year of debate at the Senate, the National Assembly and the Constitutional Council (Danaher et al. (2014)). Finally, the first emails are sent by the government agency created to administer this law in September 2010.

HADOPI was mainly created for implementing a graduated response against online pirates. The HADOPI agency is empowered to initiate proceedings against illegal peer-to-peer file sharing. Copyright holders, beneficiary owners or their representatives such as ALPA detect an infringement using peerto-peer file sharing and inform the HADOPI authority, reporting the IP address of the infringer. The HADOPI agency checks this report and sends the IP address to Internet service providers to identify the Internet access subscriber. Then, the HADOPI agency may initiate a graduated response in a 'three-strikes' procedure. For the first strike, an email message is sent to the incriminated Internet access subscriber as a warning. Then if, in the six months following the first strike, a repeat infringement is detected, a registered letter is sent to the infringer as a second warning, with similar content to the first email message. Last if, in the one year following the second strike, a repeat infringement is detected, a second registered letter is 
sent to the infringer, informing him or her that the facts of the case are now subject to legal proceedings. The infringer can be subjected to penalties such as a fine and a loss of Internet access for one month to one year, in which case the infringer is blacklisted from Internet service providers. ${ }^{9}$ Until December 2011 (resp. 2015), 824,576 emails (resp. 4 million) were sent for the first strike, and 68,341 registered letters (resp. 400,000) were sent for the second strike.

The HADOPI law directly targets illegal peer-to-peer downloads. It may have deterred Internet users from downloading after receiving a warning from the HADOPI agency. The law may also have had an awareness and an educational effect on people who download illegally, thus giving them incentives to shift to legal consumption. Conversely, infringers may have simply switched to streaming technologies or direct downloads, which are not monitored by HADOPI. We provide in Appendix A descriptive evidence suggesting a decrease in the level of online piracy following the implementation of HADOPI, which has mainly come from peer-to-peer channels and without important transfers to other piracy channels.

\subsection{Theoretical background}

The mechanism would be as follows. Some people were downloading American films on the Internet and buying tickets for French films in theaters, because only American movies were available illegally on the Internet during their theatrical exhibition. When the access to illegal version of American movies became more difficult with the implementation of the anti-piracy law, consumers may have chosen to pay for U.S. movies rather than for French movies in theaters, because they are budget and time constrained, or because they aim at a level of expenditure - in time or money - in a given category of product (Thaler (1985), and Heath and Soll (1996)). As a result, the implementation of HADOPI can lead to more admissions for American movies. But, as a side effect, the HADOPI law may reduce the legal consumption of nonAmerican movies in theaters. We present a very simple model in Appendix A showing that the assumptions necessary to obtain this result are weak. This Appendix also provides contextual data supporting the mechanism leading to this substitution effect, namely that the average expense of moviegoers in theaters is stable over time, and that an important share of consumers enjoy watching both American and French movies in theaters.

9. Since the law was approved in 2009, only one Internet user has been suspended (for 15 days) and was also fined EUR 600. The fine cannot exceed EUR 1,500. However, the HADOPI agency has obtained 114 legal judgements within the framework of the graduated response. These figures appear low, but the graduated response is not designed to punish people and is mainly intended to educate people that they should not download illegally. Cutting off Internet access has been removed from the law in July 2013. 


\section{Data sources and descriptive statistics}

In this paper, we conduct four empirical analyses on different new datasets that we describe hereafter.

\section{$3.1 \quad$ Town-level data}

To implement a town-level approach, we use two sources of data, which we match through the Insee geographical codes for each town. These two sources are described below.

Town-level broadband Internet data. The Internet data contain information on the infrastructure of high-speed Internet connections in France during the fourth quarter of 2011. Using this dataset, we define the broadband coverage rate as the fraction of connections with download speeds higher than 512 $\mathrm{kbit} / \mathrm{s}$ over the total number of connections available in a town. All details concerning the method to compute this indicator are available in Appendix B. Throughout this paper, high speed Internet is defined as Internet connections with download speeds that exceed $512 \mathrm{kbit} / \mathrm{s}$. The Internet data come from Arcep, the French agency responsible for regulating telecommunications in France.

Table 3 presents the coverage rate of broadband Internet. In 2008, the 111 towns in our dataset were well equipped with high-speed Internet infrastructure: 50\% of these towns are supplied with at least $91 \%$ high-speed connections. This infrastructure equipment did not change during the period 2008-2011 (see Appendix B).

Table 3 - Coverage rate of broadband Internet of town-level data

\begin{tabular}{lcccc}
\hline \hline High speed Internet & \multicolumn{3}{c}{ Percentiles } & Mean \\
& p01 & p50 & p99 & \\
\hline Coverage rate (\%) & 65.9 & 91.1 & 97.2 & 90.4 \\
& & & & $(5.7)$ \\
\hline Source: Arcep. Standard deviation in parentheses.
\end{tabular}

Town-level movie sales data. The movie dataset is provided by two companies, Rentrak (part of comScore) and Médiamétrie, two audience measurement companies. The data coming from Rentrak contain the box office performance of all multiplexe cinemas ${ }^{10}$ located in 66 middle-sized towns in France by movie theater, week, and movie, between October 2008 and April 2011. The dataset coming from Médiamétrie contains the box office performance of movies in 45 middle-sized towns in France by movie theater, week, and movie, between October 2008 and April 2011. The twelve biggest cities of France are excluded from the analysis because their penetration of broadband Internet was already very high during the period of the study.

10. A multiplexe cinema is a cinema with several screens. Multiplexe cinemas accounts for most of movie admissions. 
Table 4 displays summary statistics about movie sales over the 111 towns. The number of tickets sold to American films has more increased in towns with high coverage of broadband Internet than in other towns after the adoption of the anti-piracy law. This double difference is negative for French movies, and close to zero when considering all movies.

Table 4 - Average movie admissions of town-level data

\begin{tabular}{lccccc}
\hline \hline & \multicolumn{2}{c}{ Before HADOPI } & & \multicolumn{2}{c}{ After HADOPI } \\
\cline { 2 - 3 } \cline { 5 - 6 } \cline { 5 - 6 } & $\begin{array}{c}\text { Towns with low } \\
\text { Internet coverage }\end{array}$ & $\begin{array}{c}\text { Towns with high } \\
\text { Internet coverage }\end{array}$ & & $\begin{array}{c}\text { Towns with low } \\
\text { Internet coverage }\end{array}$ & $\begin{array}{c}\text { Towns with high } \\
\text { Internet coverage }\end{array}$ \\
\hline U.S. movies & $23,565.9$ & $24,339.5$ & & $28,177.3$ & $29,078.4$ \\
& $(21,722.0)$ & $(27,099.5)$ & & $(24,650.7)$ & $(28,381,0)$ \\
Other movies & $17,956.5$ & $17,865.6$ & & $14,976.1$ & $14,681.2$ \\
& $(13,668.9)$ & $(13,230.3)$ & & $(13,456.5)$ & $(12,886.6)$ \\
All movies & $41,652.8$ & $42,570.5$ & & $43,071.9$ & $44,012.9$ \\
& $(33,710,0)$ & $(37,926.9)$ & & $(34,156.2)$ & $(36,839.8)$ \\
\hline
\end{tabular}

Standard errors in parentheses. Source: Arcep and Mediamétrie.

\subsection{Data of movie sales in France}

The second dataset we use consists of all movies released on at least 100 screens in France between 2007 and 2011. The data include the number of admissions and the number of screens during the release week in theaters in France. The data also contain rich information on movie characteristics: genre, nationality, producers, distributors, average press reviews, and consumer reviews on Allocine.fr, age restriction, art house movie classification, and awards in two main film competitions (Cannes Festival and Oscars). Finally, the data include total marketing expenditures. Most of the data are provided by the CNC, the French public administrative organization under the authority of the Ministry of Culture and Communication, which is responsible for monitoring the French movie industry, and from websites. Marketing data come from Kantar Media, which is a leading market research group.

Table 5 provides the main descriptive statistics for French and American movies. French movies are released on fewer screens than are American ones. They are also less successful than American movies: the admissions per screen are 810 for French movies and 925 for American movies. This feature is consistent with higher consumer ratings for American movies (with an average of 3.15 on a scale of 5) than for French movies (with an average of 2.87). Finally, 32\% of French films are classified as art-house whereas only $13 \%$ of American films are classified as art-house.

Figure 1 plots the ratio of admissions in the release week on the corresponding number of opening screens for French and American movies. Data are averaged by semester. The media and national awareness of HADOPI began in the second quarter of 2009 (Danaher et al. (2014)), before the law was adopted. 
Table 5 - Descriptive statistics of movie sales data in France

\begin{tabular}{|c|c|c|c|c|}
\hline & \multicolumn{2}{|c|}{ U.S. movies } & \multicolumn{2}{|c|}{ French movies } \\
\hline & Mean & Std. Dev. & Mean & Std. Dev. \\
\hline Number of obs. & 575 & & 456 & \\
\hline 1st week admissions/screens & 927 & 582 & 814 & 542 \\
\hline 1st week admissions & 386,582 & 452,890 & 303,546 & 415,199 \\
\hline 1st week screens & 363 & 195 & 326 & 162 \\
\hline Total admissions & 984,314 & $1,310,327$ & 898,626 & $1,667,620$ \\
\hline Art and house & 0.13 & 0.34 & 0.32 & 0.47 \\
\hline Average user rating & 3.15 & .48 & 2.87 & 0.58 \\
\hline Average Press rating & 2.82 & 0.80 & 2.92 & 0.74 \\
\hline
\end{tabular}

After this period, the ratio of American movies substantially increases and remains larger than the French counterpart in all subsequent quarters. This increase was sustained after the actual adoption of the law and the beginning of the enforcement of the graduated response. This graphical evidence suggests a positive association between HADOPI and U.S. movies' box office performance.

Figure 1 - Admissions per screen between 2007 and 2011 (averaged by semester)(Source: CNC)

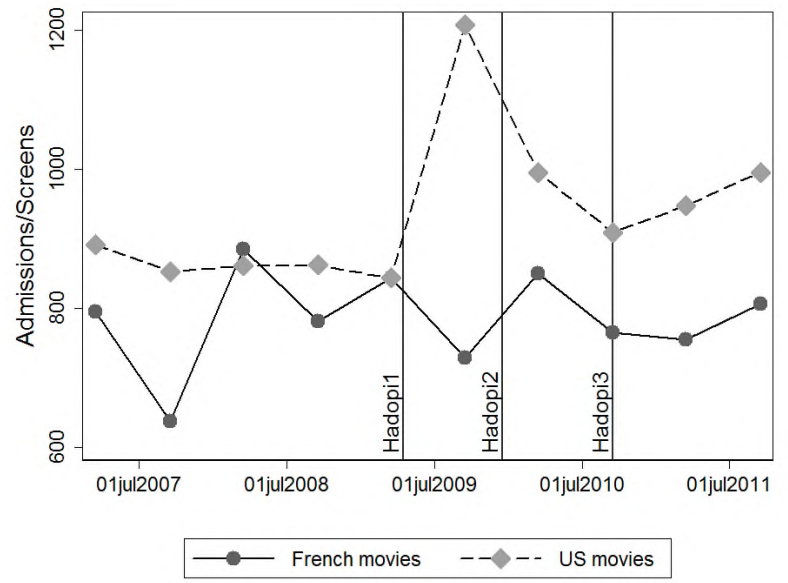

\subsection{International movie sales data}

The data consist of weekly box office gross in 18 European countries during the period beginning in January 2007 and ending in December 2011. The data only include movie-level box office revenues for the top-10 or top-20 movies (depending on the country, but the criteria do not change over time for a given country) for a defined period (3-, 4-, or 5-day "weekends"). The data set contains the name of the movie, its distributor(s) in different countries, the release date in each country, and the number of opening screens and box office gross in U.S. dollars. The data were collected in September 2012 from ScreenDaily.com. In 
addition, we have annual information by country on GDP per capita and broadband penetration. Upon close inspection, the data are reliable and are provided in a common format across our period of interest for nine countries: Belgium, Finland, France, Germany, Italy, the Netherlands, Spain, Switzerland, and the United Kingdom. Movie revenues are converted into the number of tickets sold based on the current conversion rates and average ticket prices. Data cover $85 \%$ to $90 \%$ of the total number of admissions.

\subsection{Consumer-level data}

In France, a consumer has the option to subscribe to unlimited access movie cards issued by movie theater companies. This annual contract costs approximately 20 euros per month. The monthly fee is automatically debited to a bank account until cancellation. This card provides unlimited access to the movies exhibited in the theaters that accept the card. It includes all theaters that are part of the chain issuing the card and the independent theaters that have an agreement with that chain. The other option for a consumer to watch a movie in a theater is to pay approximately 10 euros per movie or to purchase a five-ticket pass for 40 euros. Note that students, unemployed persons, and seniors also have access to reduced-fare tickets.

We gathered unique sales data from three theaters in two medium-sized French cities that belong to the same chain and that all accepted the unlimited access card between 2008 and 2011. ${ }^{11}$ These data contain the age and the gender of the cardholder, the movie, the theater, and the date of each transaction and visit.

The combined market share of the three theaters accounts for between $80 \%$ and $90 \%$ of the market of the respective city. Another independent movie theater specialized in art-house movies is present in each city. We do not have sales data for those independent art-house movie theaters, but because the three movie theaters we use clearly dominate the local markets, we are confident that no competitive effect interferes with the subsequent analysis.

The unlimited access cards were introduced in 2003 and in 2006 in each city. Figures 2(a) and 2(b) display the monthly growth rate and the monthly number of subscribers to this program. The economic success of this program has been substantial; with an average monthly growth rate about $1.25 \%$. The growth rate increases consistently over time. It also follows a seasonal pattern, with a drop during summer and a pronounced shift upward at the end of the year because of usual price promotions. The growth rate does not sharply increase with the HADOPI law. There are several lines of evidence of increase in the

11. In the first town, there are two large theaters located in the inner city and in the suburbs. In the second town, there is one theater located in the inner city. 
growth rate before the law was passed and several of decrease after the law. Therefore, consumers have probably not changed their subscription behavior in response to the law. The graphs also show that the number of cardholders has increased more quickly for younger consumers than for older consumers.

Figure 2 - Growth in the number of consumers holding an unlimited access card
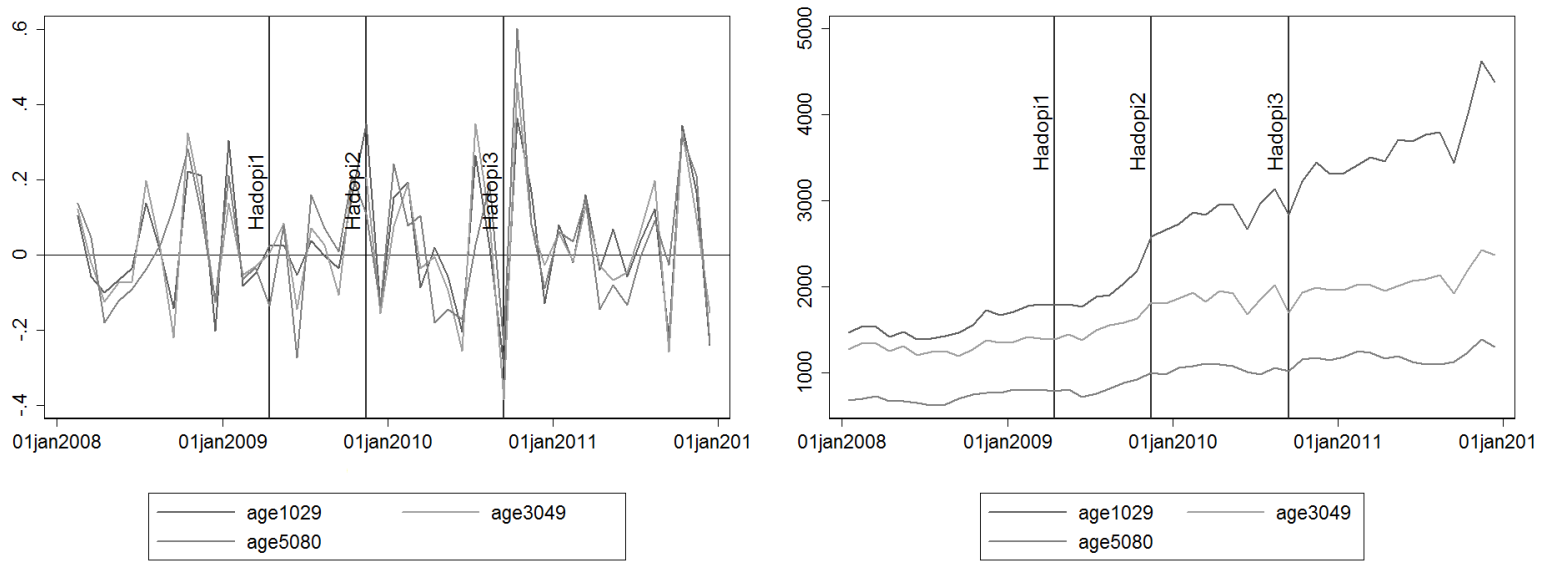

(a) Monthly growth rate of the number of unique mem- (b) Monthly number of unique members consuming bers consuming movies movies

Table 6 presents the percentage of U.S. films watched by consumers with card. This percentage is higher after the law was adopted. It is particularly the case for younger consumers, aged between 10 and 29, who generally download more than older consumers. This table presents unconditional statistics, we obtain stronger results in the regressions where we control for several confounding factors.

Table 6 - Percentage of U.S. movies watched by consumers with unlimited access card

\begin{tabular}{lcc}
\hline \hline & Before HADOPI & After HADOPI \\
\hline All consumers with card & $51,2 \%$ & $53,8 \%$ \\
Consumers aged between 10 and 29 & $58,2 \%$ & $60,9 \%$ \\
Consumers aged between 30 and 49 & $52,4 \%$ & $53,4 \%$ \\
Consumers aged between 50 and 80 & $37,9 \%$ & $39,4 \%$ \\
\hline Source: A French movie theater company. & &
\end{tabular}

\section{Empirical strategies and results}

In this section, we develop four empirical analyses to assess the effects of the anti-piracy law from different perspectives. Throughout this section, we test whether the law had an effect using an indicator that equals one beginning in November 2009 (hereafter $H A D O P I$ ), when the law was adopted, and zero 
otherwise. In addition, Danaher et al. (2014) argue that the HADOPI law began to have an effect on digital music sales in March 2009, when the law had yet to be enacted but was highly visible in the public debate with a wide media coverage. As a consequence, to test whether such an effect is also present for movie sales, we allow for heterogeneous effects of the HADOPI law in our estimations with respect to three periods of time:

- A first indicator for the period between April 2009 and October 2009 (hereafter HADOPI1), which corresponds to the period between the beginning of the debate among lawmakers and the adoption of the first version of the law.

- A second indicator for the period between November 2009 and August 2010 (hereafter HADOPI2), which is the period when the law was first adopted.

- A third indicator for the period between September 2010 and December 2011 (hereafter HADOPI3), which is the period during which the graduated response came into force.

The variable $H A D O P I 1$ captures what is happening just before the law was adopted, at the time of public debates and high media coverages. The variables HADOPI2 and HADOPI3 are a simple decomposition, over time, of the $H A D O P I$ indicator.

\subsection{Analysis 1: Town-level approach}

\subsubsection{Empirical strategy}

To examine the effects of the HADOPI law on the market for movie theaters in France, we compare box office performance in towns with a high-level of piracy to that in towns with a low-level of online piracy. This empirical strategy aims at isolating the law's effect from common shocks at the national level in France that would be concomitant with HADOPI. For instance, these coincident shocks could have been the release of unpredictably successful American movies or the release of poorly performing French movies.

We operationalize the level of online piracy before HADOPI in each town using broadband Internet coverage rate as a proxy. Our empirical approach assumes that towns with high broadband Internet coverage rate experience more illegal downloads than towns with low broadband Internet coverage. The underlying assumption is that broadband Internet coverage rate is able to proxy for variation in piracy intensity, because it directly constrains the possibility of downloading large files such as movies, and because it captures the number of broadband Internet subscribers. Indeed, high-speed Internet facilitates and reduces time for downloading. A 1 Gb file takes 34 hours to download with a $56 \mathrm{kbit} / \mathrm{s}$ connection but only 4 hours with a $512 \mathrm{kbit} / \mathrm{s}$ connection and 1 hour with a $2000 \mathrm{kbit} / \mathrm{s}$ connection. Without broadband connections, it is nearly impossible to use peer-to-peer networks to download heavy files. Besides, 
this variable is significantly correlated with the number of broadband Internet subscribers, as shown in Appendix C. As a result, towns with a higher level of broadband Internet coverage should have been more affected by the HADOPI law.

Weekly movie sales in a theater can be very erratic and depend on the presence of blockbuster movies. These volatile variations in sales are not linked to the HADOPI law but can hamper an accurate measurement of its effects. To compare a stable level of American movie sales with French movie sales by town before and after the HADOPI law, theater movie sales data are aggregated by town, by month and by nationality. ${ }^{12}$ This aggregation mitigates the competitive effects between theaters in a town and smooths most of the erratic variation in movie sales in each town. We estimate the following equation: ${ }^{13}$

$$
\text { Outcome }_{c t}=\rho_{c}+\tau_{t}+\alpha H A D O P I_{t} \times \text { Internet }_{c}+x_{c t}^{\prime} \beta+\epsilon_{c t}
$$

where Outcome $c$ is an economic outcome (the market share of American movies, the logarithm of admissions to all movies, to U.S. movies, or to other (French) movies) in town $c$ during month $t, H A D O P I_{t}$ equals one after the implementation of HADOPI, Internet Is $_{\text {is }}$ the fraction of connections eligible to highspeed Internet over the total number of connections in town $c$, and $x_{c t}$ is a set of time-varying covariates we describe below. The standard errors are clustered at the town level, as recommended by Bertrand et al. (2004), to take into account the autocorrelation between observations belonging to the same town.

The broadband Internet coverage rate is likely to be exogenous. Indeed, the infrastructure to access high-speed Internet in France is based on the physical network providing fixed telephone lines. The spatial variation in Internet infrastructure is linked to the geographical extent of the network and to its progressive diffusion in France, and is due to limited funding. It is thus unlikely to co-vary with the key correlates of movie attendance, and the timing of the installation of high-speed Internet infrastructure is not correlated with the HADOPI law and did not vary substantially over the period $2008-2011$. Besides, the theoretical maximum download speed of an Internet connection depends on the physical infrastructure and is not the result of consumer choice, which strengthen the relevance of our proxy. Internet service providers only advertise the maximum speeds they deliver in France as a whole. In principle, most consumers do not know the speed of their Internet connection before moving into their homes. However, any well-advised consumer can find this information using detailed maps available on the Internet. In remote areas, that some homes have poor Internet connections can be common knowledge. This feature might weaken the power of our

12. Bi-national movies such as Harry Potter are considered American.

13. To obtain a decomposition of the HADOPI effect over time, we also estimate the following equation: Outcome $_{c t}=\rho_{c}+\tau_{t}+\alpha_{1} H A D O P I 1_{t} \times$ Internet $_{c}+\alpha_{2} H A D O P I 2_{t} \times$ Internet $_{c}+\alpha_{3} H A D O P I 3_{t} \times$ Internet $_{c}+x_{c t}^{\prime} \beta+$ $\epsilon_{c t}$. The interpretation of the HADOPI2 coefficient, for instance, is the same as for the HADOPI coefficient, but is only valid for the sub-period associated to $H A D O P I 2$. 
proxy but we focus this study on middle-sized towns that are not remote by definition. Another good feature of our proxy is that all Internet packages were unlimited over the period $2008-2011$, and hence, a consumer could not choose to restrict the speed of his or her Internet connection by paying less.

Unobservable town-level shocks and unobservable common time shocks that are correlated with movie performance are controlled for with town and month fixed effects. We also control for a local time-varying indicator with $x_{c t}$, which contains factors influencing the box office performance of movies. That is, we control for the quality of all American and French movies available in town $c$ during month $t$ using the results of an ancillary estimation. We obtain these two movie quality indicators by estimating $\hat{\xi}_{i}$ using the following equation: $\log \left(\right.$ admissions $\left._{i c e t}\right)=\gamma_{t}+\phi_{c}+\nu_{e}+\mu\left(t-r_{i}\right)+\xi_{i}+\zeta_{\text {icet }}$, where $\log \left(\right.$ admissions $\left._{i c e t}\right)$ is the logarithm of the admissions of movie $i$, in town $c$, in theater $e$, during week $t$, where $\gamma_{t}$ is a week indicator, $\phi_{c}$ is a town indicator, $\nu_{e}$ is a movie theater establishment indicator, $r_{i}$ is the release date of movie $i$ in France, such that $\mu$ controls for the common decay effect of movie sales, and $\xi_{i}$ is a movie indicator. $\hat{\xi}_{i}$ are then aggregated by month, town, and nationality of movies. ${ }^{14}$

We visually check for the lack of differential pre-treatment trends in the market share of American films between towns with high penetration of broadband Internet and towns with low ones in Figure 3 . Furthermore, a test presented in Appendix D confirms that broadband coverage is not correlated with changes in box office revenues before the HADOPI law started to be debated among lawmakers. This test alleviates the concerns that American films could have benefited more from social media or from the additional ability to advertise to consumers through the Internet.

\subsubsection{Results}

Table 7, Table 8, Table 9, and Table 10 respectively report the results with the market share of American movies, the log of admissions to American movies, the log of admissions to other movies, and the $\log$ of total admissions as the outcomes of interest. Columns 1-2 control for town fixed effects and month fixed effects, columns 3-4 additionally control for the time-varying quality of American movies and French movies, and columns 5-6 drop the 50\% of towns with high-speed Internet infrastructure closest to the median.

The results from Table 7 indicate that American movies' market share increased after the implementation of the anti-piracy law (columns 1, 3,5). This effect appears before the law was actually adopted, as the

14. The movie fixed effect $\xi_{i}$ captures the average ability of movie $i$ to generate admissions, controlling for its release week in France, the seasonality, and the fixed characteristic of the markets in which it is exhibited (see Einav (2007) for a detailed discussion). By summing the estimated movie fixed effects of the movies exhibited in town $c$ during month $t$ by nationality, we are able to capture the total quality of French movies and of U.S. movies available in each market. 
Figure 3 - Difference in market share of U.S. films in towns with the highest penetration rate of broadband Internet versus towns with the lowest one

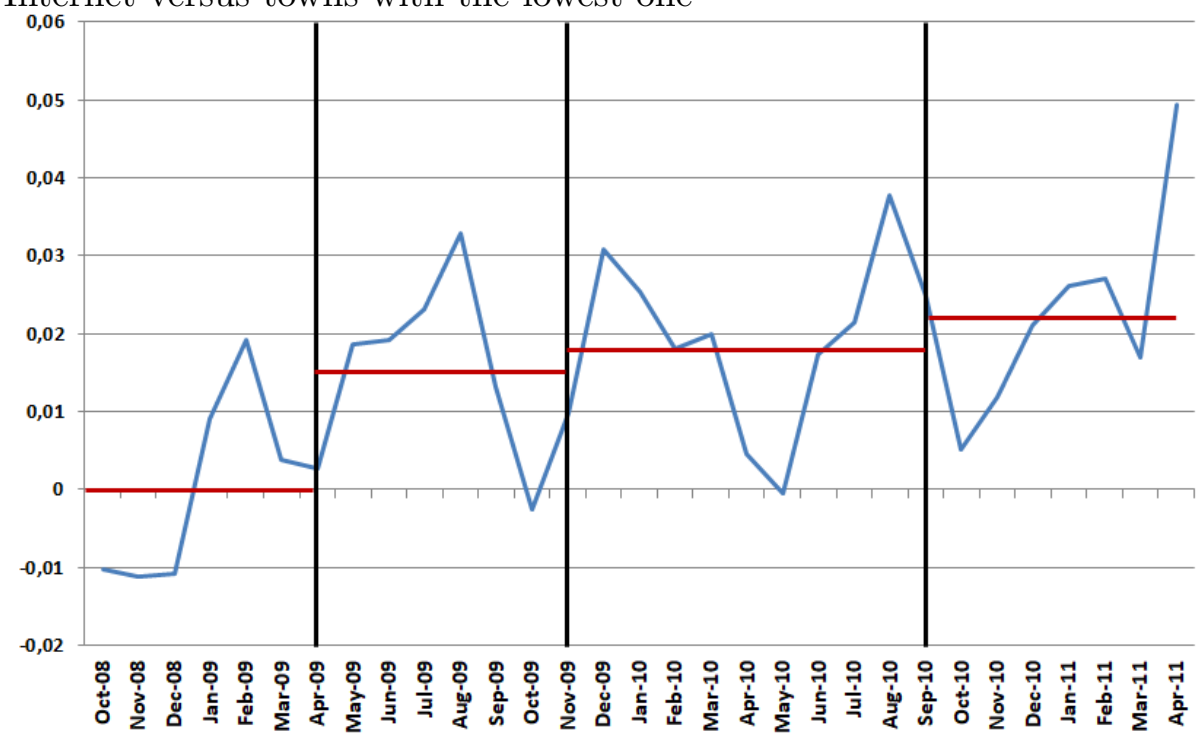

Reading key: In September 2011, the market share of U.S. films was $4.3 \%$ higher in the half of towns with the highest penetration rate of broadband Internet compared to the half of towns with the lowest one, once the quality of French and U.S. films, and other fixed effects are controlled for. The first vertical line corresponds to the beginning of the harsh debates preceding the adoption of the low (April 2009), the second vertical line corresponds to the validation of the law by the Constitutional Council (22nd of October 2009), and the second line corresponds to first warnings being sent by HADOPI (September 2010). Sources: Arcep, Médiamétrie. 
coefficient of $H A D O P I 1$ is significantly positive (columns $2,4,6$ ). As a consequence, in the specifications where we estimate the average effect of the law using the variable HADOPI (i.e., in columns 1, 3, and 5), we remove the period between the beginning of the debate and the adoption of the law from the analysis (i.e., we remove the observations where $H A D O P I 1=1$ ), so that the control period is unaffected by the treatment. ${ }^{15}$ Estimated coefficients can be interpreted as follows. For instance, the coefficient $\beta$ from column 3 means that U.S. movies' market share increased by 0.15 percentage points when the broadband Internet coverage rate increases by 1 percentage point, after the HADOPI law was passed.

Results from Tables 8, 9, and 10 provide a better understanding of the effect. The law is associated to an important increase in the number of admissions to American movies (Table 8), which occurs at the cost of a significant decrease in the number of admissions to other (French) movies (Table 9), resulting in a smaller and sometimes significant increase in the total number of admissions in France (Table 10). They also indicate that the market expansion effect was likely to be a temporary effect while the decrease in the admissions to other (French) movies was likely to last for a longer period.

Table 7 - Estimates of equation (1) when the outcome is the U.S. market share

\begin{tabular}{|c|c|c|c|c|c|c|}
\hline & \multicolumn{6}{|c|}{ U.S. market share } \\
\hline & (1) & (2) & (3) & (4) & $(5)$ & (6) \\
\hline HADOPI $\times$ Internet & $\begin{array}{c}0.211^{* * *} \\
(0.0522)\end{array}$ & & $\begin{array}{c}0.151^{* * *} \\
(0.0432)\end{array}$ & & $\begin{array}{c}0.143^{* * *} \\
(0.0470)\end{array}$ & \\
\hline HADOPI $1 \times$ Internet & & $\begin{array}{c}0.237^{* * *} \\
(0.0486)\end{array}$ & & $\begin{array}{c}0.223^{* * *} \\
(0.0442)\end{array}$ & & $\begin{array}{c}0.183^{* * *} \\
(0.0479)\end{array}$ \\
\hline HADOPI $2 \times$ Internet & & $\begin{array}{c}0.217^{* * *} \\
(0.0504)\end{array}$ & & $\begin{array}{c}0.196 * * * \\
(0.0438)\end{array}$ & & $\begin{array}{c}0.164^{* * *} \\
(0.0445)\end{array}$ \\
\hline HADOPI $3 \times$ Internet & & $\begin{array}{c}0.212^{* * *} \\
(0.0617)\end{array}$ & & $\begin{array}{c}0.153^{* * *} \\
(0.0572)\end{array}$ & & $\begin{array}{c}0.122^{* *} \\
(0.0565)\end{array}$ \\
\hline Town fixed effect & yes & yes & yes & yes & yes & yes \\
\hline Month fixed effect & yes & yes & yes & yes & yes & yes \\
\hline Quality of French films & no & no & yes & yes & no & no \\
\hline Quality of U.S. films & no & no & yes & yes & no & no \\
\hline Constant & yes & yes & yes & yes & yes & yes \\
\hline Observations & 2581 & 3338 & 2581 & 3338 & 1213 & 1570 \\
\hline R-squared & 0.751 & 0.787 & 0.762 & 0.790 & 0.774 & 0.804 \\
\hline
\end{tabular}

The results about the market expansion are mixed and it is important to know whether an anti-piracy law increase the size of the legal market or not. Therefore, in a robustness check, we add some structure by implementing a discrete choice model. Specifically, we estimate the monthly demand for movies with a logit model on the data used in this analysis. Using the parameter estimates, we run a counterfactual simulation of what would have been the number of admissions of American movies, of other movies, and of

15. This is a common practice. For instance, in competition analysis, the starting date of a cartel is often unknown. Therefore, Practitioners usually remove the period that is presumably surrounding the creation date of the cartel. 
Table 8 - Estimates of equation (1) when the outcome is the admissions to American movies

\begin{tabular}{lcccccc}
\hline \hline & \multicolumn{5}{c}{$\log (\mathrm{U} . \mathrm{S}$. Admissions $)$} \\
\cline { 2 - 7 } & $(1)$ & $(2)$ & $(3)$ & $(4)$ & $(5)$ & $(6)$ \\
\hline HADOPI $\times$ Internet & $0.634^{* *}$ & & $0.422^{*}$ & & 0.301 & \\
& $(0.247)$ & & $(0.219)$ & & $(0.212)$ & \\
HADOPI1 $\times$ Internet & & $0.753^{* * *}$ & & $0.679^{* * *}$ & & $0.538^{* * *}$ \\
& & $(0.197)$ & & $(0.173)$ & & $(0.189)$ \\
HADOPI2 $\times$ Internet & & $0.773^{* * *}$ & & $0.661^{* * *}$ & & $0.484^{* *}$ \\
& & $(0.248)$ & & $(0.218)$ & & $(0.214)$ \\
HADOPI3 $\times$ Internet & & 0.391 & & 0.127 & & 0.00352 \\
& & $(0.246)$ & & $(0.231)$ & yes & yes \\
Town fixed effect & yes & yes & yes & yes & yes & yes \\
Month fixed effect & yes & yes & yes & yes & no & no \\
Quality of French films & no & no & yes & yes & no & no \\
Quality of U.S. films & no & no & yes & yes & yes & yes \\
Constant & yes & yes & yes & yes & 1570 \\
Observations & 2581 & 3338 & 2581 & 3338 & 1213 & 1570 \\
R-squared & 0.642 & 0.712 & 0.656 & 0.720 & 0.625 & 0.704 \\
\hline
\end{tabular}

Source: Arcep, CNC, Médiamétrie, Rentrak

Standard errors clustered by town in parentheses. ${ }^{*} p<0.10,{ }^{* *} p<0.05,{ }^{* * *} p<0.01$

Table 9 - Estimates of equation (1) when the outcome is the admissions to other (French) movies

\begin{tabular}{|c|c|c|c|c|c|c|}
\hline & \multicolumn{6}{|c|}{ log(Other Admissions) } \\
\hline & (1) & $(2)$ & $(3)$ & (4) & (5) & (6) \\
\hline HADOPI $\times$ Internet & $\begin{array}{c}-0.463^{* * *} \\
(0.176)\end{array}$ & & $\begin{array}{c}-0.433^{* *} \\
(0.172)\end{array}$ & & $\begin{array}{c}-0.475^{* *} \\
(0.179)\end{array}$ & \\
\hline HADOPI $1 \times$ Internet & & $\begin{array}{c}-0.388^{* *} \\
(0.187)\end{array}$ & & $\begin{array}{c}-0.414^{* *} \\
(0.190)\end{array}$ & & $\begin{array}{c}-0.331^{*} \\
(0.181)\end{array}$ \\
\hline HADOPI $2 \times$ Internet & & $\begin{array}{c}-0.393^{* *} \\
(0.184)\end{array}$ & & $\begin{array}{c}-0.432^{* *} \\
(0.189)\end{array}$ & & $\begin{array}{c}-0.414^{* *} \\
(0.181)\end{array}$ \\
\hline HADOPI $3 \times$ Internet & & $\begin{array}{c}-0.650^{* * *} \\
(0.225)\end{array}$ & & $\begin{array}{c}-0.715^{* * *} \\
(0.230)\end{array}$ & & $\begin{array}{c}-0.636^{* * *} \\
(0.233)\end{array}$ \\
\hline Town fixed effect & yes & yes & yes & yes & yes & yes \\
\hline Month fixed effect & yes & yes & yes & yes & yes & yes \\
\hline Quality of French films & no & no & yes & yes & no & no \\
\hline Quality of U.S. films & no & no & yes & yes & no & no \\
\hline Constant & yes & yes & yes & yes & yes & yes \\
\hline Observations & 2586 & 3344 & 2586 & 3344 & 1218 & 1576 \\
\hline $\mathrm{R}$-squared & 0.745 & 0.747 & 0.746 & 0.748 & 0.768 & 0.773 \\
\hline
\end{tabular}

Source: Arcep, CNC, Médiamétrie, Rentrak

Standard errors clustered by town in parentheses. ${ }^{*} p<0.10, * * p<0.05$, *** $p<0.01$ 
Table 10 - Estimates of equation (1) when the outcome is the total admissions

\begin{tabular}{|c|c|c|c|c|c|c|}
\hline & \multicolumn{6}{|c|}{$\log$ (Total Admissions) } \\
\hline & (1) & $(2)$ & (3) & (4) & (5) & (6) \\
\hline HADOPI $\times$ Internet & $\begin{array}{c}0.226 \\
(0.160)\end{array}$ & & $\begin{array}{c}0.141 \\
(0.153)\end{array}$ & & $\begin{array}{l}0.0532 \\
(0.146)\end{array}$ & \\
\hline HADOPI1 $\times$ Internet & & $\begin{array}{c}0.305^{* *} \\
(0.140)\end{array}$ & & $\begin{array}{c}0.256^{*} \\
(0.133)\end{array}$ & & $\begin{array}{c}0.197 \\
(0.134)\end{array}$ \\
\hline HADOPI $2 \times$ Internet & & $\begin{array}{c}0.353^{* *} \\
(0.166)\end{array}$ & & $\begin{array}{l}0.279 * \\
(0.155)\end{array}$ & & $\begin{array}{c}0.190 \\
(0.150)\end{array}$ \\
\hline HADOPI $3 \times$ Internet & & $\begin{array}{r}-0.0197 \\
(0.167)\end{array}$ & & $\begin{array}{l}-0.158 \\
(0.171)\end{array}$ & & $\begin{array}{l}-0.196 \\
(0.154)\end{array}$ \\
\hline Town fixed effect & yes & yes & yes & yes & yes & yes \\
\hline Month fixed effect & yes & yes & yes & yes & yes & yes \\
\hline Quality of French films & no & no & yes & yes & no & no \\
\hline Quality of U.S. films & no & no & yes & yes & no & no \\
\hline Constant & yes & yes & yes & yes & yes & yes \\
\hline Observations & 2586 & 3344 & 2586 & 3344 & 1218 & 1576 \\
\hline R-squared & 0.686 & 0.711 & 0.689 & 0.714 & 0.668 & 0.705 \\
\hline
\end{tabular}

all movies without the HADOPI law. The details of the model and the results are presented in Appendix E. The simulations confirm the results from our reduced-form analysis. That is, we find a strong increase in the number of admissions to American movies ( +21 million) as well as a strong decrease in the number of admissions to other movies ( -17 million). The resulting effect on total admissions is positive ( +4 million) but non-statistically different from zero (with a large confidence interval) and much smaller in size than the effect on American or other movies. Therefore, this test supports that the HADOPI effect is likely to be a business stealing effect that benefits U.S. movies at the expense of other (French) movies, with a possible but smaller expansion of the market that is non significant.

3D movies were introduced at the same time as HADOPI with the release of Avatar near the end of 2009. This technological innovation could have influenced the demand for movies in theaters and 3D films were mainly American. Thus, in a robustness check presented in Appendix F, we rule out the advent of $3 \mathrm{D}$ movies as an alternative mechanism that could potentially drive our results.

\subsection{Analysis 2: American vs French movies in France}

\subsubsection{Empirical strategy}

The methodology requires supplementary analyses to exclude other competing explanations. A competing explanation would be a supply-side reaction to the law. In particular, distributors may have adjusted their release strategy to maximize their profit in this new setting for instance through their release strategy, their marketing campaign, or the number of opening screens (See McCalman (2005) for a theoretical 
argument). ${ }^{16}$ Moreover, U.S. distributors could have manipulated their release strategy to boost movie revenues with a view to convince governments of the efficiency of anti-piracy actions. ${ }^{17}$

We check that our results are not driven by supply reactions by conducting an analysis at the French national level in a difference-in-differences setting. The "treatment" group comprises American movies, and the "control" group is composed of French movies. The baseline estimation is as follows:

$$
\text { Outcomes }_{i t}=\rho_{t}+\beta X_{i}+\gamma U S_{i}+\alpha H A D O P I_{t} \times U S_{i}+\epsilon_{i t}
$$

for movie $i$ during release week $t$, where $U S_{i}$ equals 1 if movie $i$ is from the US and 0 otherwise, and where $X_{i}$ is a set of movie variables including the production budget, the advertising expenditures, the number of screens on the release day, consumers' rating, press rating, fixed effects for genre, nationality, art-house movies, age restrictions, and distributors. We test four possible supply reactions to the HADOPI law: the $\log$ of the number of screens on which movies are released, the log of the production budget in dollars, the log of the total marketing expenditures, and the quality of movies measured by consumer ratings.

In addition, we also verify that the market share of U.S. movies has increased thanks to the anti-piracy law. To this end, we estimate equation (2) using the logarithm of admissions during the release week, and the logarithm of the ratio between the number of admissions during the release week and the corresponding number of screens as dependent variables. This ratio is commonly used in the industry and enables rescaling all movies, thus making comparisons more relevant and controlling for the main supply reaction. We focus on the release week because the asymmetry in the level of online piracy between American and French films is the highest during the opening week.

This approach does not allow us to disentangle the market creation effect from the business stealing effect. It identifies relative business stealing by comparing American to French movies: admissions to American movies are directly impacted by the law, and admissions to French movies are indirectly impacted through the greater competition from American films following the law.

16. Note that prices are fixed in the movie industry, i.e., there is no movie-by-movie pricing (Einav and Orbach (2007)). This prevents any finely tailored pricing reaction to the law.

17. U.S. major film studios lobby the foreign governments through the Motion Picture Association (MPA) to enforce anti-piracy actions. The MPA is the international offshoot of the MPAA and represents the interests of the six main U.S. major film studios. The MPA particularly aims at promoting the protection of the copyrights of these companies. It works to shape and advise on the public policies of foreign countries insofar as they affect the interest of MPA members. 


\subsubsection{Results}

We present the results of the supply reaction in Table 11. They indicate that there was no change in the number of opening screens for U.S. movies during the HADOPI (columns 1 and 2), that there was no variation in the production budget of American movies (columns 3 and 4), and a decrease in consumer ratings (column 7 and 8). We also observe a small increase in marketing expenditure during the third period of HADOPI (columns 5 and 6). Overall, these results exclude supply side reactions to the law as the main explanation for the increase in American movies' market share. They tend to indicate a decrease in American movie quality (the consumer ratings) during the HADOPI effect, which actually reinforces the main result of an increase in demand for American movies. The increase in the marketing expenditure of American movies during the third period of HADOPI could have explained the rise in U.S. movies' market share, but we confirm the increase in U.S. movie sales relative to French ones, while controlling for advertising expenditure in Table 12 presented just below. ${ }^{18}$ Then, this increase in advertising spending does not entail an increase in the number of screens and, hence, it might be linked to the legal reduction of the time to release a movie on video. ${ }^{19}$

The results in Table 12 confirm that HADOPI is associated with an increase in admissions for U.S. movies relative to French ones (columns 1 and 3). They also indicate that HADOPI may have had an effect before its actual implementation during the period of legislative debate, that is April 2009 - October 2009 (columns 2 and 4). Finally, they also show that the HADOPI effect may have been temporary and ended in September 2010 (columns 2 and 4), the period during which the graduated response began to be enforced.

In a supplementary test, we examine the heterogeneity of the HADOPI effect on movie admissions according to the variable movie genre, available in the dataset of this analysis. The most pirated movies are usually those aimed at a teenager audience such as Fantasy, Science Fiction, and Horror movies (see Danaher et al. (2010), Danaher and Waldfogel (2012), Variety $2019^{20}$, and all the yearly rankings of the most pirated movies). Therefore, we expect the HADOPI law to have a positive effect on the admissions to the most pirated films. Results from this supplementary test are presented in Appendix G. They show that the HADOPI law significantly increases the admissions to American sci-fi/fantasy/horror movies, at

18. In addition to this robustness check, we verify that the efficiency of advertising has not increased simultaneously with HADOPI implementation by estimating the following equation for U.S. movies: $\log \left(\right.$ Admissions $\left._{i t}\right)=$ $\rho_{t}+\delta \log \left(\right.$ AdSpending $\left._{i}\right)+\beta \log \left(\right.$ AdSpending $\left._{i}\right) \times H A D O P I_{t}+\gamma X_{i t}+\epsilon_{i t}$, where $X_{i t}$ includes the usual control variables. It appears that $\beta$ is not significantly different from zero.

19. Simultaneously with the HADOPI law, the minimum period of time to release a movie on video after the theatrical release was reduced from six to four months.

20. https://variety.com/2019/digital/news/avengers-endgame-piracy-box-office-1203198888/ 
Table 11 - Estimates of equation (2) when the outcome is a supply indicator: number of opening screens, production budgets, advertising expenditures, or consumer ratings

\begin{tabular}{|c|c|c|c|c|c|c|c|c|}
\hline & \multicolumn{2}{|c|}{$\log ($ Screens $)$} & \multicolumn{2}{|c|}{$\log ($ Budget $)$} & \multicolumn{2}{|c|}{$\log (\mathrm{Ad})$} & \multicolumn{2}{|c|}{ Consumer rating } \\
\hline & (1) & $(2)$ & $(3)$ & (4) & (5) & (6) & $(7)$ & (8) \\
\hline HADOPI × U.S. & $\begin{array}{r}-0.00205 \\
(0.0458)\end{array}$ & & $\begin{array}{l}-0.0994 \\
(0.0959)\end{array}$ & & $\begin{array}{c}0.0858 \\
(0.0696)\end{array}$ & & $\begin{array}{c}-0.292^{* * *} \\
(0.0650)\end{array}$ & \\
\hline HADOPI1 $\times$ U.S. & & $\begin{array}{c}0.0180 \\
(0.0733)\end{array}$ & & $\begin{array}{c}0.151 \\
(0.166)\end{array}$ & & $\begin{array}{l}0.211^{* *} \\
(0.0974)\end{array}$ & & $\begin{array}{c}-0.312^{* * *} \\
(0.102)\end{array}$ \\
\hline HADOPI2 × U.S. & & $\begin{array}{c}0.0761 \\
(0.0641)\end{array}$ & & $\begin{array}{l}-0.157 \\
(0.138)\end{array}$ & & $\begin{array}{l}0.0286 \\
(0.103)\end{array}$ & & $\begin{array}{c}-0.345^{* * *} \\
(0.0957)\end{array}$ \\
\hline HADOPI3 × U.S. & & $\begin{array}{l}-0.0602 \\
(0.0528)\end{array}$ & & $\begin{array}{c}-0.00168 \\
(0.114)\end{array}$ & & $\begin{array}{l}0.202^{* *} \\
(0.0793)\end{array}$ & & $\begin{array}{c}-0.346^{* * *} * \\
(0.0764)\end{array}$ \\
\hline $\log$ (Budget) & $\begin{array}{c}0.231^{* * *} \\
(0.0332)\end{array}$ & $\begin{array}{l}0.232^{* * * *} \\
(0.0325)\end{array}$ & & & $\begin{array}{l}0.0678^{*} \\
(0.0353)\end{array}$ & $\begin{array}{l}0.0643^{*} \\
(0.0358)\end{array}$ & $\begin{array}{l}0.00678 \\
(0.0327)\end{array}$ & $\begin{array}{l}0.00575 \\
(0.0325)\end{array}$ \\
\hline $\log (\mathrm{Ad})$ & $\begin{array}{c}0.360^{* * *} \\
(0.0351)\end{array}$ & $\begin{array}{l}0.361^{* * * *} \\
(0.0346)\end{array}$ & & & & & $\begin{array}{l}0.0649^{*} \\
(0.0359)\end{array}$ & $\begin{array}{c}0.0712^{* *} \\
(0.0357)\end{array}$ \\
\hline $\log ($ Screens $)$ & & & & & $\begin{array}{c}0.880^{* * * *} \\
(0.0564)\end{array}$ & $\begin{array}{c}0.880 * * * \\
(0.0552)\end{array}$ & $\begin{array}{l}-0.0299 \\
(0.0581)\end{array}$ & $\begin{array}{l}-0.0282 \\
(0.0582)\end{array}$ \\
\hline Consumer rating & $\begin{array}{l}-0.0131 \\
(0.0257)\end{array}$ & $\begin{array}{l}-0.0124 \\
(0.0258)\end{array}$ & $\begin{array}{c}0.0450 \\
(0.0606)\end{array}$ & $\begin{array}{c}0.0500 \\
(0.0607)\end{array}$ & $\begin{array}{l}0.0693^{*} \\
(0.0397)\end{array}$ & $\begin{array}{l}0.0762^{*} \\
(0.0398)\end{array}$ & & \\
\hline Press rating & $\begin{array}{c}0.0363^{* *} \\
(0.0182)\end{array}$ & $\begin{array}{l}0.0341^{*} \\
(0.0182)\end{array}$ & $\begin{array}{l}0.00224 \\
(0.0429)\end{array}$ & $\begin{array}{l}0.00261 \\
(0.0428)\end{array}$ & $\begin{array}{c}-0.00846 \\
(0.0258)\end{array}$ & $\begin{array}{r}-0.00842 \\
(0.0260)\end{array}$ & $\begin{array}{c}0.359 * * * \\
(0.0563)\end{array}$ & $\begin{array}{c}0.358 * * * \\
(0.0558)\end{array}$ \\
\hline Month fixed effect & yes & yes & yes & yes & yes & yes & yes & yes \\
\hline Nationality fixed effect & yes & yes & yes & yes & yes & yes & yes & yes \\
\hline Art and House fixed effect & yes & yes & yes & yes & yes & yes & yes & yes \\
\hline Age restriction fixed effect & yes & yes & yes & yes & yes & yes & yes & yes \\
\hline Distributor fixed effect & yes & yes & yes & yes & yes & yes & yes & yes \\
\hline Genre fixed effect & yes & yes & yes & yes & yes & yes & yes & yes \\
\hline Constant & yes & yes & yes & yes & yes & yes & yes & yes \\
\hline$N$ & 812 & 812 & 814 & 814 & 812 & 812 & 812 & 812 \\
\hline$R^{2}$ & 0.773 & 0.775 & 0.769 & 0.770 & 0.783 & 0.785 & 0.551 & 0.556 \\
\hline
\end{tabular}


Table 12 - Estimates of equation (2) when the outcome is a demand indicator: number of admissions, or number of admissions per screen

\begin{tabular}{|c|c|c|c|c|}
\hline & \multicolumn{2}{|c|}{$\log$ (Admissions) } & \multicolumn{2}{|c|}{$\log \left(\frac{\text { Admissions }}{\text { Screens }}\right)$} \\
\hline & (1) & $(2)$ & (3) & $(4)$ \\
\hline HADOPI × U.S. & $\begin{array}{c}0.117^{*} \\
(0.0635)\end{array}$ & & $\begin{array}{c}0.117^{*} \\
(0.0662)\end{array}$ & \\
\hline HADOPI1 × U.S. & & $\begin{array}{c}0.221^{*} \\
(0.120)\end{array}$ & & $\begin{array}{c}0.228^{*} \\
(0.120)\end{array}$ \\
\hline HADOPI $2 \times$ U.S. & & $\begin{array}{l}0.223^{* *} \\
(0.0868)\end{array}$ & & $\begin{array}{c}0.248^{* * *} \\
(0.0908)\end{array}$ \\
\hline HADOPI3 × U.S. & & $\begin{array}{c}0.104 \\
(0.0766)\end{array}$ & & $\begin{array}{c}0.0856 \\
(0.0797)\end{array}$ \\
\hline $\log ($ Screens $)$ & $\begin{array}{c}1.348^{* * *} * \\
(0.0738)\end{array}$ & $\begin{array}{c}1.341^{* * *} \\
(0.0729)\end{array}$ & & \\
\hline $\log (A d)$ & $\begin{array}{c}0.153^{* * *} \\
(0.0444)\end{array}$ & $\begin{array}{c}0.151^{* * *} \\
(0.0443)\end{array}$ & $\begin{array}{c}0.282^{* * *} \\
(0.0410)\end{array}$ & $\begin{array}{c}0.278^{* * *} \\
(0.0406)\end{array}$ \\
\hline $\log ($ Budget $)$ & $\begin{array}{l}-0.0244 \\
(0.0387)\end{array}$ & $\begin{array}{l}-0.0213 \\
(0.0384)\end{array}$ & $\begin{array}{c}0.0537 \\
(0.0385)\end{array}$ & $\begin{array}{c}0.0556 \\
(0.0378)\end{array}$ \\
\hline Consumer rating & $\begin{array}{c}0.205^{* * *} \\
(0.0409)\end{array}$ & $\begin{array}{c}0.211^{* * *} \\
(0.0408)\end{array}$ & $\begin{array}{c}0.198 * * * \\
(0.0424)\end{array}$ & $\begin{array}{c}0.205^{* * *} \\
(0.0421)\end{array}$ \\
\hline Press rating & $\begin{array}{c}0.110^{* * *} * \\
(0.0295)\end{array}$ & $\begin{array}{c}0.107^{* * *} \\
(0.0293)\end{array}$ & $\begin{array}{c}0.121^{* * *} \\
(0.0295)\end{array}$ & $\begin{array}{c}0.116^{* * *} \\
(0.0293)\end{array}$ \\
\hline Month fixed effect & yes & yes & yes & yes \\
\hline Nationality fixed effect & yes & yes & yes & yes \\
\hline Art and House fixed effect & yes & yes & yes & yes \\
\hline Age restriction fixed effect & yes & yes & yes & yes \\
\hline Distributor fixed effect & yes & yes & yes & yes \\
\hline Genre fixed effect & yes & yes & yes & yes \\
\hline Constant & yes & yes & yes & yes \\
\hline$N$ & 812 & 812 & 812 & 812 \\
\hline$R^{2}$ & 0.801 & 0.803 & 0.454 & 0.459 \\
\hline
\end{tabular}


the expense of French adventure, drama, and thriller/crime movies. This finding helps to understand why the effect of HADOPI is different between American and French movies, and to identify the type of cultural products whose production is potentially affected by the anti-piracy law.

The redistribution from French to American films could be explained by word of mouth effects, as in Peukert et al. (2017), where blockbuster films benefited from the shutdown of Megaupload at the expense of small independent films. According to them, illegal downloads benefit small film through sampling or word of mouth. Although the HADOPI law diminishes the ability to illegally sample movies or to spread the word, this information-spreading mechanism does not explain our result. We provide in Appendix $\mathrm{H}$ a second robustness check showing that blockbuster films, U.S. blockbusters in particular, have not benefited from higher revenues after the HADOPI law. ${ }^{21}$ Besides, French movies are not available on the Internet before their introduction on the theatrical market thus they cannot benefit from word of mouth through this channel, while the opposite applies to U.S. movies. Therefore, the introduction of an anti-piracy law cuts off this information-spreading mechanism and the admissions to American films should decrease. However, we find the opposite result, which is contradictory with a sampling or a word of mouth effect. ${ }^{22}$

Finally, we implement a robustness check to assess the impact of extreme values. A few movies can capture nearly the entire audience, and the estimated HADOPI effects may simply be driven by few outstanding American (French) movies that coincidentally performed well (poorly) during the HADOPI period. With a two-step procedure, we first estimate the main specifications and then re-estimate the same specifications having dropped the $20 \%$ of movies with the highest absolute residual values from the first estimate. The results are consistent with those obtained from the full sample. They are presented in Appendix I in Table 25.

\subsection{Analysis 3: International comparisons}

\subsubsection{Empirical strategy}

We began to rule out the supply-side reaction explanation in the previous section by comparing the release strategy of American movies to that of French movies. However, it is possible that U.S. majors

21. In this test, we define a blockbuster film according to the total amount of advertising expenditures or to the number of opening screens.

22. In addition, we believe that the sampling effect of online piracy may be so not relevant to the theatrical market. The theatrical market is characterized by a strong decay in revenues over time, which mainly reflects that most people only watch a movie once. American movies are generally available on the Internet a couple of weeks before their release in theaters. Therefore, it seems unlikely that a consumers that illegally watched a movie online will want to pay and watch it again in a theater just a couple of weeks later. The sampling effect may be more appropriate to the market for recorded music, where consumers listen to an album a bunch of times. 
decided to open their movies on more screens in France, as a response to the law, relative to their strategy in other European countries. To further assess the positive effects of the HADOPI law on American movies' box office performance, we compare some outcomes relative to the supply level of American movies between France and a control group composed of different European countries at the movie level.

The estimation equation is the following one :

$$
\text { Outcome }_{i c t}=\rho_{c}+\rho_{t}+\beta X_{i}+\alpha H A D O P I_{t} \times \text { France }_{c}+\epsilon_{i c t}
$$

where $X_{i}$ a set of movie variables that are defined as above and $H A D O P I_{t}$ is a dummy variable that equals one after the adoption of the HADOPI law. We compare U.S. movies between different countries, so it is important to account for the competition they face from other movies in each country. To control for differences in competition, we include two variables (Comp. age top $5_{c t}$ and Comp.perc. new screens $s_{c t}$ ) that represent the average age of movies in the top 5 and the percentage of screens on which new movies are released each week in each country (Elberse and Eliashberg (2003)). ${ }^{23}$ Our dependent variables are the logarithm of the ratio between the number of admissions for movie $i$ during release week $t$ in country c, Admissions $s_{i c t}$, and the corresponding number of screens Screens $s_{i c t}$. We also directly test two possible supply reactions to the law: the quantity of U.S. movies exported to country $c$, measured by the log of the number of opening screens of exported movies, and the speed of exports, measured by the time lag in days between the date of release in the U.S. and the foreign release date (McCalman (2005)).

As a check of the main effects of HADOPI law on consumer demand, we compare France to other European countries with some aggregate outcomes of movie performance in a difference-in-differences setting. To detect a total demand creation effect and a redistributive effect between American movies and domestic movies, we aggregate movie-level admissions data by country and by month. We use the following simple specification with data at the country $\times$ month level (see Adermon and Liang (2014) for a similar approach):

$$
\text { Outcome }_{c t}=\rho_{c}+\rho_{t}+\alpha H A D O P I_{t} \times \text { France }_{c}+\epsilon_{c t}
$$

where $c$ is a country index and $t$ a time period index. $H A D O P I_{t}$ is a post-HADOPI dummy variable equal to one after November 2009. Finally, $\rho_{c}$ is a country fixed effect, $\rho_{t}$ a quarterly fixed effect, and $\epsilon_{c t}$ an idiosyncratic error term. We study the effect on two aggregate outcomes: (1) the log of the total

23. In the movie industry, the winner takes all and movie revenues are decaying over time. Therefore, when the average age of movies in the top 5 is higher, the level of competition is lower. Besides, the number of opening screens usually proxies the expected revenues of a movie. Thus when the percentage of screens on which new movies are released is high, the level of competition is higher. 
number of admissions and (2) the log of American movies' market shares. We have few clusters (countries) in this analysis. Therefore, we implement the wild cluster-bootstrap procedure suggested in Cameron et al. (2008) to compute the standard errors and improve the inference with few clusters.

An important issue for the identification strategy is to have a convincing control group (Meyer (1995)). During the period 2008-2011, no measure similar to the French HADOPI law was implemented in Europe other than a 2009 Swedish law. Hence Sweden is always excluded from the control group. Then, to select the countries to be included in the control group, we use a methodology that ensures that the pre-treatment trends in the dependent variables of interest are similar to the trend in the treated country. We first visually check that there is no divergence in trends between France and a candidate control country. Then, we regress the variable of interest in France on this variable in the candidate control country for the months preceding the beginning of the public debate on HADOPI (April 2009) to select the candidates that are significantly correlated with France, as proposed by Hilger et al. (2011). Details on the construction of the control group are available in Appendix J.

\subsubsection{Results}

The results from equation 3 are presented in Table 13. They indicate that American movies performed substantially better in France than in other countries after the implementation of HADOPI (columns 1 and 2 ). There is, however, no change in the speed of their exports (columns 3), except a temporary increase during $H A D O P I 1$ period that disappears consecutively (column 4). ${ }^{24}$ There is, however, a decrease in the number of opening screens for American movies in France (column 5), particularly during the HADOPI3 period (column 6). This decrease actually strengthens our main result. For a supply reaction to explain the positive effect of the anti-piracy law on American movie admissions, the number of screens should have increase together with anti-piracy enforcement. Overall, this analysis confirms that a supply reaction is not the main explanation for the positive effect of the HADOPI law on American movies.

Table 14 provides the estimation results from equation 4. The regressions indicate that American movies' market share increased by approximately $8 \%$ in France thanks to HADOPI relative to the control group (columns 1 and 2). This effect seems permanent and does not appear before the actual implementation of the law. We also find statistically weak evidence of an $8 \%$ market expansion effect in column 3 (with a p-value of 0.20). In column 4, the coefficients associated to HADOPI2 and HADOPI3 are also high in magnitude with respective p-values of 0.11 and 0.25 . We cannot reject the null hypothesis that there was no market expansion. The p-values have been computed using 1000 wild bootstrap replications

24. The HADOPI law has also reduced the legal delay between the release date of movies in theaters and the video release date from 6 to 4 months, which may explain this increase in the time lag in France. 
Table 13 - Estimates of equation (3) when the outcome is the ratio of admissions per screen, the number of screens, and the time lag of international release of U.S. movies

\begin{tabular}{|c|c|c|c|c|c|c|}
\hline & \multicolumn{2}{|c|}{$\log \left(\frac{\text { Admissions }}{\text { Screens }}\right)$} & \multicolumn{2}{|c|}{ Lag } & \multicolumn{2}{|c|}{$\log ($ Screens $)$} \\
\hline & $(1)$ & $(2)$ & $(3)$ & $(4)$ & $(5)$ & $(6)$ \\
\hline HADOPI $\times$ France & $\begin{array}{l}0.217^{* * *} \\
(0.0419)\end{array}$ & & $\begin{array}{c}0.292 \\
(0.795)\end{array}$ & & $\begin{array}{c}-0.132^{* * *} \\
(0.0429)\end{array}$ & \\
\hline HADOPI $\times$ France & & $\begin{array}{c}0.0599 \\
(0.0682)\end{array}$ & & $\begin{array}{l}2.143^{*} \\
(1.270)\end{array}$ & & $\begin{array}{l}-0.0977 \\
(0.0621)\end{array}$ \\
\hline HADOPI $2 \times$ France & & $\begin{array}{c}0.224^{* * *} \\
(0.0737)\end{array}$ & & $\begin{array}{l}-0.106 \\
(1.459)\end{array}$ & & $\begin{array}{l}-0.0651 \\
(0.0677)\end{array}$ \\
\hline HADOPI $3 \times$ France & & $\begin{array}{c}0.230^{* * *} \\
(0.0455)\end{array}$ & & $\begin{array}{l}1.129 \\
(0.879)\end{array}$ & & $\begin{array}{c}-0.195^{* * *} \\
(0.0492)\end{array}$ \\
\hline $\log$ (Budget) & $\begin{array}{l}0.240^{* * *} \\
(0.0314)\end{array}$ & $\begin{array}{c}0.240^{* * *} \\
(0.0314)\end{array}$ & $\begin{array}{l}-1.444 \\
(1.198)\end{array}$ & $\begin{array}{l}-1.442 \\
(1.199)\end{array}$ & $\begin{array}{c}0.424^{* * *} \\
(0.0307)\end{array}$ & $\begin{array}{c}0.425^{* * *} \\
(0.0307)\end{array}$ \\
\hline Consumer rating & $\begin{array}{c}0.354^{* * *} \\
(0.0528)\end{array}$ & $\begin{array}{c}0.354^{* * *} \\
(0.0528)\end{array}$ & $\begin{array}{c}0.637 \\
(1.123)\end{array}$ & $\begin{array}{c}0.652 \\
(1.122)\end{array}$ & $\begin{array}{l}0.129^{* * *} \\
(0.0453)\end{array}$ & $\begin{array}{c}0.128^{* * *} \\
(0.0451)\end{array}$ \\
\hline Press rating & $\begin{array}{l}-0.0341 \\
(0.0337)\end{array}$ & $\begin{array}{l}-0.0341 \\
(0.0337)\end{array}$ & $\begin{array}{l}0.0194 \\
(0.580)\end{array}$ & $\begin{array}{l}0.0251 \\
(0.576)\end{array}$ & $\begin{array}{l}0.00939 \\
(0.0321)\end{array}$ & $\begin{array}{l}0.00879 \\
(0.0320)\end{array}$ \\
\hline Comp. age top 5 & $\begin{array}{c}0.0370^{* * *} \\
(0.0123)\end{array}$ & $\begin{array}{c}0.0371^{* * *} \\
(0.0123)\end{array}$ & $\begin{array}{c}0.265 \\
(0.329)\end{array}$ & $\begin{array}{c}0.265 \\
(0.331)\end{array}$ & $\begin{array}{l}0.00786 \\
(0.0172)\end{array}$ & $\begin{array}{l}0.00888 \\
(0.0173)\end{array}$ \\
\hline Comp. perc. new screens & $\begin{array}{c}-1.025^{* * *} \\
(0.181)\end{array}$ & $\begin{array}{c}-1.025^{* * *} \\
(0.181)\end{array}$ & $\begin{array}{c}6.800 \\
(5.253)\end{array}$ & $\begin{array}{c}6.899 \\
(5.329)\end{array}$ & $\begin{array}{c}-0.896^{* * *} \\
(0.217)\end{array}$ & $\begin{array}{c}-0.894^{* * *} \\
(0.217)\end{array}$ \\
\hline Genre fixed effect & yes & yes & yes & yes & yes & yes \\
\hline Nationality fixed effect & yes & yes & yes & yes & yes & yes \\
\hline Art and House fixed effect & yes & yes & yes & yes & yes & yes \\
\hline Age restriction fixed effect & yes & yes & yes & yes & yes & yes \\
\hline Month fixed effect & yes & yes & yes & yes & yes & yes \\
\hline Constant & yes & yes & yes & yes & yes & yes \\
\hline Observations & 3228 & 3228 & 1605 & 1605 & 1254 & 1254 \\
\hline R-squared & 0.393 & 0.393 & 0.157 & 0.158 & 0.870 & 0.870 \\
\hline
\end{tabular}


following Cameron et al. (2008) to account for the small number of clusters (countries) in this analysis. We obtain similar results, in terms of statistical significance, when using the alternative method of Conley and Taber (2011). To summarize, this difference-in-differences analysis supports the presence of a significant positive effect to the benefit of American movies, following the law. This analysis also provides statistically weak evidence showing that the law has generated a market expansion effect.

Table 14 - Estimates of equation (4) when the outcome is the number of admissions or the U.S. market share

\begin{tabular}{|c|c|c|c|c|}
\hline & \multicolumn{2}{|c|}{$\log ($ U.S. market share) } & \multicolumn{2}{|c|}{$\log$ (Admissions) } \\
\hline & (1) & $(2)$ & (3) & (4) \\
\hline HADOPI $\times$ France & $\begin{array}{c}0.0805^{* * *} \\
(0.000)\end{array}$ & & $\begin{array}{l}0.0833 \\
(0.204)\end{array}$ & \\
\hline HADOPI1 $\times$ France & & $\begin{array}{c}0.00190 \\
(0.872)\end{array}$ & & $\begin{array}{r}-0.0211 \\
(0.300)\end{array}$ \\
\hline HADOPI $2 \times$ France & & $\begin{array}{c}0.0894^{* * *} \\
(0.000)\end{array}$ & & $\begin{array}{l}0.0821 \\
(0.108)\end{array}$ \\
\hline HADOPI $3 \times$ France & & $\begin{array}{c}0.0756^{* * *} \\
(0.000)\end{array}$ & & $\begin{array}{l}0.0770 \\
(0.258)\end{array}$ \\
\hline Country fixed effect & yes & yes & yes & yes \\
\hline Month fixed effect & yes & yes & yes & yes \\
\hline Constant & yes & yes & yes & yes \\
\hline Observations & 420 & 420 & 420 & 420 \\
\hline R-squared & 0.651 & 0.651 & 0.978 & 0.978 \\
\hline
\end{tabular}

\subsection{Analysis 4: Consumer-level approach}

In this section, we provide some evidence to better understand the consumer behavior underlying the redistributive effect that benefits American movies.

Consumers who download more should be more sensitive to the anti-piracy law. For such consumers, we should observe a more important shift in their legal consumption of American movies in theaters. Using consumer-level data, our last approach provides additional evidence supporting this mechanism using the difference in characteristics (age) between consumers who have unlimited access card.

The benefit of this data collection approach is that it provides us with information on the type of consumers who purchase movies in theaters. Because we could only collect those data for a specific type of consumers in two middle-sized cities in France, the results in this section are not nationally representative. The effect in France as a whole could admittedly be different from that we describe hereafter. 


\subsubsection{Empirical strategy}

On average, young consumers download illegally more often than old consumers (see Hadopi (2011)). Indeed, younger individuals tend to be more Internet savvy, to earn lower income, and to have more free time. Thus, they are more likely to be affected by the HADOPI law. We use the information on the age of consumers with unlimited access cards to investigate which types of consumers were influenced by the anti-piracy law. ${ }^{25}$

This strategy exploits a difference in illegal downloading between young and older people. We implicitly assume that consumers with cards illegally download movies despite having unlimited access to movies in theaters. Such behavior might be due to a time constraint. Indeed, the opportunity cost of watching a movie in a theater is higher than that of watching a movie at home. The costs of commuting and of waiting at the theater are the main components of this time cost. Besides, it is easier to stop watching a bad movie at home than in a movie theater. Another explanation would be a preference for watching movies as soon as they are available, on the Internet, even if they will subsequently be available in theaters.

We aggregate individual transaction data from consumers with unlimited access cards by movie, week, theater and three different age groups: Consumers between 10 and 29 years old, between 30 and 49 years old, and between 50 and 80 years old. The equation we estimate is as follows:

$$
\begin{aligned}
\text { Sales }_{i j t a} & =\delta_{i}+\delta_{j}+\delta_{t}+\phi N u m b e r C a r d s_{j t a}+\sum_{\tau=1}^{14} \theta_{\tau} \mathbb{1}_{\left\{t-r_{i}=\tau\right\}}+\sum_{a=1}^{2} \gamma_{a} A_{g} e_{a}+\sum_{a=1}^{2} \lambda_{a} U S A_{i} * \text { Age }_{a} \\
& +\sum_{a=1}^{2} \eta_{a} H A D O P I_{t} * \text { Age }_{a}+\mu H A D O P I_{t} * U S A_{i}+\sum_{a=1}^{2} \beta_{a} H A D O P I_{t} * U S A_{i} * \text { Age }_{a}+\epsilon_{i j t a}
\end{aligned}
$$

where the left-hand-side variable is the log of sales (number of admissions) from consumers with unlimited access cards belonging to age group $a$ for movie $i$, during week $t$, in theater $j{ }^{26}$ The 1 to 14 summation of dummy variables accounts for the common decay effect of movie admissions, Age $_{a}$ is an indicator variable that equals one for sales associated with consumers who belong to age group $a$. NumberCards $s_{j a}$ is the number of consumers belonging to age group $a$ who have used an unlimited card at least once during month $t$ at theater $j$. This variable accounts for the economic success of the movie pass program of the cinema chain and particularly the large increase in the number of young cardholders.

25. We also tested for a difference between women and men, but no significant difference was found.

26. $a=1$ corresponds to people aged between 10 and $29, a=2$ being people aged between 30 and 49 , and $a=3$ matching people aged between 50 and 80 . 
The coefficients of interest are now $\beta_{1}$ and $\beta_{2}$. They measure the increase in the sales of American movies relative to other movies after the HADOPI law was passed from consumers with cards, separately for those aged between 10-29 years and between 30-49 years, in comparison to the increase by consumers with cards aged between 50-80 years. $\eta_{1}$ and $\eta_{2}$ are also interesting because they indicate whether the sales of French films among younger consumers increased after the law relative to consumption by older consumers. Standard errors are clustered at the movie and the theater level, to account for within-movie dependence. A detailed discussion of the interpretation of the $\beta_{a}$ coefficients is provided in Appendix K. From this discussion, it is direct to see that the market expansion effect is captured by $2 \times \eta+\beta$.

\subsubsection{Results}

The columns 1 and 2 of Table 15 report the estimation results for equation (5). We observe an increase in American movies sales for younger consumers, relative to older ones, associated with HADOPI enforcement. The increase in the consumption of American movies is decreasing with age. Compared to consumers between 50 and 80 years of age, and compared to the sales of French movies, the increase in American movie sales following HADOPI is approximately 19\% (statistically significant at the 1\% level) for consumers between 10 and 29 years old and is twice the value of the increase for consumers between 30 and 49 years old, which is approximately $10 \%$. A test confirms that $\beta_{1}$ is statistically different from $\beta_{2}$ at the $1 \%$ level. This is consistent with illegal media consumption on the Internet decreasing with

age (see Hadopi (2011)). The coefficients $\eta_{1}$ and $\eta_{2}$ are negative and indicate that sales of French movies to younger consumers decreased after the introduction of the HADOPI law. It confirms the substitution effect of the anti-piracy law to the benefit of American movies. The fact that $2 \times \eta_{1}+\beta_{1}, 2 \times \eta_{2}+\beta_{2}$, and $2 \times \eta_{1}+2 \times \eta_{2}+\beta_{1}+\beta_{2}$ are slightly negative provides evidence of a strong substitution effect between American and French films without growth in total demand.

As a robustness check, we estimate equation (5) by restricting the sample on the opening week. The results are presented in columns 3 and 4 , and remain similar.

The anti-piracy law has modified the behavior of young consumers who are subscribed to an unlimited access card to movies. They could have increased their legal consumption of American movies while maintaining the level of French ones, but they chose to reduce their consumption of French movies. This result is surprising because these consumers are not money constrained. Thus, the amount of free time dedicated to going to the movies could explain this finding and may represent an important limitation to the expansion of leisure expenses (Thaler (1985), Thaler (1999)). This should especially be the case for products with low price, such as movies, for which the monetary constraint is not necessarily binding.

Several reasons can explain why time may bind the choice of young consumers who are not budget- 
Table 15 - Estimates of equation (5)

\begin{tabular}{|c|c|c|c|c|}
\hline & \multicolumn{2}{|c|}{ Full sample } & \multicolumn{2}{|c|}{ Opening week only } \\
\hline & $(1)$ & $(2)$ & (3) & (4) \\
\hline HADOPI $\times$ Age10-29 & $\begin{array}{l}-0.125^{* *} \\
(0.0616)\end{array}$ & & $\begin{array}{l}-0.119^{*} \\
(0.0720)\end{array}$ & \\
\hline HADOPI $\times$ Age $30-49$ & $\begin{array}{c}-0.148^{* * *} \\
(0.0335)\end{array}$ & & $\begin{array}{c}-0.176^{* * *} \\
(0.0365)\end{array}$ & \\
\hline HADOPI $\times$ USA $\times$ Age10-29 & $\begin{array}{l}0.192^{* * *} \\
(0.0668)\end{array}$ & & $\begin{array}{l}0.198^{* *} \\
(0.0815)\end{array}$ & \\
\hline HADOPI $\times$ USA $\times$ Age $30-49$ & $\begin{array}{l}0.103^{* *} \\
(0.0443)\end{array}$ & & $\begin{array}{c}0.0720 \\
(0.0519)\end{array}$ & \\
\hline HADOPI1 $\times$ Age10-29 & & $\begin{array}{c}-0.102 \\
(0.0861)\end{array}$ & & $\begin{array}{r}-0.0727 \\
(0.103)\end{array}$ \\
\hline HADOPI $\times$ Age $30-49$ & & $\begin{array}{l}-0.0558 \\
(0.0505)\end{array}$ & & $\begin{array}{c}-0.00479 \\
(0.0595)\end{array}$ \\
\hline HADOPI $2 \times$ Age10-29 & & $\begin{array}{l}-0.0694 \\
(0.0797)\end{array}$ & & $\begin{array}{l}-0.0729 \\
(0.0934)\end{array}$ \\
\hline HADOPI $2 \times$ Age $30-49$ & & $\begin{array}{l}-0.103^{* *} \\
(0.0471)\end{array}$ & & $\begin{array}{l}-0.109^{* *} \\
(0.0525)\end{array}$ \\
\hline HADOPI3 $\times$ Age10-29 & & $\begin{array}{c}-0.253^{* * *} \\
(0.0808)\end{array}$ & & $\begin{array}{r}-0.211^{* *} \\
(0.0916)\end{array}$ \\
\hline HADOPI3 × Age30-49 & & $\begin{array}{c}-0.205^{* * *} \\
(0.0427)\end{array}$ & & $\begin{array}{c}-0.220^{* * *} \\
(0.0453)\end{array}$ \\
\hline HADOPI $\times$ USA $\times$ Age10-29 & & $\begin{array}{c}0.289^{* * *} \\
(0.104)\end{array}$ & & $\begin{array}{c}0.472^{* * *} \\
(0.129)\end{array}$ \\
\hline HADOPI $2 \times$ USA $\times$ Age10-29 & & $\begin{array}{l}0.198^{* *} \\
(0.0945)\end{array}$ & & $\begin{array}{c}0.316^{* * *} \\
(0.115)\end{array}$ \\
\hline HADOPI $\times$ USA $\times$ Age10-29 & & $\begin{array}{c}0.337^{* * *} \\
(0.0826)\end{array}$ & & $\begin{array}{c}0.371^{* * *} \\
(0.100)\end{array}$ \\
\hline HADOPI $1 \times$ USA $\times$ Age $30-49$ & & $\begin{array}{c}0.182^{* * *} \\
(0.0690)\end{array}$ & & $\begin{array}{c}0.236^{* * *} \\
(0.0834)\end{array}$ \\
\hline HADOPI $2 \times$ USA $\times$ Age $30-49$ & & $\begin{array}{l}0.132^{* *} \\
(0.0640)\end{array}$ & & $\begin{array}{c}0.131^{*} \\
(0.0749)\end{array}$ \\
\hline HADOPI $3 \times$ USA $\times$ Age $30-49$ & & $\begin{array}{c}0.182^{* * *} \\
(0.0551)\end{array}$ & & $\begin{array}{l}0.160^{* *} \\
(0.0638)\end{array}$ \\
\hline Number of unique cardholders & $\begin{array}{c}0.000649^{* * *} \\
(0.0000744)\end{array}$ & $\begin{array}{c}0.000727^{* * * *} \\
(0.0000876)\end{array}$ & $\begin{array}{c}0.000558^{* * *} \\
(0.0000881)\end{array}$ & $\begin{array}{c}0.000605^{* * *} \\
(0.0000995)\end{array}$ \\
\hline Movie fixed effect & yes & yes & yes & yes \\
\hline Week fixed effect & yes & yes & yes & yes \\
\hline Movie's age fixed effect & yes & yes & yes & yes \\
\hline Observations & 21522 & 21522 & 5990 & 5990 \\
\hline R-squared & 0.813 & 0.814 & 0.779 & 0.781 \\
\hline
\end{tabular}


constrained even if they usually enjoy more free time that people who work. Going to the movies takes a lot of time, and the value of time can be regarded as the opportunity cost of enjoying another option. Spiller (2011) shows that individuals take opportunity cost in consideration when they have alternative options. Young individuals tend to have bigger social networks (Cumming and Henry (1961), McPherson et al. (2006)), so that the number of options available to them might be greater and more valuable than these of older adults, which is consistent with our result. Besides, new media like the Internet or video games represent alternative options in themselves that are more appealing to younger people. Finally, the first age group (10-29) contains young workers, who usually work a lot.

\subsection{Perspectives on the results}

The four empirical analyses all lead to the conclusion that the market share of American movie increased after the advent of the anti-piracy law. The estimated values of the coefficients are different, but they have similar implications after some adjustments are made to compute the total change in the number of admissions to U.S. films in France after the law. Using simple back-of-the-envelop calculations detailed in Appendix L, we find that all analyses converge to show an increase in the U.S. market share of approximately 9\%. Table 32 in Appendix L also provides a summary of the four analyses in the form of their pros and cons.

In the short-term, some consumers experience a loss of surplus because they watch less non-U.S. movies legally in theaters. In the longer-run, it could be possible that the investments in the French film industry decline as a reaction, especially for adventure, drama, and thriller/crime movies as shown in analysis 2 . Actually, we observe a small decrease in the average investment per film. ${ }^{27}$ It could be linked to the HADOPI law. However, the French film industry is highly subsidized by the Government, so it seems difficult to conclude on this subject. On the contrary, the anti-piracy law may increase the production of U.S. films, especially American blockbuster movies like fantasy, sci-fi, or horror movies, which should increase total welfare. For instance, Giorcelli and Moser (2016) show that the adoption of copyright laws within Italy during the Napoleonic wars has increased the number and quality of new operas. Telang and Waldfogel (2018) find a similar result in the Indian movie industry.

27. According to data from the CNC, the average production budget of a French film has decreased by $12 \%$, from 5.5 to 4.8 million euros, between the period 2005-2009 and the period 2010-2014. However, the total investment in the production budget of all French films had remained unchanged, leading to the production of more French movies, but probably with a lower quality. 


\section{Conclusion}

In this paper, we examine the asymmetric effects of online piracy on movies' box office performance. We use the French anti-piracy law known as HADOPI as an natural experiment on the level of online file sharing. Four empirical analyses converge on the same conclusions. The HADOPI law clearly benefited American movies at the expense of other movies, with statistically weak evidence of an increase in the total demand for movies in theaters. These two effects are not driven by a positive quality shock on U.S. movies concomitant but unrelated to the law, by the advent of 3D movies, by a supply reaction of distributors, or by informative effects such as word of mouth.

Asymmetric online piracy distorts the competition between American and domestic movies in favor of domestic ones. Thus, implementing a regulation that deters illegal downloads levels the playing field. It reestablishes a fair allocation of sales between U.S. and home movies according to their value to consumers. This anti-piracy law seems to be effective in fighting illegal file sharing since our results are consistent with a decrease in the level of online piracy. However, these effects are not in line with a cultural policy aimed at supporting the production of domestic films and a cultural diversity, to prevent a single culture from dominating the others. Knowing that, governments have to decide how to balance their decisions. Maybe the recent reaction of the European Commission represents a good example of the compromise that can be found. Indeed, the European Commission strongly supports the enforcement of right owners. However, with the increase in the adoption of SVOD services and the competition effects induced by digital distribution, the European Union has proposed a new law to require streaming video providers like Netflix or Amazon Prime Video to dedicate at least 30\% of their catalogs to European content. They also will have to invest in films and TV shows produced in Europe.

Online piracy was recently perceived as posing a lower threat on movies and TV shows, thanks to the strong development of streaming platforms like Netflix or Amazon Prime Video. However, online piracy is far from being dead. It has been increasing again worldwide since 2015, as shown in the last Sandvine Report of October 2018 (The Global Internet Phenomena Report). According to their report, piracy is booming again thanks to the increase in the number of streaming platforms and the generalization of exclusive content offered by these platforms. Then, it becomes very expensive for a consumer to obtain access to the most successful TV shows: The Marvelous Ms. Maisel for Amazon Prime, Game of Thrones for HBO, The Handmaid's Tale for Hulu, or The Crown for Netflix. As a consequence, consumers usually subscribe to one or two services and may illegally download the rest of the shows. This is particularly relevant to Europe, where geographical viewing restrictions can prevent access to popular content on a single platform. Moreover, nearly all major TV networks are planning to launch their own streaming service, 
with exclusive content, in the coming years. The increase in exclusive contents that are only available on a single streaming platform may drive future piracy issues, creating asymmetries in the intensity of piracy between products. For instance, the platforms providing the biggest catalogs will probably be less pirated than other ones. Also, the platforms proposing many movies that have been previously released in the American continent, where pirate teams are very active, are likely to be more pirated than other ones. Findings from our study could help to understand future resulting effects.

American movies tend to be more internationally released on the same date in all markets. Then the asymmetry in piracy may disappear on the French theatrical market, as U.S. films would be less available illegally on the Internet. However, as pirate teams are still much more active on the American continent than in France and in other European countries, a (smaller) asymmetry is still likely to remain. Besides, the sequential release of U.S. movies in different countries is also used to help distributors to learn about their movies' quality from performance in successive markets (Holloway (2017)). Therefore, sequential releases may continue to be used, as this can reduce distribution costs.

Finally, the effect of an anti-piracy law is likely to have large effects on the video game market or the software market because the legal version of these products can be easily replaced by their pirated copies. It would be interesting to examine the asymmetric effects of online piracy in these markets.

\section{References}

A. Adermon and C.Y. Liang. Piracy and music sales: The effects of an anti-piracy law. Journal of Economic Behavior and Organization, 105:90-106, 2014.

L. Aguiar, J. Claussen, and C. Peukert. Catch me if you can: Effectiveness and consequences of online copyright enforcement. Information Systems Research, 29(3):656-678, 2018.

J. Bai and J. Waldfogel. Movie piracy and sales displacement in a sample of chinese college students. Information Economics and Policy, 24(3):187-196, 2012.

P. Belleflamme and M Peitz. Digital piracy: Theory. The Oxford Handbook of the Digital Economy, 2012.

M. Bertrand, E. Duflo, and S. Mullainathan. How much should we trust differences-in- differences estimates? Quarterly Journal of Economics, 119(1):249-275, 2004.

S. Bhattacharjee, D. Gopal, R., K. Lertwachara, and R. Marsden, J. Impact of legal threat on online music sharing activity: An analysis of music industry legal actions. Journal of Law and Economics, 49 (1):91-114, 2006. 
S. Bhattacharjee, R. Gopal, K. Lertwachara, J. Marden, and R. Telang. The effects of digital sharing technologies on music markets: A survival analysis of albums on ranking charts. Management Science, 53(9):1359-1374, 2007.

A. C. Cameron, J. B. Gelbach, and D. L. Miller. Bootstrap-based improvements for inference with clustered errors. The Review of Economics and Statistics, 90(3):414-427, 2008.

T. G. Conley and C. R. Taber. Inference with "difference in differences" with a small number of policy changes. The Review of Economics and Statistics, 93(1):113-125, 2011.

E. Cumming and W.E. Henry. Growing old: The process of disengagement. New York: Basic Books, 1961.

B. Danaher and M. D. Smith. Gone in 60 seconds: The impact of the megaupload shutdown on movie sales. International Journal of Industrial Organization, 33:1-8, 2014.

B. Danaher and J. Waldfogel. Reel piracy: the effect of online film piracy of international box office sales. Working Paper, 2012.

B. Danaher, S. Dhanaobhon, M.D. Smith, and R. Telang. Converting pirates without cannabilizing purchasers: The impact of digital ditribution on physical sales and internet piracy. Marketing Science, 29 (6):125-139, 2010.

B. Danaher, M.D. Smith, and S. Telang, R.and Chen. The effect of graduated response anti-piracy laws on music sales:evidence from an event study in france. Journal of Industrial Economics, 62(3):541-553, 2014.

B. Danaher, M. D. Smith, and R. Telang. Copyright enforcement in the digital age: Empirical evidence and policy implications. Communications of the ACM, 60(2):68-75, 2017.

E. Darmon, S. Dejean, and T. Pénard. La réponse graduée de l'hadopi a-t-elle un effet sur le piratage du musique et des films? Une étude empirique des pratiques de consommation en ligne. Revue économique, 67(2):181-206, 2016.

L. Einav. Seasonality in the u.s. motion picture industry. Rand Journal of Economics, 38(1):127-145, 2007.

L. Einav and B. Orbach. Uniform prices for differentiated goods: The case of the movie-theater industry. International Review of Law and Economics, 27(2):129-153, 2007. 
A. Elberse and J. Eliashberg. Demand and supply dynamics for sequentially released products in international markets: The case of motion pictures. Marketing Science, 22(3):329-354, 2003.

C. Forman, A. Ghose, and A. Goldfarb. Competition between local and electronic markets: How the benefit of buying online depends on where you live. Management Science, 55(1):'47-57, 2009.

M. Gentzkow. Valuing new goods in a model with complementarity: Online newspapers. American Economic Review, 97(3):713-744, 2007.

A. Ghose, M.D. Smith, and R. Telang. Internet exchanges for used books: An empirical analysis of product cannibalization and welfare impact. Information Systems Research, 17, 2006.

M. Giorcelli and P. Moser. Copyright and creativity: Evidence from italian operas. Working Paper, 2016.

Hadopi. Hadopi, biens culturels et usages d'internet : pratiques et perceptions des internautes français. Report, 2011.

C. Heath and B. Soll, J. Mental budgeting and consumer decisions. The Journal of Consumer Research, 23(1):40-52, 1996.

T. Hennig-Thurau, V. Henning, and H. Sattler. Consumer file sharing of motion pictures. Journal of Marketing, 71(4):1-18, 2007.

J. Hilger, G. Rafert, and S. Villas-Boas. Expert opinion and the demand for experience goods: An experimental approach in the retail wine market. Review of Economics and Statistics, 93(4):1289-1296, 2011.

I. R. Holloway. Learning via sequential market entry: Evidence from international releases of u.s. movies. Journal of International Economics, 104:104 - 121, 2017.

S. Liebowitz. File-sharing: Creative destruction or just plain destruction? Journal of Law and Economics, 49(1):1-28, 2006.

S. Liebowitz. Testing file-haring's impact by examining record sales in cities. Management Science, 54(4): $852-859,2008$.

S. Liebowitz and A. Zentner. Clash of the titans: Does internet use reduce television viewing? The Review of Economics and Statistics, 94(1):234-245, 2012. 
L. Ma, A.L. Montgomery, P. V. Singh, and M.D. Smith. An empirical analysis of the impact of pre-release movie piracy on box office revenue. Information Systems Research, 25(3):590-603, 2014.

P. McCalman. International diffusion and intelectual property rights: An empirical analysis. Journal of International Economics, 67(2):353-372, 2005.

J. McKenzie. Graduated response policies to digital piracy: Do they increase box office revenues of movies? Information Economics and Policy, 38(Supplement C):1 - 11, 2017.

M. McPherson, L. Smith-Lovin, and M.E. Brashears. Social isolation in america: Changes in core discussion networks over two decades. American Sociological Review, 71:353-375, 2006.

B.D. Meyer. Natural and quasi-experiments in economics. Journal of Business and Economic Statistics, 13(2):151-161, 1995.

F. Oberholzer-Gee and K. Strumpf. The effect of file sharing on record sales: An empirical analysis. Journal of Political Economy, 115(1):1-42, 2007.

C. Peukert, J. Claussen, and T. Kretschmer. Piracy and box office movie revenues: Evidence from megaupload. International Journal of Industrial Organization, 52:188-215, 2017.

I. Reimers. Can private copyright protection be effective? evidence from book publishing. The Journal of Law and Economics, 59(2):411-440, 2016.

R. Rob and J. Waldfogel. Piracy on the high c s: Music downloading, sales displacement, and social welfare in a sample of college students. The Journal of Law and Economics, 49(1):29-62, 2006.

R. Rob and J. Waldfogel. Piracy on the silver screen. Journal of Industrial Economics, 55(3):379-393, 2007.

Sandvine. Global Internet Phenomena Report. Report, 2011.

M. Smith and R. Telang. Assessing the academic literature regarding the impact of media piracy on sales. Working Paper, 2012.

S.A. Spiller. Opportunity cost consideration. Journal of Consumer Research, 38(4):595-610, 2011.

R. Telang and J. Waldfogel. Piracy and new product creation: A bollywood story. Information Economics and Policy, 43:1 - 11, 2018.

R. Thaler. Mental accounting and consumer choice. Marketing Science, 4(3):199-214, 1985. 
R. Thaler. Mental accounting matters. Journal of Behavioral Decision Making, 12:183-206, 1999.

J. Waldfogel. Digital piracy: Empirics. The Oxford Handbook of the Digital Economy, 2012a.

J. Waldfogel. Copyright research in the digital age: Moving from piracy to the supply of new product. American Economic Review, 102(3):337-342, 2012b.

A. Zentner. File sharing and international sales of copyrighted music: An empirical analysis with a panel of countries. Topics in Economic Analysis and Policy, 5(2):1452-1452, 2005.

A. Zentner. Measuring the effect of file sharing on music purchases. The Journal of Law and Economics., 49(1):63-90, 2006.

A. Zentner. Measuring the impact of file sharing on the movie industry: An empirical analysis using a panel of countries. Working Paper, pages 1-35, 2010.

A. Zentner, D. Smith, M., and C. Kaya. How video rental patterns change as consumers move online. Management Science, 59(11):2622-2634, 2012.

L. Zhang. Intellectual property strategy and the long tail: Evidence from the recorded music industry. Management Science, 64(1):24-42, 2018. 


\section{Online Appendix}

\section{A Theoretical background and supporting evidence}

Theoretical background. We provide a very simple model to show how the implementation of HADOPI can lead to more admissions for American movies but fewer admissions for French movies, the overall effect being a total demand in theaters that remains constant.

We assume, that consumers have two units of time: one unit of time to consume online contents like a pirated version of a movie or a series and one unit of time to consume a movie in theaters. We abstract from the pricing of such contents because theaters practice uniform pricing for all movies. These units of time reflects the fact that consumers are budget or time constrained, or that they aim at a level of expenditure (in time or money) in a given category of product (Thaler (1985), and Heath and Soll (1996)).

For simplicity, we assume that the utility for consumer $i$ in linear: $U_{i}=x_{i, j}+y_{i, k}$ where $x$ is the utility that consumer $i$ derives from the offline product $j$ and $y$ the utility derived from the online product $k$. For the offline product, the consumers must choose between a French movie which generates a random utility $x_{i, F}$ with cdf $F($.$) in [0, \bar{x}]$ and an American movie which generates a random utility $x_{i, A}$ with cdf $F($. in $[0, \bar{x}]$. Before the anti-piracy law, a consumer can choose between the pirated version of the American movie which generates an utility $\alpha x_{i, A}$ with $\alpha<1$ because of the quality degradation from consuming a non genuine version of the movie, and another type of content which generates an utility $x_{i, O}$ with cdf $F($.) in $[0, \bar{x}]$. We further assume that an individual will not consume offline a movie he has already watched online via a pirated copy. This assumption seems quite reasonable in the context of the movie industry, as most people only watch a movie once.

Before HADOPI, the market share of French $s_{F}$ and American movies $s_{A}$ in theaters are the followings:

$$
\begin{aligned}
& s_{F}=\operatorname{Prob}\left[x_{i, F}>x_{i, A} \& x_{i, O}>\alpha x_{i, A}\right]+\operatorname{Prob}\left[x_{i, O} \leq \alpha x_{i, A}\right] \\
& s_{A}=\operatorname{Prob}\left[x_{i, F}<x_{i, A} \& x_{i, O}>\alpha x_{i, A}\right]
\end{aligned}
$$

It is easy to see that $s_{A}+s_{F}=1$ and $s_{F}>s_{A}$.

After the anti-piracy law, consumers cannot choose anymore to see the pirated version of the American movie online so that all them choose the other type of online content. The market share of French and 
American movies in theaters are now the followings:

$$
\begin{aligned}
& \hat{s}_{F}=\operatorname{Prob}\left[x_{i, F}>x_{i, A}\right]=1 / 2 \\
& \hat{s}_{A}=\operatorname{Prob}\left[x_{i, F}<x_{i, A}\right]=1 / 2
\end{aligned}
$$

with $\hat{s}_{F}+\hat{s}_{A}=1, \hat{s}_{F}<s_{F}$, and $\hat{s}_{A}<s_{A}$.

In this very simple model, the total demand remains unchanged before and after the adoption of the anti-piracy law, and there is a redistribution effect at the expense of French movies after the law because American movies do not suffer anymore from a substitution effect with the online pirated version.

A business stealing effect is plausible. We provides contextual data supporting the mechanism leading to this substitution effect, namely that the average expense of moviegoers in theaters is stable over time, and that an important share of consumers enjoy watching both American and French movies in theaters. We also shows that consumers tend to prefer American movies, which strengthens this mechanism.

The results of this paper indicate that the increase in American market share mainly stems from cannibalization at the expense of other movies. Indeed, over the period 2008-2011, the aggregate market share of American movies was 46\% (48\%) before (after) the law was passed, while for French ones, it was $42 \%(38 \%)$ before (after) the law was passed. The mechanism involves a decrease in illegal sharing of movies, a binding budget and time constraint, some consumers enjoying both U.S. and French movies, and a general preference for U.S. movies.

The law has presumably decreased the level of online piracy for several reasons. First, many sources tend to show that there was a decline in peer-to-peer use from September 2010 to December 2011, when the graduated response started being implemented in France. ${ }^{28}$ Nielsen noted an important reduction of $50 \%$ in the audience levels of websites offering links (see graph 4(a)), whereas Peer Media also measured a drop of $43 \%$ in the illegal sharing of films on peer-to-peer networks in France during 2011 (see graph 4(b)). ${ }^{29}$ This decline is consistent with the considerable number of messages sent by the HADOPI agency. Moreover, in a survey conducted in 2011 (Hadopi (2011)), 72\% of warned Internet users reported that they had reduced or completely stopped their illegal usage following this warning.

Mediametrie/NetRatings report a stability in usage patterns of streaming and direct download services in 2010 and 2011 (see graph 5). Although the HADOPI law was adopted at the end of 2009, it is worth reminding that this law came into force during the last third of 2010, which validates in part the comparison

28. Unfortunately, comparable figures for the period preceding the HADOPI law are not available.

29. Peer Media is an American company providing anti-piracy services targeted at peer-to-peer networks. 
Figure 4 - A clear decline in illegal downloading in France

(Sources: (a) IFPI / Nielsen, "Digital Music Report 2012", January 2012, total duplicated audience offering links to P2P files and applications, across approximately $40 \mathrm{P} 2 \mathrm{P}$ services, in thousand of unique visitors. (b) Peer Media Technologies, February 2012, sharing of internationally-observed films, change between December 2009 and December 2011, in millions of downloads initiated. Sample of 200 to 300 recent films in rotation.)

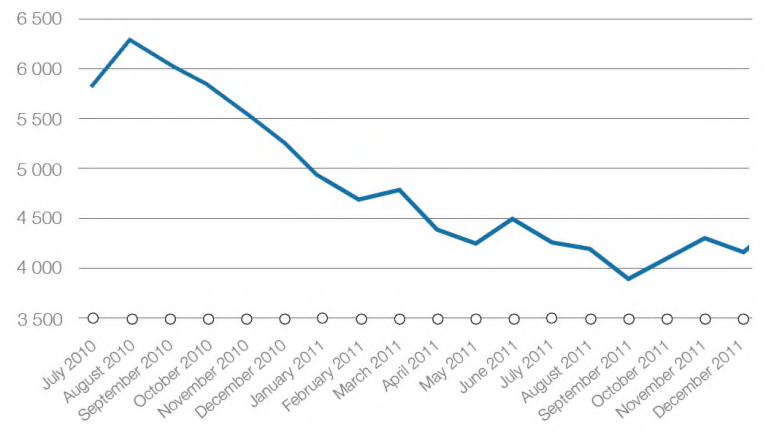

(a) The fall in audience levels of websites offering links to peer-to-peer files and applications

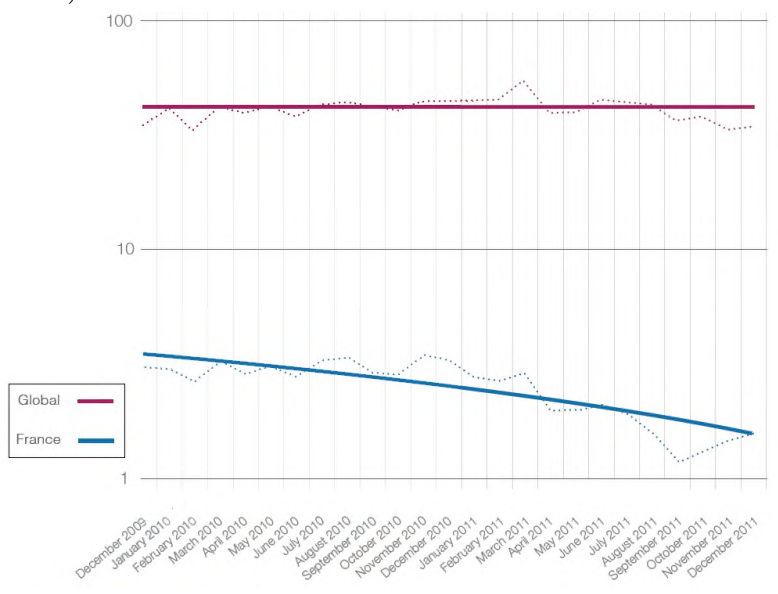

(b) The drop in illegal sharing of movies on peer-to-peer networks in France compared to the rest of the world

between (end of) years 2010 and 2011. Darmon et al. (2016) show using a survey of 2000 individuals conducted in 2012 that $78 \%$ of Internet users rightly believed that the HADOPI agency monitored illegal peer-to-peer downloads, but $68 \%$ (respectively $37 \%$ and $12 \%$ ) of them also thought that the HADOPI monitored illegal direct downloads (respectively illegal streaming and illegal offline file sharing) while this is not the case. This body of evidence converges to show a decrease in online piracy that has mainly come from peer-to-peer channels and without important transfers to other piracy channels.

Data from the French national accounts on household consumption show that the share of consumption of movies in theaters in the shopping basket of the average French household has been stable since 1990 (see graph 6(a)). Data from the CNC also show that the average number of admissions per moviegoers is stable since 1998 (see graph 6(b)). This supports the view that budget and time constraints might constitute important limitations to the expansion of the market for theatrical exhibition, or that individuals set monetary or time budgets for categories of expenses (Heath and Soll (1996)).

Next, a survey conducted by Observatoire de la satisfaction shows that the distribution of audiences for American and French movies overlap significantly in terms of gender, age, and satisfaction rate (see graphs 7(a), 7(b), and 7(c)). ${ }^{30}$ They use a sample of 598 movies widely released in France between January

30. Observatoire de la satisfaction is an independent research and polling institute specialized in the movie industry. 
Figure 5 - The stability in usage patterns of streaming and direct download services in France. (Source: Mediametrie/NetRatings.)

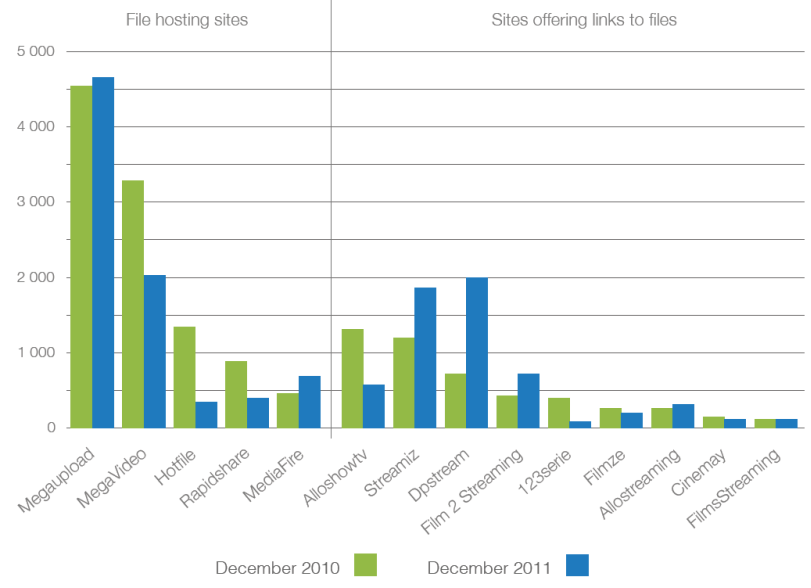

of 2006 and November of 2009. Thus, many consumers are likely to enjoy both French and U.S. movies.

Finally, several evidence show that many French consumers tend to prefer American movies to French ones, which is a necessary condition to obtain a business stealing effect (the production budget, marketing expenditures, number of screens during the release week, and consumer ratings are significantly higher for American movies than for French ones. Indeed, the average production budget is tremendously higher for U.S. movies (\$63 millions) than for French ones (\$9 millions). This difference reflects for instance a more famous casting or better special effects associated. The audience may also anticipate that U.S. films are superior because marketing expenditures are also higher ( $\$ 2$ millions for U.S. movies against $\$ 1.1$ millions for French ones). The observed ex post satisfaction of consumers is higher for U.S. movies. Indeed, the average user rating on www.allocine.fr, the major French content aggregator on movies (www.allocine.fr), is 3.1 for U.S. films when it is 2.8 for French films. Finally, during their release week, U.S. movies are played on 360 screens on average in France when French movies are played on 320 screens. Note that these figures correspond to the sample we use in section 4, that is biased toward big French movies. For instance, French movies are released on 180 screens on average in France, when considering all movies.

\section{B Details on the Internet data for analysis 1}

In France, there are 33 millions local loops, also called connections, that can provide Internet to households, distributed over 15000 Internet local exchanges. Even if all local exchanges can provide DSL technology, not all connections qualify for broadband Internet. The download speed of an Internet 
Figure 6 - Average consumers expenditures in movie theaters are stable over time (Sources: (a) Insee, French National Account. (b) CNC)
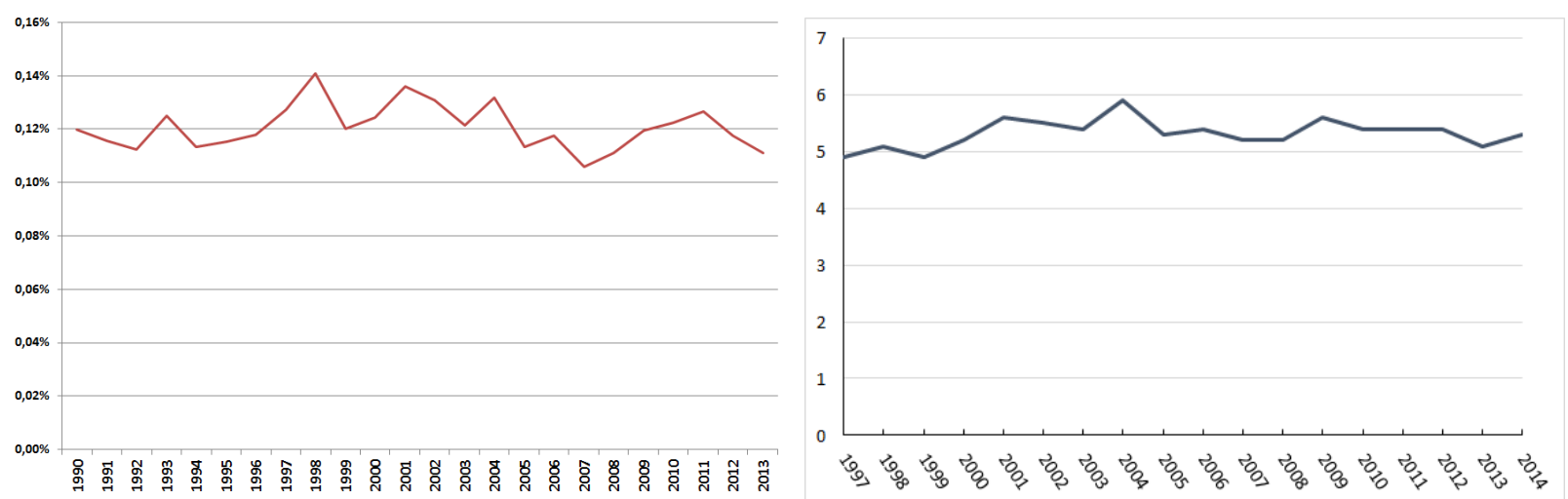

(a) The share of consumption of movies in theaters over total consumption of households is stable.

(b) The average number of admissions per moviegoer is stable

Figure 7 - The audiences of U.S. and French movies overlap(Source: Observatoire de la satisfaction.)

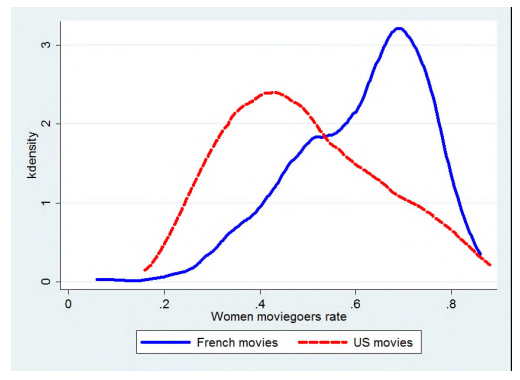

(a) Women prefer French movies

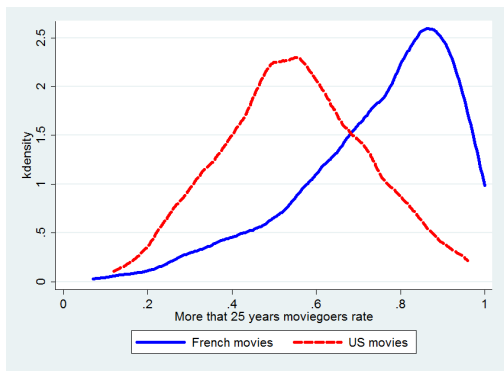

(b) Elders prefer French movies

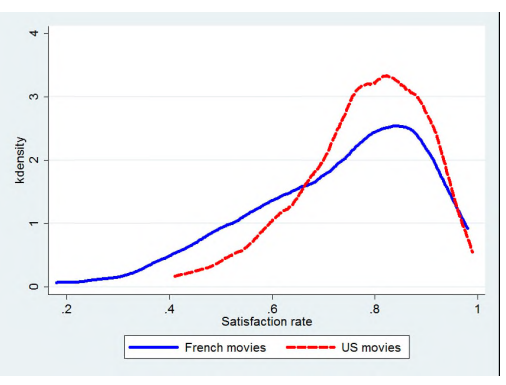

(c) French movies are more disappointing 
connection depends on three factors. Firstly, the length of an Internet line reduces its download speed, and homes located far away from a local exchange have lower download speed. Secondly, the diameter of the Internet cable also matters, where larger cables allow for faster connections. Last, and to a lesser extent, the technology embedded into a local exchange can affect the download speed.

A given town can be served by one local exchange point or by several local exchanges if the town is not small. Conversely, a local exchange can equip different small towns. A local exchange provides Internet access to users through Internet connections with different speed levels. The coverage rate of high speed Internet infrastructure is defined as the fraction of connections with download speeds higher than 512 kbit/s over the total number of connections delivered by a local exchange. For instance, a local exchange can reach 30,000 households, with 27,000 connections with download speeds exceeding $512 \mathrm{kbit} / \mathrm{s}$, and the remaining connections providing download speed inferior to $512 \mathrm{kbits} / \mathrm{s}$. The coverage rate of this local exchange is $90 \%$. For a given town, the average coverage rate is computed using the rates of all local exchanges the connections to its inhabitants, weighted by the number of connections supplied by each local exchange. As an example, take a town provided by two local exchange. If the first local exchange can connect 30000 households and has a high speed Internet coverage rate of $90 \%$ while the second one can connect 10000 households and has a coverage rate of $80 \%$, then the coverage rate of the town is $87.5 \%$.

The number of broadband subscribers is observed in the data for all local exchanges only when they become unbundled by at least one alternative Internet service provider (ISP). The process called local loop unbundling allows an alternative ISP to propose Internet subscriptions at lower costs, and with a better service, without having to rely on the historical incumbent. However, many local exchanges were still not unbundled during the time period of the study, so that the number of subscribers is missing for many local exchanges in the data. Therefore, the number of broadband subscribers cannot be aggretated for each town the same way as it is done for the Internet coverage rate. However, it is possible to study the correlation between the coverage rate and the number of broadband subscribers at the local exchange level, using the local exchange for which we know the number of broadband subscribers.

It is noteworthy that there has been no significant change in broadband Internet infrastructure during 2008-2001. Indeed, the period of 2008-2011 corresponds to a transitory period in the development of Internet in France. It matches the end of the roll-out of high-speed Internet (DSL) and it precedes the introduction of very high Internet (optical fiber) in France. The coverage rate of broadband Internet was already very high in 2008. For instance, the percentage of lines connected to DLS technology in France increased from $99 \%$ to $99.5 \%$ over the period of 2008-2011. The main technological change that was still in progress over that period is the process called unbundling. The European regulation allows alternative 
Internet operators to install their own equipment in the end of network facilities of the historical incumbent (the local exchange) to directly sell broadband Internet access to the final consumer. This process was initiated in 2002 in France. About $65 \%$ of lines were unbundled in 2008, to reach the number of $80 \%$ in 2011. However, this increase mainly occurred in the country-side of France as the unbundling process started first in the biggest towns of France. In our sample, i.e., the towns for which we observe movie admissions in theaters, the mean number of unbundled lines increased from $95 \%$ to $99 \%$ over the period of 2008-2011; the local exchanges located in the towns in our sample were already unbundled.

\section{Robustness checks for analysis 1: The correlation between the coverage rate and the use of broadband Internet}

To validate the use of the coverage rate as a proxy for online piracy, we need to show that it is significantly correlated with the rate of broadband Internet subscribers. We know the number of subscribers at the local exchange level, but not for all local exchanges. A local exchange is an important piece of the ADSL infrastructure, that connects the phone line of individuals to the Internet. On average, it takes several local exchanges to serve a middle-sized town. Therefore, we do not have complete information to compute the number of broadband Internet users at the town-level. However, we can study the correlation between the broadband Internet coverage rate and the broadband Internet use rate at the local exchange level, for the local exchanges for which we observe the number of subscribers.

In practice, we estimate the following specification:

$$
\text { Subscribers }_{j}=\beta \times \text { CoverageRate }_{j}+X_{j}^{\prime} \theta+e_{j}
$$

where Subscriber $_{j}$ is the number of subscribers of local exchange $j$ during the first quarter of 2008 (i.e, before the Hadopi law was ever mentioned), and CoverageRage ${ }_{j}$ is the percentage of lines of local exchange $j$ that are eligible to broadband Internet. $X_{j}$ accounts for additional controls.

Results are presented in Table 16. In column 1, we only include the coverage rate as an explanatory variable. The variable is positively and significantly correlated with the number of broadband subscribers. Moreover, it explains an important share of the number of broadband subscribers, as the R2 is close to 0.40. Adding the number of lines that are served by the local exchange as a control variable (column 2) leaves the results unchanged. 
Table 16 - Effect of the coverage rate on the use of broadband Internet

\begin{tabular}{lcc}
\hline \hline & \multicolumn{2}{c}{ Number of broadband subscribers } \\
\cline { 2 - 3 } & $(1)$ & $(2)$ \\
\hline Coverage rate & $0.888^{* * *}$ & $0.890^{* * *}$ \\
& $(0.0275)$ & $(0.0272)$ \\
Number of lines & & $0.00000225^{* * *}$ \\
& & $(0.000000114)$ \\
Constant & $-0.288^{* * *}$ & $-0.305^{* * *}$ \\
& $(0.0250)$ & $(0.0247)$ \\
\hline Observations & 3839 & 3839 \\
R-Squared & 0.383 & 0.417 \\
\hline Robust standard errors. ${ }^{*} p<0.10,{ }^{* *} p<0.05, * * *$ & $p<0.01$
\end{tabular}

\section{Robustness checks for analysis 1: the absence of difference in pre-treatment trends}

To validate the identification strategy of analysis 1 , we test whether broadband use is correlated with changes in box office revenues and in American market share during the pre-HADOPI period. We focus on the period before April 2009, that is the period before the law was discussed in the public debate. To test for the absence of difference in pre-treatment trends, we estimate the following equation:

$$
\text { Outcome }_{c t}=\theta_{c}+\delta_{t}+X_{c t} \beta^{\prime}+\alpha \times \text { Three_Months_Before }_{t} \times \text { Internet }_{c}+\epsilon_{c t}
$$

where Three_Months_Before $e_{t}$ is an indicator equal to one during the three months before the HADOPI law was started o be discussed. We do not have many observation during that period preceding the debate of the HADOPI law (we only have six months), so we decide to cut the sample into half to run this test. Outcome $_{c t}$ can be the market share of U.S. movies, the number of American admissions, the number of French admissions, or the total number of admissions. Results are presented in Tables 17. They confirm the absence of differential pre-treatment trends.

Table 17 - Checking the absence of pre-treatment trends

\begin{tabular}{|c|c|c|c|c|}
\hline & $\begin{array}{l}\text { U.S. market share } \\
(1)\end{array}$ & $\begin{array}{c}\log \text { (U.S. adm) } \\
(2)\end{array}$ & $\begin{array}{c}\log (\text { Other adm }) \\
(3)\end{array}$ & $\begin{array}{c}\log (\text { Total adm }) \\
(4)\end{array}$ \\
\hline Before $\times$ Internet & $\begin{array}{l}-0.0653 \\
(0.0912)\end{array}$ & $\begin{array}{r}-0.0256 \\
(0.348)\end{array}$ & $\begin{array}{c}0.164 \\
(0.226)\end{array}$ & $\begin{array}{l}0.0837 \\
(0.220)\end{array}$ \\
\hline Town fixed effect & yes & yes & yes & yes \\
\hline Month fixed effect & yes & yes & yes & yes \\
\hline Quality of French films & yes & yes & yes & yes \\
\hline Quality of U.S. films & yes & yes & yes & yes \\
\hline Constant & yes & yes & yes & yes \\
\hline Observations & 760 & 760 & 703 & 760 \\
\hline R-squared & 0.663 & 0.597 & 0.605 & 0.569 \\
\hline
\end{tabular}




\section{E Additional test for analysis 1: Estimating the market expan- sion effect with a logit model}

To try to determine the size of the market expansion effect, we add some structure by implementing a discrete choice model. Specifically, we estimate the monthly demand for movies with a logit model. Let $M_{c t}$ be the potential consumers of each market $c t$ (a town during a given month) that we proxy with the monthly population of that town, as obtained from the French census. We abstract from the choice of a specific movie and we model instead the choice between American and other movies, as it is the focus of this article. The utility of consumer $i$ from buying a movie of type $j$ (that is either American or not American) during month $t$ in town $c$ is given by:

$$
u_{i j c t}=\delta_{j c t}+\epsilon_{i j c t}
$$

The utility is decomposed into two parts: (1) $\delta_{j c t}$, a deterministic part that is equal for all consumers, and $(2) \epsilon_{i j c t}$, a random deviation from that mean, specific to each consumer. We assume that $\epsilon_{i j c t}$ is distributed extreme values.

The outside option consists of any other activities a consumer can choose instead of going to the movies. The utility of consumer $i$ from the outside option in town $c$ during month $t$ is given by:

$$
u_{i 0 c t}=\delta_{0 c t}+\epsilon_{i 0 c t}
$$

where $\delta_{0 c t}$ is normalized to zero and $\epsilon_{i 0 c t}$ has the same properties as $\epsilon_{i j c t}$.

We specify the mean utility for choosing movie of type $j$ in town $c$ during month $t$ as:

$$
\begin{aligned}
\delta_{j c t} & =C+\alpha U S_{j}+\rho_{c j}+\tau_{t j}+\gamma Q_{j c t} \\
& +\beta_{1} H A D O P I_{t} \times \text { Internet }_{c}+\beta_{2} H A D O P I_{t} \times \text { Internet }_{c} \times U S_{j}+\xi_{j c t}
\end{aligned}
$$

Where $C$ is a constant, $\rho_{c j}$ is a town fixed-effect specific to movies of nationality $j, \tau_{t j}$ is a month fixed-effect specific to movies of nationality $j, U S_{j}$ is a dummy equal to one for American movies, and $Q_{j c t}$ capture the quality of American or that of other (French) movies available in the market $c t$, as before. $H A D O P I_{t}$ and Internet $_{c}$ are also defined as before. The HADOPI effect is captured with the same identification strategy as in analysis 1 . 
By aggregating individual choices over all consumers, the assumed distribution of $\epsilon_{i j c t}$ generates the logit formula of the conditional choice probability that approximates $s_{j c t}$, the market share of movies of type $j$ in town $c$ during month $t$ :

$$
s_{j c t}=\frac{e^{\delta_{j c t}}}{\sum_{k=0}^{J_{c c t}} e^{\delta_{k c t}}}
$$

Equation 8 can be inverted to obtain the following relation that can be directly estimated with OLS:

$$
\begin{aligned}
\log \left(s_{j c t}\right)-\log \left(s_{0 c t}\right) & =C+\alpha U S_{j}+\rho_{c j}+\tau_{t j}+\gamma Q_{j c t} \\
& +\beta_{1} H A D O P I_{t} \times \text { Internet }_{c}+\beta_{2} H A D O P I_{t} \times \text { Internet }_{c} \times U S_{j}+\xi_{j c t}
\end{aligned}
$$

Results are presented in Table 18. The HADOPI effect is significantly positive for American movies while it is significantly negative for other movies. The results also reveals a general preference for American movies, and they confirm that the quality of the movies available within one alternative matters.

\begin{tabular}{lc}
\multicolumn{2}{c}{ Table $18-$ Estimates of the logit model } \\
\hline \hline U.S. & $\log \left(s_{j c t}\right)-\log \left(s_{0 c t}\right)$ \\
& $0.192^{* * *}$ \\
HADOPI $\times$ Internet & $(0.0291)$ \\
& $-0.519^{* * *}$ \\
HADOPI $\times$ Internet $\times$ U.S. & $(0.186)$ \\
& $1.047^{* * *}$ \\
Quality & $(0.259)$ \\
& $0.00761^{* * *}$ \\
Town $\times$ U.S. fixed effects & $(0.00174)$ \\
Town $\times$ Others fixed effects & Yes \\
Month $\times$ U.S. fixed effects & Yes \\
Month $\times$ Others fixed effects & Yes \\
Constant & Yes \\
& $-3.474^{* * *}$ \\
\hline Observations & $(0.0221994)$ \\
R-Squared & 5167 \\
\hline Standard errors clustered by town. ${ }^{*} p<0.10, * *$ & 0.984 \\
\hline
\end{tabular}

Using the parameter estimates, we run a counterfactual simulation of what would have been the total number of admissions of American movies, of other movies, and of all movies without the HADOPI law. We compare these outcomes with the predictions of the model with the HADOPI law and we compute the difference that is induced by the anti-piracy law. Because a primary objective is to estimate whether the market expansion induced by the HADOPI law is significant or not, it is important to compute the precision of the simulated outcomes. Therefore, we bootstrap the simulations using 10000 replications, re-estimating the model each time, to obtain a distribution of the simulated outcomes. We implement a 
block bootstrap procedure that is clustered at the town level.

Simulated counterfactuals are presented in Table 19. They show that the HADOPI law has significantly increased by 21 million the admissions for American movies at the expense of a drop of 17 million admissions for other movies. The overall effect is positive on the total size of the market, but this effect is not statistically different from zero as it can be seen from the confidence interval. The estimated market expansion effect is about four million admissions, which is not zero, but it is small compared to the redistributive effect highlighted between U.S. and other movies. These simulations are contingent upon the sample used in this analysis. Because the sample was selected to maximize the variation in the Internet infrastructure, it is possible that the overall effect in France is smaller.

Table 19 - Counterfactual simulation of the HADOPI effect (in number of admissions)

\begin{tabular}{|r|rrr|}
\hline & American movies & Other movies & All movies \\
\hline HADOPI effect & 20981866 & -17055861 & 3926005 \\
95\%-CI Lower & 7470851 & -44933042 & -27559201 \\
95\%-CI Upper & 37572159 & -3170752 & 29178515 \\
\hline
\end{tabular}

\section{F Robustness checks for analysis 1: Ruling out the advent of 3D movies}

3D movies were introduced at essentially the same time as Hadopi with the release of Avatar near the end of 2009. This might have influenced the effect of the anti-piracy law because this technological innovation could have increased the demand for movies in theaters and 3D films were mainly American. ${ }^{31}$ The effect of 3D films might also have been different across towns because the diffusion of digital projectors in France was progressive and due to limited funding.

We observe the nature of the session (i.e., whether a movie is exhibited in $3 \mathrm{D}$ or not) for the data provided by Médiamétrie. As a consequence, in this robustness check, we additionally control for the number of movies played in 3D in town $c$ during month $t$, using only the data from Médiamétrie. In this way, we also control for the rapid conversion to digital projectors in France, as 3D movies require digital projectors to be exhibited in theaters. Results are presented in Table 20 and 21 for the U.S. market share and the log of total admissions. Columns 1-2 control for town fixed effects and month fixed effects, columns 3-4 additionally control for the time-varying quality of American movies and French movies, columns 5-6

31. Avatar was followed by other 3D releases such as How to Train Your Dragon (2010), Alice in Wonderland (2010), and so forth. 
add the control for 3D screenings, and columns 7-8 contain all of the control variables and drop the $50 \%$ of towns with high-speed Internet infrastructure closest to the median.

They show that the advent of 3D movies did not interfere with the effects of the Hadopi law.

Table 20 - Estimates of parameters from equation (1) when the outcome is the U.S. market share

\begin{tabular}{|c|c|c|c|c|c|c|c|c|}
\hline & \multicolumn{8}{|c|}{ 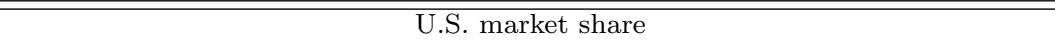 } \\
\hline & (1) & $(2)$ & $(3)$ & (4) & (5) & (6) & (7) & (8) \\
\hline Hadopi $\times$ Internet & $\begin{array}{c}0.539 \\
(0.330)\end{array}$ & & $\begin{array}{c}0.529^{*} \\
(0.282)\end{array}$ & & $\begin{array}{l}0.569^{*} \\
(0.309)\end{array}$ & & $\begin{array}{c}0.816^{* *} \\
(0.318)\end{array}$ & \\
\hline Hadopi1 $\times$ Internet & & $\begin{array}{c}0.621 \\
(0.520)\end{array}$ & & $\begin{array}{c}0.547 \\
(0.491)\end{array}$ & & $\begin{array}{c}0.533 \\
(0.493)\end{array}$ & & $\begin{array}{c}0.600 \\
(0.561)\end{array}$ \\
\hline Hadopi2 $\times$ Internet & & $\begin{array}{c}0.840 \\
(0.574)\end{array}$ & & $\begin{array}{c}0.766 \\
(0.507)\end{array}$ & & $\begin{array}{c}0.780 \\
(0.513)\end{array}$ & & $\begin{array}{l}0.979^{*} \\
(0.552)\end{array}$ \\
\hline Hadopi3 $\times$ Internet & & $\begin{array}{l}0.915^{*} \\
(0.505)\end{array}$ & & $\begin{array}{c}0.902^{* *} \\
(0.432)\end{array}$ & & $\begin{array}{c}0.959^{* *} \\
(0.463)\end{array}$ & & $\begin{array}{c}1.363^{* * *} \\
(0.456)\end{array}$ \\
\hline Town fixed effect & yes & yes & yes & yes & yes & yes & yes & yes \\
\hline Month fixed effect & yes & yes & yes & yes & yes & yes & yes & yes \\
\hline Quality of French films & no & no & yes & yes & yes & yes & yes & yes \\
\hline Quality of U.S. films & no & no & yes & yes & yes & yes & yes & yes \\
\hline 3D shows & no & no & no & no & yes & yes & yes & yes \\
\hline Constant & yes & yes & yes & yes & yes & yes & yes & yes \\
\hline Observations & 2087 & 2087 & 2087 & 2087 & 2087 & 2087 & 990 & 990 \\
\hline R-squared & 0.880 & 0.880 & 0.886 & 0.886 & 0.886 & 0.887 & 0.892 & 0.893 \\
\hline
\end{tabular}

Table 21 - Estimates of parameters from equation (1) when the outcome is the total admissions

\begin{tabular}{|c|c|c|c|c|c|c|c|c|}
\hline & \multicolumn{8}{|c|}{ log(Total Admissions) } \\
\hline & (1) & (2) & (3) & (4) & (5) & (6) & (7) & (8) \\
\hline Hadopi $\times$ Internet & $\begin{array}{c}3.585 \\
(2.599)\end{array}$ & & $\begin{array}{c}2.872 \\
(2.112)\end{array}$ & & $\begin{array}{c}2.959 \\
(2.158)\end{array}$ & & $\begin{array}{c}2.351 \\
(2.145)\end{array}$ & \\
\hline Hadopi1 $\times$ Internet & & $\begin{array}{c}1.680 \\
(1.531)\end{array}$ & & $\begin{array}{c}1.081 \\
(1.545)\end{array}$ & & $\begin{array}{c}1.048 \\
(1.554)\end{array}$ & & $\begin{array}{c}-0.170 \\
(1.821)\end{array}$ \\
\hline Hadopi2 $\times$ Internet & & $\begin{array}{c}4.315 \\
(3.084)\end{array}$ & & $\begin{array}{c}3.154 \\
(2.496)\end{array}$ & & $\begin{array}{c}3.185 \\
(2.521)\end{array}$ & & $\begin{array}{c}1.969 \\
(2.526)\end{array}$ \\
\hline Hadopi3 $\times$ Internet & & $\begin{array}{c}4.710 \\
(2.999)\end{array}$ & & $\begin{array}{c}3.840 \\
(2.522)\end{array}$ & & $\begin{array}{c}3.970 \\
(2.557)\end{array}$ & & $\begin{array}{c}2.628 \\
(2.549)\end{array}$ \\
\hline Town fixed effect & yes & yes & yes & yes & yes & yes & yes & yes \\
\hline Month fixed effect & yes & yes & yes & yes & yes & yes & yes & yes \\
\hline Quality of French films & no & no & yes & yes & yes & yes & yes & yes \\
\hline Quality of U.S. films & no & no & yes & yes & yes & yes & yes & yes \\
\hline 3D shows & no & no & no & no & yes & yes & yes & yes \\
\hline Constant & yes & yes & yes & yes & yes & yes & yes & yes \\
\hline Obervations & 2087 & 2087 & 2087 & 2087 & 2087 & 2087 & 990 & 990 \\
\hline R-squared & 0.941 & 0.941 & 0.942 & 0.942 & 0.942 & 0.942 & 0.934 & 0.934 \\
\hline
\end{tabular}

Source: Arcep, Médiamétrie. Standard errors clustered by town. ${ }^{*} p<0.10,{ }^{* *} p<0.05,{ }^{* * *} p<0.01$. 


\section{G Robustness checks for analysis 2: The role of movie genres}

We examine the heterogeneity of the HADOPI effect on movie admissions according to the variable movie genre, available in the dataset of this analysis. The most pirated movies are usually those aimed at a teenager audience such as Fantasy, Science Fiction, and Horror movies (see Danaher et al. (2010), Danaher and Waldfogel (2012), Variety $2019^{32}$, and all the yearly rankings of the most pirated movies). Therefore, we expect the HADOPI law to have a positive effect on the admissions to the most pirated films. We estimate a specification that is similar, in the spirit, to that of equation (2):

$$
\text { Outcomes }_{i t}=\rho_{t}+\beta X_{i}+\gamma U S_{i}+\sum_{\substack{k \\ k \neq c o m}} \alpha_{k} \times H A D O P I_{t} \times \mathbb{1}_{\left[i \in \text { Genre }_{k}\right]}+\epsilon_{i t}
$$

We use the logarithm of admissions during the release week and the logarithm of the ratio between the number of admissions during the release week and the corresponding number of screens as dependent variables. Movies are grouped in six separated genres: adventure, animated, comedy, drama, scifi/fantasy/horror, and thriller/crime. The sci-fi/fantasy/horror genre contains most of the U.S. blockbusters such as superhero movies that are the most pirated ones. As shown in Table 22, the comedy genre is the most frequent genre, representing $37 \%$ of movies in our sample, and the sci-fi/fantasy/horror genre is almost entirely composed of American movies. We use the comedy genre as reference group in our specification. In an alternative specification, we also decompose the HADOPI effect on movie genres between American and French movies to obtain more detailed effects.

Table 22 - Distribution of movies by genre and nationality

\begin{tabular}{lccc}
\hline \hline Genre & All movies & French movies & U.S. movies \\
\hline Animated & $8,5 \%$ & $27,9 \%$ & $72,1 \%$ \\
Adventure & $17,5 \%$ & $16,4 \%$ & $83,6 \%$ \\
Comedy & $37,3 \%$ & $61,5 \%$ & $38,5 \%$ \\
Drama & $16,6 \%$ & $62,4 \%$ & $37,6 \%$ \\
Thriller / Crime & $11,0 \%$ & $50,0 \%$ & $50,0 \%$ \\
SF / Fantasy / Horror & $9,2 \%$ & $4,1 \%$ & $95,9 \%$ \\
\hline Total & 767 & $44,4 \%$ & $55,6 \%$ \\
\hline
\end{tabular}

Columns (1) and (3) of Table 23 present the estimated results of equation 9 without differentiating between American and French movies. The HADOPI law significantly increases the admissions to scifi/fantasy/horror movies while it decreases those to drama, thriller/crime, and adventure movies. The anti-piracy law has no effect on animated movies. Columns (2) and (4) decompose the HADOPI effect according to movie genres between American and French movies. The HADOPI law significantly increases the admissions to American sci-fi/fantasy/horror movies (there are no French sci-fi/fantasy/horror movies

32. https://variety.com/2019/digital/news/avengers-endgame-piracy-box-office-1203198888/ 
in our sample), at the expense of French adventure, drama, and thriller/crime movies. This finding helps to understand why the effect of HADOPI is different between American and other (French) movies and to identify the type of cultural products whose production is potentially affected by the anti-piracy law.

Table 23 - Heterogeneity of the HADOPI effect on movie admissions according to the movie genre

\begin{tabular}{|c|c|c|c|c|}
\hline & \multicolumn{2}{|c|}{$\log$ (Admissions) } & \multicolumn{2}{|c|}{$\log$ (Admissions/Screens) } \\
\hline & (1) & (2) & (3) & (4) \\
\hline HADOPI $\times$ Anim. & $\begin{array}{l}0.0142 \\
(0.163)\end{array}$ & & $\begin{array}{l}-0.0142 \\
(0.157)\end{array}$ & \\
\hline HADOPI $\times$ Adven & $\begin{array}{l}-0.123 \\
(0.0904)\end{array}$ & & $\begin{array}{l}-0.156^{*} \\
(0.0904)\end{array}$ & \\
\hline HADOPI $\times$ Drama & $\begin{array}{r}-0.211^{* *} \\
(0.0891)\end{array}$ & & $\begin{array}{r}-0.188^{* *} \\
(0.0924)\end{array}$ & \\
\hline HADOPI $\times$ SF_Fan_Hor & $\begin{array}{c}0.326^{* * *} \\
(0.122)\end{array}$ & & $\begin{array}{c}0.380 * * * \\
(0.130)\end{array}$ & \\
\hline HADOPI $\times$ ThrilCrime & $\begin{array}{c}-0.209^{* *} \\
(0.105)\end{array}$ & & $\begin{array}{c}-0.258^{* *} \\
(0.104)\end{array}$ & \\
\hline HADOPI $\times$ Anim.$\times$ FR & & $\begin{array}{c}-0.00900 \\
(0.170)\end{array}$ & & $\begin{array}{c}-0.0699 \\
(0.166)\end{array}$ \\
\hline HADOPI $\times$ Anim. $\times$ US & & $\begin{array}{l}0.0186 \\
(0.190)\end{array}$ & & $\begin{array}{c}0.00280 \\
(0.185)\end{array}$ \\
\hline HADOPI $\times$ Adven. $\times$ FR & & $\begin{array}{c}-0.336^{* * *} \\
(0.126)\end{array}$ & & $\begin{array}{c}-0.385^{* * *} \\
(0.126)\end{array}$ \\
\hline HADOPI $\times$ Adven. $\times$ US & & $\begin{array}{l}-0.0865 \\
(0.0940)\end{array}$ & & $\begin{array}{l}-0.116 \\
(0.0942)\end{array}$ \\
\hline HADOPI $\times$ Drama $\times$ FR & & $\begin{array}{r}-0.231^{* *} \\
(0.0976)\end{array}$ & & $\begin{array}{c}-0.216^{* *} \\
(0.101)\end{array}$ \\
\hline HADOPI $\times$ Drama $\times$ US & & $\begin{array}{l}-0.184 \\
(0.113)\end{array}$ & & $\begin{array}{l}-0.148 \\
(0.119)\end{array}$ \\
\hline HADOPI $\times$ SF_Fan_Hor $\times$ FR & & $\begin{array}{c}0 \\
(.)\end{array}$ & & $\begin{array}{c}0 \\
(.)\end{array}$ \\
\hline HADOPI $\times$ SF_Fan_Hor $\times$ US & & $\begin{array}{c}0.328^{* * *} \\
(0.122)\end{array}$ & & $\begin{array}{c}0.382^{* * *} \\
(0.131)\end{array}$ \\
\hline HADOPI $\times$ Thril_Crime $\times$ FR & & $\begin{array}{c}-0.241^{* *} \\
(0.113)\end{array}$ & & $\begin{array}{c}-0.296^{* *} \\
(0.116)\end{array}$ \\
\hline HADOPI $\times$ Thril_Crime $\times$ US & & $\begin{array}{l}-0.170 \\
(0.159)\end{array}$ & & $\begin{array}{l}-0.210 \\
(0.149)\end{array}$ \\
\hline $\log ($ Screens $)$ & $\begin{array}{l}1.298^{* * *} \\
(0.0765)\end{array}$ & $\begin{array}{l}1.295^{* * *} \\
(0.0763)\end{array}$ & & \\
\hline $\log (\mathrm{Ad})$ & $\begin{array}{c}0.197^{* * *} \\
(0.0436)\end{array}$ & $\begin{array}{c}0.196^{* * *} \\
(0.0438)\end{array}$ & $\begin{array}{c}0.309^{* * *} \\
(0.0379)\end{array}$ & $\begin{array}{c}0.305^{* * *} \\
(0.0383)\end{array}$ \\
\hline $\log$ (Budget) & $\begin{array}{c}-0.0302 \\
(0.0383)\end{array}$ & $\begin{array}{c}-0.0289 \\
(0.0382)\end{array}$ & $\begin{array}{c}0.0395 \\
(0.0363)\end{array}$ & $\begin{array}{c}0.0405 \\
(0.0363)\end{array}$ \\
\hline Consumer rating & $\begin{array}{c}0.181^{* * *} \\
(0.0404)\end{array}$ & $\begin{array}{c}0.186^{* * *} \\
(0.0406)\end{array}$ & $\begin{array}{c}0.175^{* * *} \\
(0.0416)\end{array}$ & $\begin{array}{c}0.181^{* * *} \\
(0.0419)\end{array}$ \\
\hline Press rating & $\begin{array}{c}0.121^{* * *} \\
(0.0302)\end{array}$ & $\begin{array}{c}0.116^{* * *} \\
(0.0303)\end{array}$ & $\begin{array}{c}0.129^{* * *} \\
(0.0302)\end{array}$ & $\begin{array}{c}0.124^{* * *} \\
(0.0304)\end{array}$ \\
\hline Genre fixed effect & yes & yes & yes & yes \\
\hline Nationality fixed effect & yes & yes & yes & yes \\
\hline Art and house fixed effect & yes & yes & yes & yes \\
\hline Age restriction fixed effect & yes & yes & yes & yes \\
\hline Distributor fixed effect & yes & yes & yes & yes \\
\hline Month fixed effect & yes & yes & yes & yes \\
\hline Constant & yes & yes & yes & yes \\
\hline$N$ & 802 & 802 & 802 & 802 \\
\hline$R^{2}$ & 0.804 & 0.804 & 0.460 & 0.463 \\
\hline
\end{tabular}




\section{H Robustness checks for analysis 2: Ruling out the informative effect explanation}

In this robustness check, we rule out the long-tail explanation proposed by Peukert et al. (2017), that is, informative effect of online piracy benefits small movies. If the informative effect was explaining our results, then blockbuster films would have benefited from higher revenues after the HADOPI law. Therefore, we estimate the following equation in a difference-in-differences setting:

$$
\text { Admissions }_{i t}=\rho_{t}+\gamma \times \text { Size }_{i}+\alpha \times H A D O P I_{t} \times \text { Size }_{i}+\beta X_{i}+\epsilon_{i t}
$$

for movie $i$ during release week $t$, where $\rho_{t}$ is a week fixed effect, where $S i z e_{i}$ is a dummy variable equal to one when a movie's size is above its median, where $H A D O P I_{t}$ is a post-HADOPI dummy variable equal to one after November 2009, and where $X_{i}$ is a set of movie variables including the production budget, consumers' rating, press rating, fixed effects for genre, nationality, art-house movies, age restrictions, and distributors. We test two variables for the size of a movie: the total advertising expenditures and the number of screens during the release week. The production budget is not a good indicator of the potential audience of a movie in the French theatrical market, as American movies usually have higher production budgets than French ones because they are designed to be sold on much more markets (countries). The advertising expenditures and the number of opening screens reflect the expectations of distributors about movies' revenues. Results are presented in Table 24 and demonstrate the absence of a positive effect on revenues of blockbuster films after the introduction of the HADOPI law when a blockbuster is defined in terms of high advertising expenditures (Column 1) or high number of opening screens (Column 2).

This test would not be valid if the absence of an increase in the revenues of blockbuster films after the HADOPI law was hiding an increase in revenues to American blockbusters compensating a decrease in revenues of French ones. We confirm the validity of the previous test by estimating the following equation in a triple-difference setting:

$$
\begin{aligned}
\text { Admissions }_{i t}= & \rho_{t}+\gamma \times \text { Size }_{i}+\delta \times U S_{i}++\lambda U S_{i} \times \text { Size }_{i}+\mu \times H A D O P I_{t} \times U S_{i} \\
& +\alpha \times H A D O P I_{t} \times \text { Size }_{i}+\phi \times H A D O P I_{t} \times U S_{i} \times \text { Size }_{i}+\beta X_{i}^{\prime}+\epsilon_{i t}
\end{aligned}
$$

where Size $_{i}$ and $H A D O P I_{t}$ are defined are before, where $U S_{i}$ is an indicator equal to one for U.S. movies, and where $X_{i}$ is a set of movie variables including the production budget, consumers' rating, press rating, fixed effects for genre, art-house movies, age restrictions, and distributors. With this specification, 
we identify separately the anti-piracy law effect on American blockbuster films and on French ones. Results are presented in Column 3 and 4 and they confirm the absence of a positive effect on admissions to American blockbuster film after the anti-piracy law was adopted. This effect is actually negative although non significant.

Overall, these results are contradictory with the mechanism proposed in Peukert et al. (2017). We do not find that American blockbuster films have benefited more from the anti-piracy law. Therefore, an informative effect from online piracy profitable to small independent films does not explain our results.

Table 24 - DiD small vs. blockbuster film in France (first week): ruling out the information effect explanation

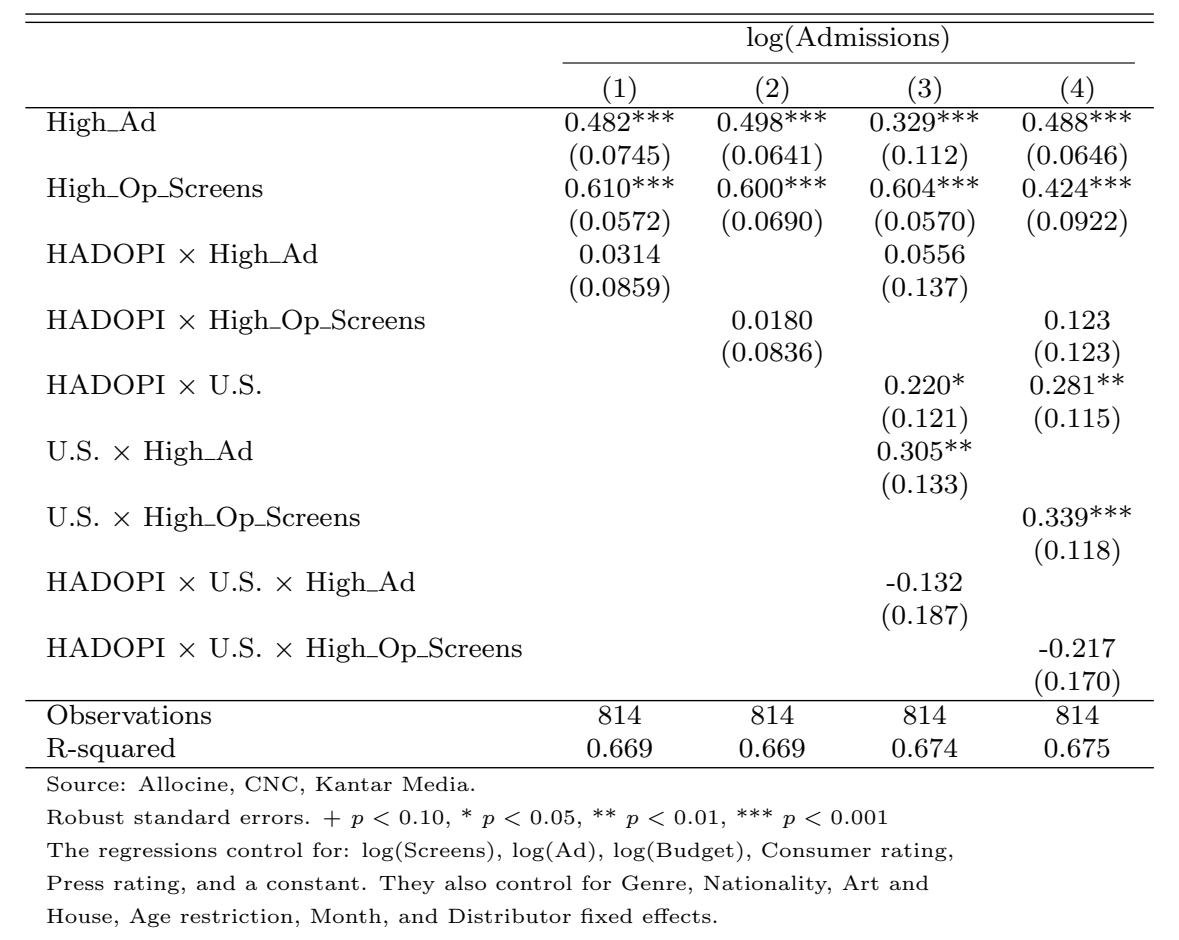




\section{Robustness checks for analysis 2: Extreme values}

Table 25 - DiD French vs. U.S. in France (first week), a robustness test on demand reaction

\begin{tabular}{lccccc}
\hline \hline & \multicolumn{2}{c}{$\log ($ Admissions $)$} & & \multicolumn{2}{c}{$\log ($ Admissions $/$ Screens $)$} \\
\cline { 2 - 3 } \cline { 5 - 6 } & $(1)$ & $(2)$ & & $(3)$ & $(4)$ \\
\hline HADOPI $\times$ U.S. & $0.146^{* * *}$ & & $0.130^{* * *}$ & \\
& $(0.0469)$ & & & $(0.0481)$ & \\
HADOPI1 $\times$ U.S. & & $0.192^{* *}$ & & $0.228^{* * *}$ \\
& & $(0.0796)$ & & $(0.0827)$ \\
HADOPI2 $\times$ U.S. & & $0.294^{* * *}$ & & $0.305^{* * *}$ \\
& & $(0.0616)$ & & $(0.0622)$ \\
HADOPI3 $\times$ U.S. & & $0.101^{*}$ & & 0.0889 \\
& & $(0.0566)$ & & $0.0578)$ \\
\hline$N$ & 656 & 656 & 656 & 656 \\
$R^{2}$ & 0.915 & 0.918 & 0.708 & 0.707 \\
\hline
\end{tabular}

Source: Allocine, CNC, Kantar Media.

Robust standard errors. ${ }^{*} p<0.10,{ }^{* *} p<0.05,{ }^{* * *} p<0.01$

The regressions control for: $\log$ (Screens), $\log (\mathrm{Ad}), \log$ (Budget), Consumer rating,

Press rating, and a constant. They also control for Genre, Nationality, Art and

House, Age restriction, Month, and Distributor fixed effects.

Estimates obtained after having dropped the $20 \%$ of movies with the highest absolute residual values from the first-step estimate. 


\section{J Control group selection for analysis 3}

During the period 2008-2011, no measure similar to the French HADOPI law has been implemented in Europe, besides Sweden in 2009. However, three waves of legislation in countries close to France may have stirred up the Internet users community, but we believe they did not have any significant impact on individuals because they have not been implemented. In Spain, in 2010, discussions were surrounding the Sinde Law, a provision designed to shut down websites in violation with copyright law. It was made law at the end of 2011. In Italy, in 2011, the regulation and competition authority for the communication industries, the AGCOM, expressed its intention to fight websites in violation with copyright law. The Spanish and the Italian measures are of quite a different nature compared to the HADOPI law. Finally in the United Kingdom, in 2010, the Digital Economy Act addressed online copyright infringement in a similar way to the graduated response of the HADOPI law. With this act, Internet subscribers who had downloaded illegal content using peer-to-peer file-sharing systems were supposed to receive notifications. This Act is in force although the procedure against infringers has not been implemented.

We then run the following estimation using observations in the pre-treatment period (i.e form January 2007 to March 2009) to select the relevant candidate to be included in the control group:

$$
\text { Outcome }_{F r, t}=\alpha+\beta_{s} \text { Outcome }_{c t}+\epsilon_{c t}
$$

$c$ is a country and $t$ is a month, with Outcome $_{c t}$ being repetitively $\log \left(\right.$ Admissions $_{c t} /$ Screens $\left._{c t}\right)$ for US movies, $\log \left(\right.$ Screens $\left._{c t}\right)$ for US movies, $\operatorname{Lag}_{c t}$ for US movies, $\log \left(\right.$ Admissions $\left._{c t}\right)$ for all movies, and $\log \left(\right.$ USmarketshare $\left._{c t}\right)$.

Table $26-\log \left(\right.$ Admissions $_{c t} /$ Screens $\left._{c t}\right)$ (January 2007 - March 2009)

\begin{tabular}{|c|c|c|c|c|c|c|c|c|}
\hline & $\begin{array}{l}\text { Belgium } \\
(1)\end{array}$ & $\begin{array}{c}\text { Finland } \\
(2)\end{array}$ & $\begin{array}{c}\text { Germany } \\
(3)\end{array}$ & $\begin{array}{c}\text { Italy } \\
(4)\end{array}$ & $\begin{array}{c}\text { Netherlands } \\
(5)\end{array}$ & $\begin{array}{c}\text { Spain } \\
(6)\end{array}$ & $\begin{array}{c}\text { Switzerland } \\
(7)\end{array}$ & $\begin{array}{l}\text { UK } \\
(8)\end{array}$ \\
\hline $\log ($ Admissions/Screens $)$ & $\begin{array}{c}0.459^{* * * *} \\
(0.128)\end{array}$ & $\begin{array}{c}0.381^{* * *} \\
(0.116)\end{array}$ & $\begin{array}{c}0.368^{* * *} \\
(0.0962)\end{array}$ & $\begin{array}{c}0.223 \\
(0.144)\end{array}$ & $\begin{array}{c}0.395^{* * *} \\
(0.0795)\end{array}$ & $\begin{array}{l}0.432^{*} \\
(0.245)\end{array}$ & $\begin{array}{c}0.409^{* * *} \\
(0.141)\end{array}$ & $\begin{array}{c}0.301^{* * *} \\
(0.0714)\end{array}$ \\
\hline Constant & $\begin{array}{c}3.672^{* * * *} \\
(0.855)\end{array}$ & $\begin{array}{c}4.384^{* * * *} \\
(0.724)\end{array}$ & $\begin{array}{c}4.397^{* * *} \\
(0.619)\end{array}$ & $\begin{array}{c}5.304^{* * *} \\
(0.939)\end{array}$ & $\begin{array}{c}4.246^{* * *} \\
(0.522)\end{array}$ & $\begin{array}{c}3.908^{* *} \\
(1.605)\end{array}$ & $\begin{array}{c}4.170^{* * * *} \\
(0.897)\end{array}$ & $\begin{array}{c}4.735^{* * *} \\
(0.497)\end{array}$ \\
\hline Observations & 27 & 27 & 27 & 27 & 27 & 27 & 27 & 27 \\
\hline R-squared & 0.329 & 0.464 & 0.396 & 0.109 & 0.372 & 0.301 & 0.365 & 0.437 \\
\hline
\end{tabular}

Our preferred control group when the outcome of interest is the number of admissions over the number of screens of US movies (Table 26) is constituted by Belgium, Finland, Germany, the Netherlands, Spain, Switzerland, and United Kingdom. Our preferred control group when the outcome of interest is the 
Table $27-\log \left(\right.$ Screens $\left._{c t}\right)$ (January 2007 - March 2009)

\begin{tabular}{|c|c|c|c|c|c|c|c|c|}
\hline & $\begin{array}{l}\text { Belgium } \\
(1)\end{array}$ & $\begin{array}{c}\text { Finland } \\
(2)\end{array}$ & $\begin{array}{c}\text { Germany } \\
(3)\end{array}$ & $\begin{array}{c}\text { Italy } \\
(4)\end{array}$ & $\begin{array}{c}\text { Netherlands } \\
(5)\end{array}$ & $\begin{array}{c}\text { Spain } \\
(6)\end{array}$ & $\begin{array}{c}\text { Switzerland } \\
(7)\end{array}$ & $\begin{array}{l}\text { UK } \\
(8)\end{array}$ \\
\hline $\log ($ Screens $)$ & $\begin{array}{c}0.304^{* *} \\
(0.109)\end{array}$ & $\begin{array}{c}0.123 \\
(0.120)\end{array}$ & $\begin{array}{c}0.139 \\
(0.144)\end{array}$ & $\begin{array}{c}-0.168^{*} \\
(0.0943)\end{array}$ & $\begin{array}{l}0.379^{*} \\
(0.191)\end{array}$ & $\begin{array}{c}-0.0672 \\
(0.130)\end{array}$ & $\begin{array}{l}0.0485 \\
(0.134)\end{array}$ & $\begin{array}{l}0.0674 \\
(0.193)\end{array}$ \\
\hline Constant & $\begin{array}{c}6.262^{* * *} \\
(0.661)\end{array}$ & $\begin{array}{c}7.464^{* * *} \\
(0.610)\end{array}$ & $\begin{array}{c}6.946^{* * *} \\
(1.168)\end{array}$ & $\begin{array}{c}9.396^{* * *} \\
(0.756)\end{array}$ & $\begin{array}{c}5.696^{* * * *} \\
(1.202)\end{array}$ & $\begin{array}{c}8.611^{* * *} \\
(1.043)\end{array}$ & $\begin{array}{c}7.802^{* * *} \\
(0.742)\end{array}$ & $\begin{array}{c}7.512^{* * *} \\
(1.608)\end{array}$ \\
\hline Observations & 27 & 27 & 27 & 27 & 27 & 27 & 27 & 27 \\
\hline R-squared & 0.132 & 0.020 & 0.024 & 0.041 & 0.090 & 0.003 & 0.004 & 0.003 \\
\hline
\end{tabular}

Table 28 - Lag $_{c t}$ (January 2007 - March 2009)

\begin{tabular}{|c|c|c|c|c|c|c|c|c|}
\hline & $\begin{array}{l}\text { Belgium } \\
(1)\end{array}$ & $\begin{array}{c}\text { Finland } \\
(2)\end{array}$ & $\begin{array}{c}\text { Germany } \\
(3)\end{array}$ & $\begin{array}{c}\text { Italy } \\
(4)\end{array}$ & $\begin{array}{c}\text { Netherlands } \\
(5)\end{array}$ & $\begin{array}{l}\text { Spain } \\
(6)\end{array}$ & $\begin{array}{c}\text { Switzerland } \\
(7)\end{array}$ & $\begin{array}{l}\text { UK } \\
(8)\end{array}$ \\
\hline Lag & $\begin{array}{c}0.473^{* * *} \\
(0.118)\end{array}$ & $\begin{array}{c}0.456 \\
(0.271)\end{array}$ & $\begin{array}{l}-0.119 \\
(0.166)\end{array}$ & $\begin{array}{c}0.322^{* * *} \\
(0.104)\end{array}$ & $\begin{array}{l}-0.0420 \\
(0.0395)\end{array}$ & $\begin{array}{c}-0.404^{* * *} \\
(0.0609)\end{array}$ & $\begin{array}{r}-0.0671 \\
(0.109)\end{array}$ & $\begin{array}{c}0.405^{* *} \\
(0.147)\end{array}$ \\
\hline Constant & $\begin{array}{c}2.565^{* *} \\
(1.241)\end{array}$ & $\begin{array}{l}3.722^{* *} \\
(1.694)\end{array}$ & $\begin{array}{c}8.031^{* * *} \\
(1.960)\end{array}$ & $\begin{array}{c}3.282^{* *} \\
(1.468)\end{array}$ & $\begin{array}{c}7.322^{* * *} \\
(0.804)\end{array}$ & $\begin{array}{c}11.42^{* * *} \\
(0.820)\end{array}$ & $\begin{array}{c}7.443^{* * *} \\
(0.761)\end{array}$ & $\begin{array}{c}4.886^{* * *} \\
(1.058)\end{array}$ \\
\hline Observations & 27 & 27 & 27 & 27 & 27 & 27 & 27 & 27 \\
\hline R-squared & 0.172 & 0.080 & 0.011 & 0.141 & 0.004 & 0.207 & 0.004 & 0.113 \\
\hline
\end{tabular}

Table $29-\log \left(\right.$ Admissions $\left._{c t}\right)$ (January 2007 - March 2009)

\begin{tabular}{|c|c|c|c|c|c|c|c|c|}
\hline & $\begin{array}{l}\text { Belgium } \\
(1)\end{array}$ & $\begin{array}{l}\text { Finland } \\
(2)\end{array}$ & $\begin{array}{c}\text { Germany } \\
(3)\end{array}$ & $\begin{array}{c}\text { Italy } \\
(4)\end{array}$ & $\begin{array}{c}\text { Netherlands } \\
(5)\end{array}$ & $\begin{array}{c}\text { Spain } \\
(6)\end{array}$ & $\begin{array}{c}\text { Switzerland } \\
(7)\end{array}$ & $\begin{array}{l}\text { UK } \\
(8)\end{array}$ \\
\hline $\log$ (Admissions $)$ & $\begin{array}{c}0.751^{* * *} \\
(0.105)\end{array}$ & $\begin{array}{c}0.0478 \\
(0.0759)\end{array}$ & $\begin{array}{c}0.519^{* * *} \\
(0.0809)\end{array}$ & $\begin{array}{c}0.0541 \\
(0.0449)\end{array}$ & $\begin{array}{c}0.405^{* * *} \\
(0.132)\end{array}$ & $\begin{array}{l}0.351^{*} \\
(0.174)\end{array}$ & $\begin{array}{c}0.398^{* * *} \\
(0.116)\end{array}$ & $\begin{array}{l}0.321^{*} \\
(0.176)\end{array}$ \\
\hline Constant & $\begin{array}{c}6.056^{* * *} \\
(1.453)\end{array}$ & $\begin{array}{c}15.87^{* * *} \\
(0.960)\end{array}$ & $\begin{array}{c}8.284^{* * *} \\
(1.306)\end{array}$ & $\begin{array}{c}15.64^{* * *} \\
(0.666)\end{array}$ & $\begin{array}{c}10.81^{* * *} \\
(1.885)\end{array}$ & $\begin{array}{c}10.99 * * * \\
(2.738)\end{array}$ & $\begin{array}{c}11.10^{* * * *} \\
(1.577)\end{array}$ & $\begin{array}{c}11.34^{* * * *} \\
(2.835)\end{array}$ \\
\hline Observations & 27 & 27 & 27 & 27 & 27 & 27 & 27 & 27 \\
\hline R-squared & 0.660 & 0.003 & 0.346 & 0.016 & 0.158 & 0.073 & 0.250 & 0.095 \\
\hline
\end{tabular}

Table $30-\log \left(\right.$ Admissions $_{c t} /$ Screens $\left._{c t}\right)$ (January 2007 - March 2009)

\begin{tabular}{|c|c|c|c|c|c|c|c|c|}
\hline & $\begin{array}{l}\text { Belgium } \\
\text { (1) }\end{array}$ & $\begin{array}{l}\text { Finland } \\
(2)\end{array}$ & $\begin{array}{l}\text { Germany } \\
(3)\end{array}$ & $\begin{array}{l}\text { Italy } \\
(4)\end{array}$ & $\begin{array}{l}\text { Netherlands } \\
(5)\end{array}$ & $\begin{array}{l}\text { Spain } \\
(6)\end{array}$ & $\begin{array}{l}\text { Switzerland } \\
(7)\end{array}$ & $\begin{array}{l}\text { UK } \\
(8)\end{array}$ \\
\hline $\log ($ Admissions/Screens) & $\begin{array}{c}1.918^{* * *} \\
(0.410)\end{array}$ & $\begin{array}{c}0.347 \\
(0.320)\end{array}$ & $\begin{array}{c}1.581^{* * *} \\
(0.290)\end{array}$ & $\begin{array}{c}0.955^{* * *} \\
(0.330)\end{array}$ & $\begin{array}{c}0.389 \\
(0.288)\end{array}$ & $\begin{array}{l}0.819 * \\
(0.468)\end{array}$ & $\begin{array}{c}3.370^{* * *} \\
(0.401)\end{array}$ & $\begin{array}{l}2.134^{* *} \\
(1.002)\end{array}$ \\
\hline Constant & $\begin{array}{l}-0.124^{*} \\
(0.0680)\end{array}$ & $\begin{array}{c}-0.471^{* * *} \\
(0.153)\end{array}$ & $\begin{array}{c}-0.150^{* * *} \\
(0.0535)\end{array}$ & $\begin{array}{c}-0.234^{* *} \\
(0.101)\end{array}$ & $\begin{array}{c}-0.485^{* * *} \\
(0.134)\end{array}$ & $\begin{array}{c}-0.449^{* * *} \\
(0.122)\end{array}$ & $\begin{array}{c}0.0485 \\
(0.0583)\end{array}$ & $\begin{array}{c}-0.406^{* * *} \\
(0.136)\end{array}$ \\
\hline Observations & 27 & 27 & 27 & 27 & 27 & 27 & 27 & 27 \\
\hline R-squared & 0.684 & 0.072 & 0.535 & 0.298 & 0.041 & 0.062 & 0.614 & 0.109 \\
\hline
\end{tabular}


number of screens of US movies (Table 27) is constituted by Belgium, and the Netherlands. Our preferred control group when the outcome of interest is the time lag of US movies (Table 28) is constituted by Belgium, Italy, and United Kingdom. Our preferred control group when the outcome of interest is the number of admissions of all movies (Table 29) is constituted by Belgium, Germany, the Netherlands, Spain, Switzerland, and United Kingdom. Finally, our preferred control group when the outcome of interest is the number of admissions over the number of screens of all movies (Table 30) is constituted by Belgium, Germany, Italy, Spain, Switzerland, and United Kingdom.

Figure 8 - Countries included in the control group for the Log(Admissions/Screens) of US movies.
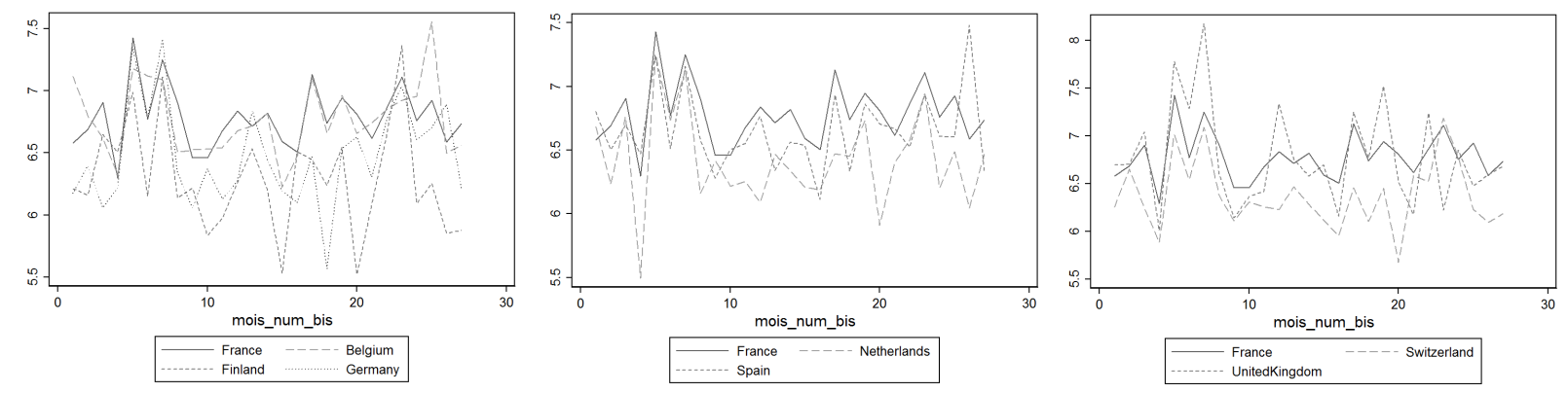

Figure 9 - Countries not included in the control group for the $\log$ (Admissions/Screens) of US movies.

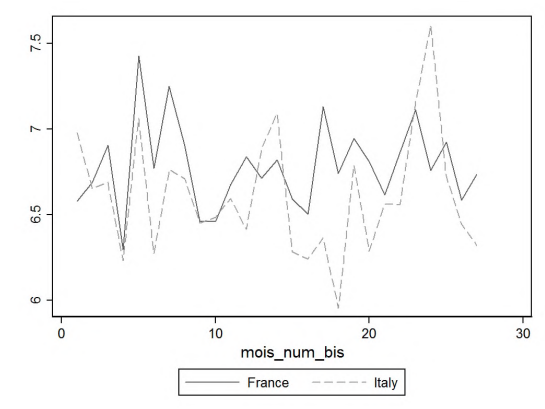


Figure 10 - Countries included in the control group for the $\log ($ Screens $)$ of US movies.

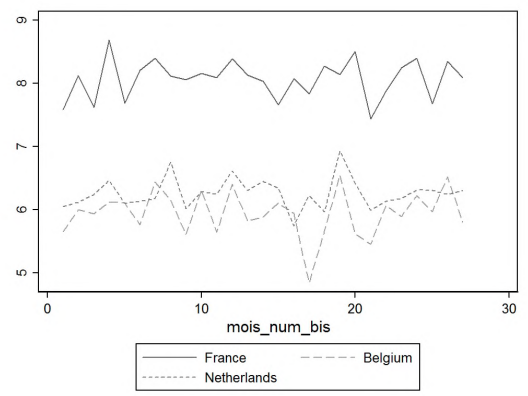

Figure 11 - Countries not included in the control group for the $\log ($ Screens $)$ of US movies.
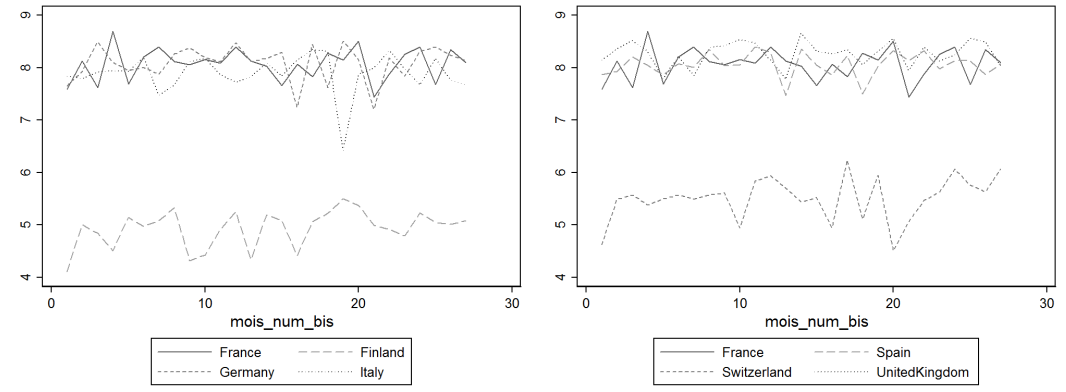

Figure 12 - Countries included in the control group for the time Lag of US movies.

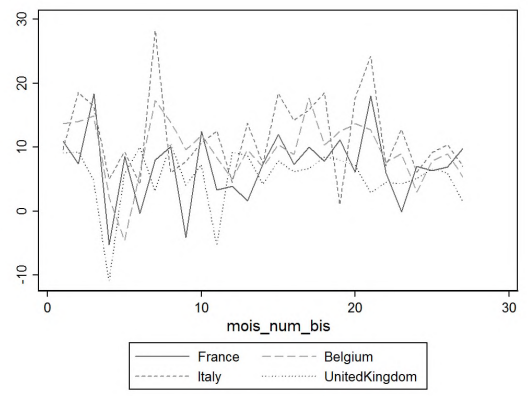

Figure 13 - Countries not included in the control group for the time Lag of US movies.
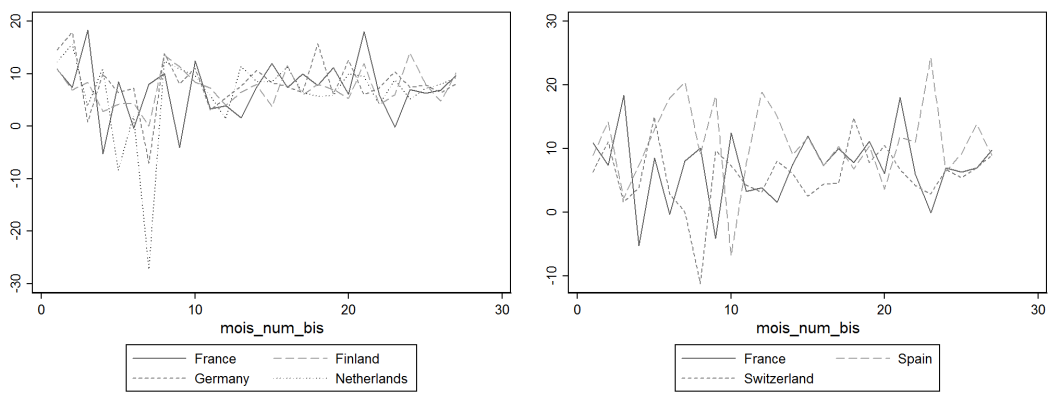
Figure 14 - Countries included in the control group for the aggregate number of admissions of all movies.
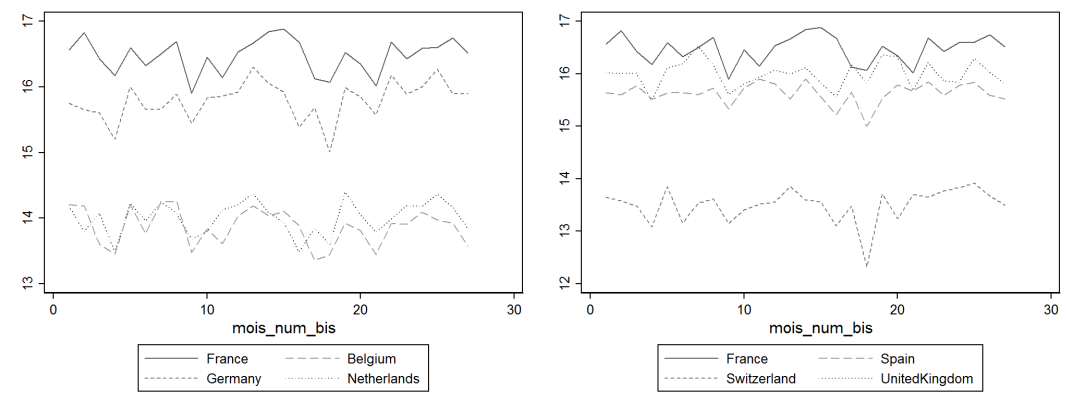

Figure 15 - Countries not included in the control group for the aggregate number of admissions of all movies.

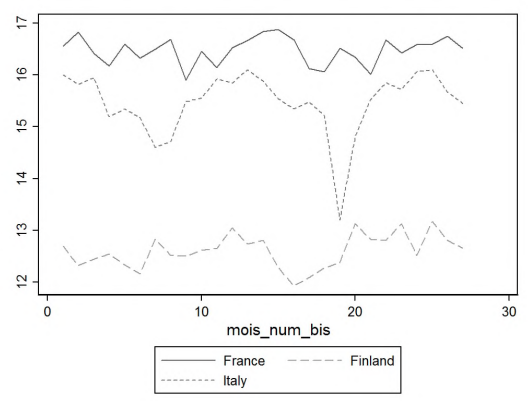

Figure 16 - Countries included in the control group for the US market share.
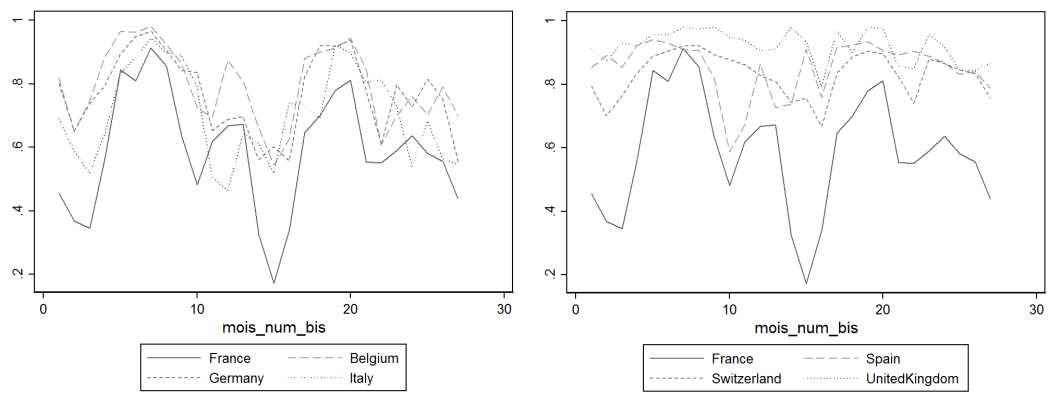
Figure 17 - Countries not included in the control group for the US market share.

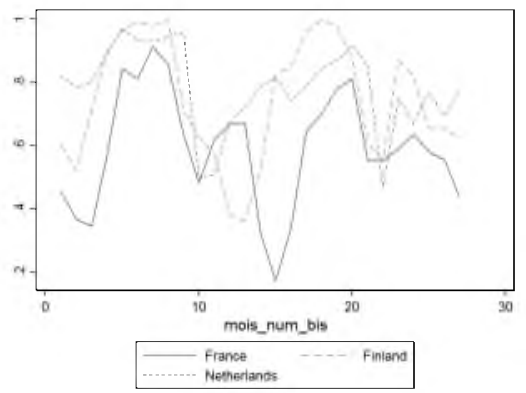




\section{K Interpretation of coefficients in the triple-differences approach of analysis 4}

A simplified version of the equation (5) we estimate in section 5.4 is the following one :

$$
\begin{aligned}
Y_{i j t a}= & \gamma_{i}+\lambda_{t}+\delta_{a}+\alpha \text { After }_{t} * U S A_{i}+\rho_{1} U S A_{i} * \text { Young }_{a}+\rho_{2} U S A_{i} * \text { Young }_{a} \\
& +\eta_{1} \text { After }_{t} * \text { Young }_{a}+\eta_{2} \text { After }_{t} * \text { Young }_{a}+\beta_{1} \text { After }_{t} * U S A_{i} * \text { Young }_{a} \\
& +\beta_{2} \text { After }_{t} * U S A_{i} * \text { Young }_{a}+\epsilon_{i j t a}
\end{aligned}
$$

Then, we define six differences:

(1) $E\left[Y_{\text {ijta }} \mid i=U S A, a=Y\right.$ oung $1, t=$ After $]-E\left[Y_{\text {ijta }} \mid i=U S A, a=\right.$ Young $1, t=$ Before $]$

$=\gamma_{U S A}+\lambda_{\text {After }}+\delta_{\text {Young } 1}+\alpha+\rho_{1}+\eta_{1}+\beta_{1}-\gamma_{U S A}-\lambda_{\text {Before }}-\delta_{Y \text { oung } 1}-\eta_{1}$

$=\lambda_{\text {After }}-\lambda_{\text {Before }}+\alpha+\rho_{1}+\beta_{1}$

(2) $E\left[Y_{i j t a} \mid i=F r, a=\right.$ Young $1, t=$ After $]-E\left[Y_{i j t a} \mid i=F r, a=\right.$ Young $1, t=$ Before $]$

$=\gamma_{F r}+\lambda_{A f t e r}+\delta_{Y o u n g 1}+\rho_{1}-\gamma_{F r}-\lambda_{\text {Before }}-\delta_{Y \text { oung } 1}$

$=\lambda_{\text {After }}-\lambda_{\text {Before }}+\rho_{1}$

(3) $E\left[Y_{i j t a} \mid i=U S A, a=Y\right.$ oung $2, t=$ After $]-E\left[Y_{i j t a} \mid i=U S A, a=\right.$ Young $2, t=$ Before $]$

$=\gamma_{U S A}+\lambda_{\text {After }}+\delta_{Y \text { oung } 2}+\alpha+\rho_{2}+\eta_{2}+\beta_{2}-\gamma_{U S A}-\lambda_{\text {Before }}-\delta_{Y \text { oung } 2}-\eta_{2}$

$=\lambda_{\text {After }}-\lambda_{\text {Before }}+\alpha+\rho_{2}+\beta_{2}$ 
(4) $E\left[Y_{i j t a} \mid i=F r, a=\right.$ Young $2, t=$ After $]-E\left[Y_{\text {ijta }} \mid i=F r, a=\right.$ Young $2, t=$ Before $]$

$=\gamma_{F r}+\lambda_{\text {After }}+\delta_{Y \text { oung } 2}+\rho_{2}-\gamma_{F r}-\lambda_{\text {Before }}-\delta_{\text {Young } 2}$

$=\lambda_{\text {After }}-\lambda_{\text {Before }}+\rho_{2}$

(5) $E\left[Y_{i j t a} \mid i=U S A, a=O l d, t=\right.$ After $]-E\left[Y_{i j t a} \mid i=U S A, a=\right.$ Old, $t=$ Before $]$

$=\gamma_{U S A}+\lambda_{\text {After }}+\delta_{\text {Old }}+\alpha-\gamma_{U S A}-\lambda_{\text {Before }}-\delta_{\text {Old }}$

$=\lambda_{\text {After }}-\lambda_{\text {Before }}+\alpha$

(6) $E\left[Y_{i j t a} \mid i=F r, a=\right.$ Old, $t=$ After $]-E\left[Y_{i j t a} \mid i=F r, a=\right.$ Old, $t=$ Before $]$

$=\gamma_{F r}+\lambda_{\text {After }}+\delta_{\text {Old }}-\gamma_{F r}-\lambda_{\text {Before }}-\delta_{\text {Old }}$

$=\lambda_{\text {After }}-\lambda_{\text {Before }}$

With those six differences, we can give the interpretation of $\beta_{1}$ and $\beta_{2}$ using difference-in-difference-indifferences:

$$
\begin{aligned}
& \beta_{1}=[(1)-(2)]-[(5)-(6)] \\
& \beta_{2}=[(3)-(4)]-[(5)-(6)]
\end{aligned}
$$

As a result, $\beta_{1}$ (resp. $\beta_{2}$ ) can be interpreted as the difference in $Y$ for U.S. movies compared to French movies, between consumers aged 10-29 (resp. 30-49) and consumers aged 50-80, after and before the law is implemented. Then, it is direct to see that the coefficients $\eta_{a}$ capture the difference in $Y$ for French movies between young and old consumers, after and before the law. This effect is captured through the sum $\beta+\eta$ for U.S. movies. The total effect, for French and U.S. movies, is captured by $2 \times \eta+\beta$. 


\section{Perspectives and summary of the results}

The estimated values of the HADOPI effect from the four empirical analyses are different, but we show below that they have similar implications after some adjustments are made to compute the total change in the number of admissions to U.S. films in France after the law.

The total number of admissions was different before and after the law, but we are only interested in the differences that are attributable to the law. Our estimation results show statistically weak evidence of a demand creation effect caused by the law. As an approximation to compute the overall effects on the admissions to American movies or on the market share of American movie sales, we fix the total number of admissions before and after the law to a constant value. Then, we note that the U.S. films' market share was equal to $48 \%$ after the HADOPI law was passed and that the total number of admissions over the post-HADOPI period was approximately 440 million. Finally, we use the distribution of broadband Internet coverage rate presented in table 3 to compute the effect from the town-level approach, and the consumer age distribution to compute the effect from the consumer-level approach. ${ }^{33}$ The implied effects are shown in Table 31.

Table 31 - Comparison of the results and variation in revenue and consumer loss

\begin{tabular}{|c|c|c|c|c|}
\hline & $\begin{array}{l}\text { Analysis 1: Town level } \\
\text { approach }\end{array}$ & $\begin{array}{lll}\text { Analysis } & 2: \text { U.S. } & \text { vs } \\
\text { French } & \text { movies } & \text { in } \\
\text { France } & & \end{array}$ & $\begin{array}{l}\text { Analysis 3: Interna- } \\
\text { tional comparisons }\end{array}$ & $\begin{array}{l}\text { Analysis 4: Consumer } \\
\text { level approach }\end{array}$ \\
\hline Estimated coefficient & $\begin{array}{l}\text { Increase in the U.S. } \\
\text { market share by } 0.6 \\
\text { percentage point when } \\
\text { the high speed Internet } \\
\text { use rate increase by } 1 \\
\text { percentage point }\end{array}$ & $\begin{array}{l}\text { Increase in the number } \\
\text { of admissions to U.S. } \\
\text { films by } 10 \%\end{array}$ & $\begin{array}{l}\text { Increase in the U.S. } \\
\text { market share by } 8 \%\end{array}$ & 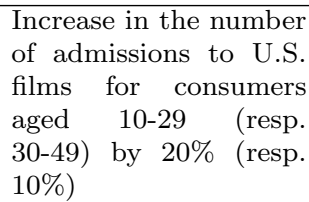 \\
\hline $\begin{array}{l}\text { Rise in the market } \\
\text { share of U.S. films }\end{array}$ & $10 \%$ & $10 \%$ & $8 \%$ & $10 \%$ \\
\hline $\begin{array}{l}\text { Rise in the number } \\
\text { of admissions to U.S. } \\
\text { films (in million) }\end{array}$ & 19.2 & 19.2 & 15.4 & 20.0 \\
\hline $\begin{array}{l}\text { Rise in the revenue to } \\
\text { U.S. films (in euros mil- } \\
\text { lion) }\end{array}$ & 121 & 121 & 97 & 126 \\
\hline $\begin{array}{l}\text { Number of consumers } \\
\text { involved in the redistri- } \\
\text { bution (in million) }\end{array}$ & 2.5 & 2.5 & 2.8 & 2.9 \\
\hline
\end{tabular}

Lecture note: For instance, with a rise in the market share of US films equal to $10 \%$, we obtain a rise in the number of admissions to US films equal to 19.2 million $(0.48 \times 440-(0.48 \times 440 / 1.10)=19.2)$.

With an increase in the U.S. market share of approximately 9\%, the increase in U.S. film admissions after the law is between 15.4 and 20.0 million. It involves a decrease in admissions to French films of

33. The distribution of moviegoers' age in France is given by the CNC and is as follows: $42.8 \%$ are aged between 6 and 29, $25.8 \%$ are aged between 30 and 49, and $31.4 \%$ are aged 50 and over. 
approximately the same amount. Given that the average ticket price was 6.3 euros in France during the post-HADOPI period, U.S. movies benefited from an increase in sales of between 97 and 126 million euros. On average, a distributor collects $38 \%$ of ticket revenue. As a consequence, the transfer in revenue from French movie distributors to U.S. distributors is between 37 and 48 million euros. Assuming that the distribution of consumers involved in the redistributive effect of the HADOPI is the same as the distribution of moviegoers, we find that between 2.2 and 2.9 million individuals switched from French movies to American ones in theaters after the implementation of the law, that is about $7 \%$ of moviegoers. ${ }^{34}$

Table 32 provides a summary of the results of the four empirical analyses in the form of their pros and cons to show the complementary between them.

Table 32 - Summary of each empirical strategy

\begin{tabular}{|c|c|c|c|c|}
\hline & Main effects identified & Results & Pros & Cons \\
\hline $\begin{array}{l}\text { (1) Local comparisons: } \\
\text { towns with high level vs. } \\
\text { towns with low level of } \\
\text { online piracy }\end{array}$ & $\begin{array}{l}\text { Local market expansion } \\
\text { effect and business } \\
\text { stealing effect in towns } \\
\text { with high level of online } \\
\text { piracy compared to ones } \\
\text { with low level of online } \\
\text { piracy }\end{array}$ & $\begin{array}{l}\text { - No significant market ex- } \\
\text { pansion effect but business } \\
\text { stealing effect } \\
\text { - The market share of } \\
\text { U.S. movies increases by } \\
0.8 \% \text { with a one per- } \\
\text { centage point increase of } \\
\text { the broadband internet use } \\
\text { rate }\end{array}$ & $\begin{array}{l}\text { - Main effects of the } \\
\text { HADOPI law are captured } \\
\text { - Rules out simultaneous } \\
\text { unrelated shocks specific } \\
\text { to U.S. or to French movies }\end{array}$ & $\begin{array}{l}\text { No conclusion at the } \\
\text { national level: localized } \\
\text { effect on middle-sized } \\
\text { towns }\end{array}$ \\
\hline $\begin{array}{l}\text { (2) National } \\
\text { comparisons: U.S. } \\
\text { movies vs. French movies } \\
\text { in France }\end{array}$ & $\begin{array}{l}\text { Relative business stealing } \\
\text { effect of U.S. movies } \\
\text { toward French movies }\end{array}$ & $\begin{array}{l}\text { - Relative increase of U.S. } \\
\text { films admissions by } 10 \% \\
\text { relatively to French films } \\
\text { - No reaction from the } \\
\text { supply side of U.S. movies } \\
\text { compared to French } \\
\text { movies, except a decrease } \\
\text { in the production budget, } \\
\text { a decrease in user ratings, } \\
\text { but an increase in the } \\
\text { marketing expenditures }\end{array}$ & $\begin{array}{l}\text { - Checks for supply re- } \\
\text { actions from U.S. film } \\
\text { distributors compared to } \\
\text { French film distributors } \\
\\
\text { - Controls for simultaneous } \\
\text { unrelated shock symmetric } \\
\text { on all movies in France }\end{array}$ & $\begin{array}{l}\text { - No conclusion on market } \\
\text { expansion effect and pure } \\
\text { business stealing effect } \\
\text { - Does not check for simul- } \\
\text { taneous unrelated shocks } \\
\text { specific to U.S. or to } \\
\text { French movies }\end{array}$ \\
\hline $\begin{array}{l}\text { (3) International } \\
\text { comparisons: France vs. } \\
\text { other European countries }\end{array}$ & $\begin{array}{l}\text { Market expansion effect in } \\
\text { France and business } \\
\text { stealing effect from U.S. } \\
\text { movies in France, } \\
\text { compared to other } \\
\text { countries }\end{array}$ & $\begin{array}{l}\text { - Business stealing effect: } \\
\text { market share of U.S. } \\
\text { movies increases by } 8 \% \\
\text { and weak evidence of a } 8 \% \\
\text { market expansion effect } \\
\text { - No change in the speed } \\
\text { nor in the quantities of } \\
\text { exports of U.S. films to } \\
\text { France }\end{array}$ & $\begin{array}{l}\text { Main effects of the } \\
\text { HADOPI law are captured } \\
\text { - Checks for supply side re- } \\
\text { actions of film distributors } \\
\text { of U.S. movies in France } \\
\text { compared to other Euro- } \\
\text { pean countries }\end{array}$ & $\begin{array}{l}\text { - Does not control for } \\
\text { simultaneous unrelated } \\
\text { shocks in France in gen- } \\
\text { eral, or specific to U.S. or } \\
\text { French movies } \\
\text { - Does not check for sup- } \\
\text { ply side reactions of U.S. } \\
\text { film distributors compared } \\
\text { to French film distributors, } \\
\text { in France }\end{array}$ \\
\hline $\begin{array}{l}\text { (4) Consumer } \\
\text { comparisons: consumers } \\
\text { with high propensity vs. } \\
\text { those with low propensity } \\
\text { to download }\end{array}$ & $\begin{array}{l}\text { Business stealing effect of } \\
\text { U.S. movies toward } \\
\text { French movies and market } \\
\text { expansion effect relative } \\
\text { to older consumers with } \\
\text { low propensity to } \\
\text { download }\end{array}$ & $\begin{array}{l}\text { - Increase in U.S. films ad- } \\
\text { missions of } 20 \% \text { for con- } \\
\text { sumers aged } 10-29 \text { and of } \\
10 \% \text { for consumers aged } \\
30-49 \text {, compared to con- } \\
\text { sumers aged } 50-80 \\
\text { - No market expansion ef- } \\
\text { fect: similar decrease in } \\
\text { admissions to other films } \\
\text { for consumers aged } 10- \\
29 \text { and } 30-49 \text { compared to } \\
\text { consumers aged } 50-80\end{array}$ & $\begin{array}{l}\text { - Main effects of the } \\
\text { HADOPI law are captured } \\
\text { - Distinguishes what type } \\
\text { of consumers are influ- } \\
\text { enced by the new regula- } \\
\text { tion }\end{array}$ & $\begin{array}{l}\text { - Very localized data col- } \\
\text { lection }\end{array}$ \\
\hline
\end{tabular}

34. The increase in U.S. admissions is approximately 11.8 to 15.4 million per year. The distribution of moviegoers' attendance in France is given by the CNC: each year on average, 1.5 million assiduous moviegoers generate 44 million admissions, 11.1 million regular moviegoers generate 95 million admissions, and 24.5 million casual moviegoers generate 60 million admissions. Using these figures, it is immediate to obtain the number of individuals involved in the redistributive effect of the law. 